\title{
Productivity and Economic Growth in Australia, New Zealand and Ireland
}

\section{Dimitri Margaritis, Frank Scrimgeour, Michael Cameron, and John Tressler}

$\mathrm{I}$

$\mathrm{t}$ is generally accepted that productivity growth is a major source of economic growth and welfare improvement. Labour productivity has accounted for roughly half of the growth in per capita GDP in the OECD over the last two decades, with the other half primarily accounted for by increases in labour utilisation, that is, changes in the demographics, unemployment and labour force participation rates. For this reason, productivity is of vital interest to economists and policymakers. An understanding of technical and efficiency change, two key factors in productivity growth, is thus important in policy decision-making.

Academics and policy makers continue to debate the relative contributions of shocks and policy changes impacting on population growth, capital accumulation, microeconomic behaviour and technological advance. Different policy settings impact on both aggregate performance and the productivity of sectors and factors.

This paper presents an analysis of the relative growth performance of Australia, New Zealand and Ireland concentrating on the underlying components of labour productivity, particularly efficiency change and technical change. Such analysis is important to policy decisions of countries seeking to improve their relative international position and outlook. It is important that policymakers identify sustainable productivity changes (largely driven by technological change) separately from measured productivity change. This separation facilitates assessment of the extent to which technology adoption and diffusion contribute to a productivity catch-up.

This work is similar in many respects to recent studies undertaken by the OECD (2004a), but with important methodological differences introduced by Margaritis, Färe and Grosskopf (2005). The individual contributions of industry productivity growth and sectoral composition to aggregate productivity are also considered. The novelty of the productivity measurement and analysis used by Margaritis, Färe and Grosskopf is that it 'derives from a decomposition of the growth in labour productivity in terms of (a) technical change both neutral and biased, (b) efficiency change, and (c) capital accumulation'. Each component's contribution to the growth in labour productivity can then be assessed.

The paper proceeds as follows. We outline the relative economic growth performance of Australia, New Zealand and Ireland over the period 1979-2002,

Dimitri Margaritis is Professor Faculty of Business, Auckland University of Technology. Frank Scrimgeour, Michael Cameron and John Tressler are respectively Professor, Doctoral Candidate and Associate Professor in the Department of Economics, University of Waikato. 
summarise the key policy reforms in the three countries and the perceived drivers of productivity growth. We then briefly discuss the methodology and rationale for the particular productivity measure used in this paper. Productivity performance of the three countries over the period is reported, focussing on efficiency change, technical change, and capital accumulation movements. Technical change is further decomposed into input-biased technical change and a neutral component. We also investigate how trends in industry productivity affect aggregate productivity performance across the OECD countries. Finally we compare our results with other studies of productivity in the three countries and provide concluding remarks.

\section{Economic Growth in Australia, New Zealand, and Ireland: 1979-2002}

The different experience of the three countries over the last two decades is readily apparent when aggregate measures of per capita output are compared. Figure 1 illustrates the growth of real per capita Gross Domestic Product (GDP) for Australia, New Zealand, Ireland, and the OECD average, over the period from 1979 to 2002. In 1979, all three countries had real per capita GDP below the OECD average. It is obvious that Ireland has outperformed most OECD countries in terms of economic growth over the last decade. By 2001, Ireland had overtaken both New Zealand and Australia and had almost reached the OECD average, with most of the catch-up by Ireland occurring after 1990. Ireland's real per capita GDP grew on average by 2.7 per cent through the 1980 s, but grew by 6.4 per cent on average through the 1990s, well ahead of the OECD average of 1.7 per cent over the same period. Australia also grew faster than the OECD average in the 1990s (2.1 per cent on average), while New Zealand fell further behind (1.4 per cent). This paper provides an explanation of the differences in the economic growth experience of the three countries.

\section{Policy and Productivity}

All three countries experienced a similar productivity slowdown during the 1970s. This period has been studied closely, and several explanations have emerged including (i) energy price shocks; (ii) inflation; (iii) changes in the composition of the labour force; (iv) increasingly regulated markets and unionisation; and (v) changes in the composition of output (Norsworthy, Harper and Kunze, 1979; Clark, 1982; Link, 1987). Energy price shocks in the 1970s encouraged diversion of investment away from increasing the capital stock, towards replacing existing energy-inefficient capital. Inflation both lowered the saving rate, and diverted investment from productive capital to the purchase of non-productive assets that would hold their value over time. The labour force grew quickly through this period, mainly due to increases in the youth and female labour force. Much of this new labour force was relatively lower-skilled, reducing the average productivity of the workforce. Government regulation such as environmental and work safety programs reduce measured productivity due to the compliance costs associated 
with them. Unionisation reduces productivity by limiting the effectiveness of incentives such as performance-based pay schemes. Finally, as the composition of industries in the economy changed increasingly towards services, labour was diverted away from manufacturing and into service industries where productivity growth is slower.

\section{Figure 1: Real per Capita GDP (1995 \$US)}

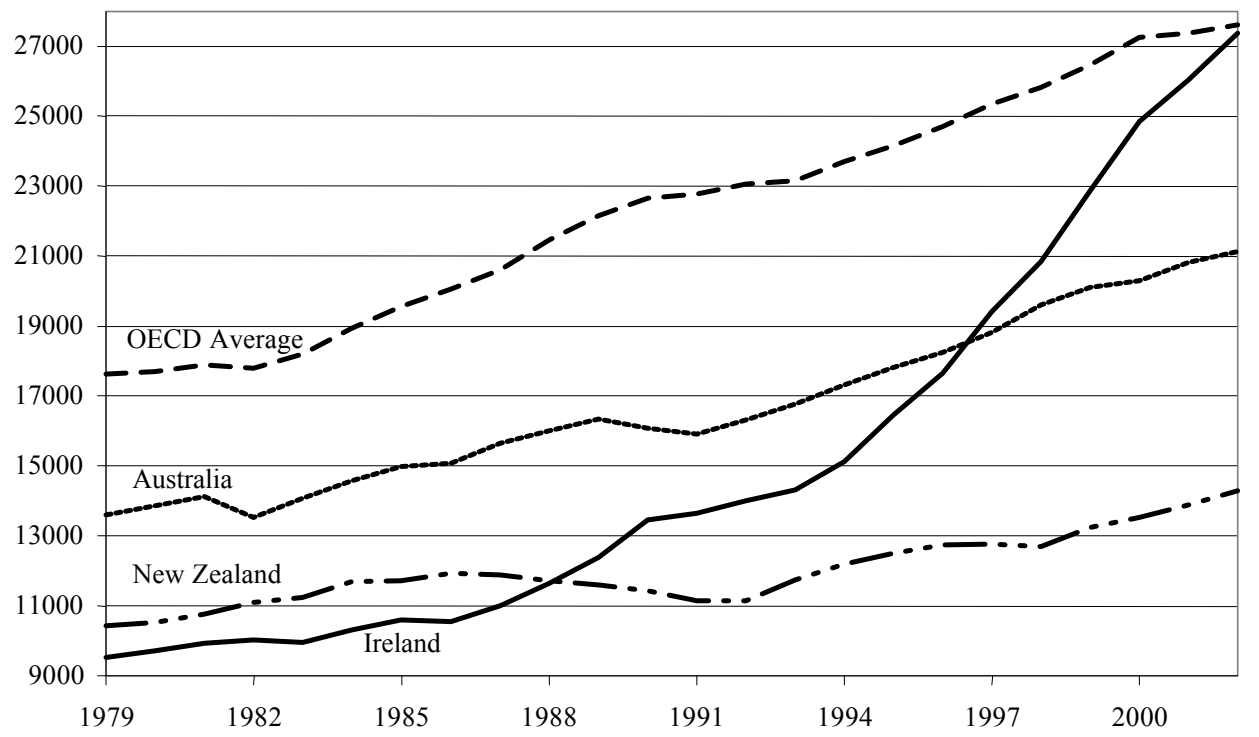

Source: World Bank Development Indicators, http://devdata.worldbank.org/dataonline/

The productivity slowdown experienced by Australia, New Zealand and Ireland, and the need to restructure and modernise, ultimately led to necessary microeconomic and macroeconomic policy reform. However, their approaches to reform were markedly different. Ireland's policy reform focused on encouraging foreign direct investment; New Zealand utilised extensive market-based policy reform; while Australia used a more measured approach concentrating on institution building.

The Irish government finally responded to the 1980s national fiscal crisis by initiating the Programme for National Recovery in 1987 - this program established an important sense of national purpose and direction for Ireland, in addition to fiscal restraint (O'Connell, 1999). One highly successful initiative was an amnesty for delinquent taxpayers. This resulted in a financial windfall of IR£500 million and set the stage for decreases in marginal tax rates through the 1990s. Low tax rates were used as an incentive for foreign high-technology firms to establish themselves in Ireland. The Irish government also deregulated several key industries, including telecommunications and the airline industry, which proved to be additional key factors in attracting foreign direct investment. 
Further, a re-orientation of the state-funded tertiary education sector to focus on science and technology graduates, coupled with the abolition of tertiary education fees, saw a huge increase in the skill level of the labour force (Burnham, 2003).

In New Zealand, extensive policy reform followed the election of a new government in 1984. Wage, price, and interest rate controls were removed and the exchange rate was devalued, and then floated (Bollard, Lattimore and Silverstone, 1996). Tariffs were removed or reduced on most imported goods, and many production incentives and subsidies were withdrawn. This forced local industry to modernise in order to compete with cheaper imported goods. Inefficient state assets were first corporatised as State-Owned Enterprises. Some were later sold to private business interests in order to raise funds to reduce public debt (Chatterjee, 1996). A new fund for research and development (the Foundation for Research, Science and Development) was created, and government research bodies were corporatised (as Crown Research Institutes). The key mechanisms of monetary policy were changed, with a new focus on keeping inflation low and stable - this goal was not achieved until 1992, and the disinflation process involved significant economic cost to the country. The labour market was extensively deregulated, and in 1991 the Employment Contracts Act significantly reduced the bargaining power of trade unions (Bollard, Lattimore and Silverstone, 1996). These pro-market reforms were completed rapidly, and virtually all markets had experienced some reform by 1991 .

Australia followed a similar path of macroeconomic and microeconomic reform to New Zealand. However, in comparison Australia employed a much more measured and cautious approach to reform, and reform in most markets occurred significantly after equivalent reform in New Zealand. Tariffs and agricultural subsidies were progressively removed from the 1970s through to the 1990 s, and export controls on many natural resources such as coal and iron ore were relaxed or removed. Government Business Enterprises were reformed so that prices reflected actual costs, but privatisation did not occur to the same extent as in New Zealand. Company taxes were cut from 49 per cent to 39 per cent in 1987, then to 33 per cent in 1993. Greater flexibility and decentralisation of the wage setting mechanism was pursued in labour market reform - in 1996, the Victorian state government introduced individual and collective contracts, almost eight years after similar reform in New Zealand (Industry Commission, 1998).

The recent literature (see OECD, 2003 for a review) suggests that (i) macroeconomic stability; (ii) regulation; (iii) financial markets; (iv) education; and (v) research and development, are important drivers of labour productivity growth. Macroeconomic stability, including fiscal prudence and low inflation, is important for business and consumer confidence and promotes efficient resource allocation. The central banks of Australia, Ireland (currently part of ECB) and New Zealand all concentrate on maintaining low stable inflation while the respective governments maintain a reasonably balanced budget. But macroeconomic stability, however beneficial it might have been for enhancing the countries growth prospects, is a necessary but not a sufficient precondition for sustainable growth. 
Business development and entrepreneurship are easily hampered by excessive regulation and administrative requirements, and by financial markets that concentrate investment on risk-averse activities. Streamlining the regulatory environment for new enterprises should have a positive effect on productivity growth, as should financial markets that provide venture capital for innovative activities in addition to financing established activities. Efficient markets for both inputs and output, characterised by increased competition, are also important. Flexible labour and input markets ensure that workers and resources will shift to the most productive (and rewarding) sectors, increasing productivity. The size of government is also thought to be important, with large tax burdens having a negative effect on output per capita and high government spending crowding out private investment due to increases in the real interest rate. Business tax burdens in both Australia and New Zealand are substantially higher than Ireland's.

Productivity growth is associated with greater specialisation of labour and capital, suggesting economies of scale are important in generating productivity growth. In small domestic markets such as New Zealand or Ireland, economies of scale in production must be generated through export promotion. Ireland, as part of the European Union and with a large United Kingdom market on its doorstep, seems particularly well placed to take advantage of economies of scale in production.

Human capital is already recognised as critically important in labour productivity. All three countries have promoted skills acquisition and re-training of the unemployed workforce, as well as increasing compulsory schooling. However, incentives for tertiary education have been quite different. While New Zealand and Australia maintain 'user-pays' education at tertiary level, Ireland abolished tertiary education fees in 1996 to broaden access to higher education for all socio-economic groups. However, since the abolition of tertiary fees occurred well after Ireland's high productivity growth had begun, it is unlikely to have made a significant contribution, but may have prolonged the period of high productivity growth by providing a highly-skilled, motivated, innovative and adaptable young workforce. Färe, Grosskopf and Margaritis (2005) estimate that about one fifth of Ireland's growth in labour productivity over 1965-1998 is due to human capital accumulation but this effect is likely to have been much more modest in recent years as a tight labour market has forced employers to hire lowskilled labour. The OECD (2004a) reports a very small contribution of human capital to labour productivity growth in Ireland (and Australia) with a slight negative contribution for New Zealand in 1990-2000.

Research and development, and in particular private sector research and development, is strongly linked to productivity growth. Research and development potentially increases productivity, either directly through innovation or through technology spill-overs. A decrease in R\&D intensity may not affect steady-state GDP per capita but is likely to reduce technological progress (see OECD, 2004a). To promote private research and development, governments should concentrate on human capital development, promotion of venture capital markets, and intellectual property rights. While all three countries have similar 
protection of intellectual property rights, incentives for research and development appear to be higher in Ireland: In 2002, private research and development accounted for 0.80 per cent of GDP in Ireland, compared with 0.73 per cent in Australia and just 0.43 per cent in New Zealand (OECD, 2004b).

\section{Methodology and Data}

In this paper, labour productivity is defined as output per labour hour worked. This is commonly accepted as a better measure of the labour input actually used in the production process than using the number of employed, and is therefore more appropriate for efficiency and productivity measurement. Since this paper concentrates on the efficiency and productivity sources of growth, the GDP per hours worked measure is used.

Care was taken to avoid measurement bias problems in the productivity index arising from restrictive assumptions about market structure or the type of technology in the measurement of technological change and diffusion. The increasingly volatile behaviour of productivity measures further complicated the task of disentangling permanent from temporary shifts in measured productivity. Margaritis, Färe and Grosskopf (2005) calculated multifactor productivity growth and its efficiency and technological change components for a sample of 19 OECD countries ${ }^{1}$ over the period 1979 to 2002 . In particular, the approach outlined below constructs an aggregate best practice frontier for the OECD region using data envelopment analysis (DEA) methods, and individual countries are compared to that frontier. Technical change is then defined as a shift in the production frontier between two time periods. Malmquist productivity indexes were also computed and decomposed into the underlying productivity components for each country. Rather than specifying and estimating a specific production function, the technologies were constructed non-parametrically using DEA (Margaritis, Färe and Grosskopf, 2005 provide a thorough discussion; for more detail on the Malmquist index, see Färe et al, 1994). Restrictive assumptions about market structure or optimising behaviour were not required other than minimal regularity conditions, and an assumption of constant returns to scale.

An important feature of the Malmquist (multifactor) productivity change index (MALM) is that it can be decomposed into an efficiency change component $(\mathrm{ECH})$ and a technological change component (TCH). Furthermore, following Kumar and Russell (2002) we can decompose the change in labour productivity between two periods (YCH) into (i) an efficiency change; (ii) technological change; and (iii) change in the capital to labour ratio $(\mathrm{KCH})$. It follows that:

$$
\begin{aligned}
Y C H & =M A L M \cdot K C H \\
& =E C H \cdot T C H \cdot K C H
\end{aligned}
$$

1 Australia, Austria, Belgium, Canada, Denmark, Finland, France, Germany, Greece, Ireland, Italy, Japan, Netherlands, New Zealand, Portugal, Spain, Sweden, United Kingdom, and the United States of America. 
Since constant returns to scale are assumed, only variation in capacity utilisation or differences in the structure of each country will affect efficiency. Further, in the absence of joint input and output neutrality, the technical change component can be decomposed into an output biased (OBTC), an input biased (IBTC), and a (net) magnitude component (MTC). Because there is only one output, OBTC is equal to one here. IBTC represents the component of technical change that relates to relative changes in the inputs giving rise to non-parallel shifts in the production frontier. MTC represents the residual (parallel) component of technical change. Summarising the relationships:

$$
Y C H=E C H \cdot I B T C \cdot M T C \cdot K C H
$$

To assess how sectoral changes contribute to productivity growth we will use a shift-share analysis. This may demonstrate whether resources have been substantially reallocated from low to high productivity industries possibly as a result of structural policies; whether these changes have added to overall productivity; and which particular industries have made the greatest contribution to aggregate productivity growth. We divide aggregate labour productivity growth into three components: an intra-sectoral or 'within' sector component measuring the (counterfactual) contribution of each industry to aggregate productivity; a static 'in between' component measuring the effect of changes in industry employment shares on aggregate productivity; and a dynamic (interaction) component capturing the residual effect of changes in both industry productivity and employment shares. The shift-share analysis was carried out for the following ten industries ${ }^{2}$ : agriculture, mining, manufacturing (low-tech), manufacturing (high-tech), utilities, construction, wholesale and retail trade, transport and communication, financial services, and general services (high-tech/high-skill).

This paper uses data on aggregate output (PPP-adjusted value-added real GDP) and employment (annual hours worked) from the Total Economy Database of Groningen University (www.ggdc.net), on PPP-adjusted real capital stock from the GGDC Total Economy Growth Accounting Database and the New Zealand Treasury, and industry output (value-added) and employment data from the GGDC's 60-industry database. The data for Australia and New Zealand are from Statistics New Zealand and Australian Bureau of Statistics databases.

\section{Review of Productivity Performance: 1979-2002}

In Figure 2 the performance of individual countries is compared with the empirically constructed OECD production frontiers in 1991 and 2002. These frontiers are a benchmark derived from the best practice prevailing in the sample of 19 OECD countries, namely, USA, France and the Netherlands in 1991, and Ireland and France in 2002. The shift in the frontier between these two periods is clearly non-parallel indicating that technical change was non-neutral. It is evident

2 For Australia, data constraints meant that only nine industries could be used: Manufacturing therefore includes both high-tech and low-tech industries. 
from figure 2 that New Zealand is far from the efficient frontier, and has not closed the gap over that period. Australia was closer to the frontier in 1991 than New Zealand, but not significantly closer in 2002, and had a large increase in capital per labour hour over that period. Ireland was in a similar position to New Zealand in 1991, but by 2002 they had pushed the efficient frontier around the medium capital intensity region significantly outwards.

Figure 2: $\quad$ Production Frontiers 1991 and 2002

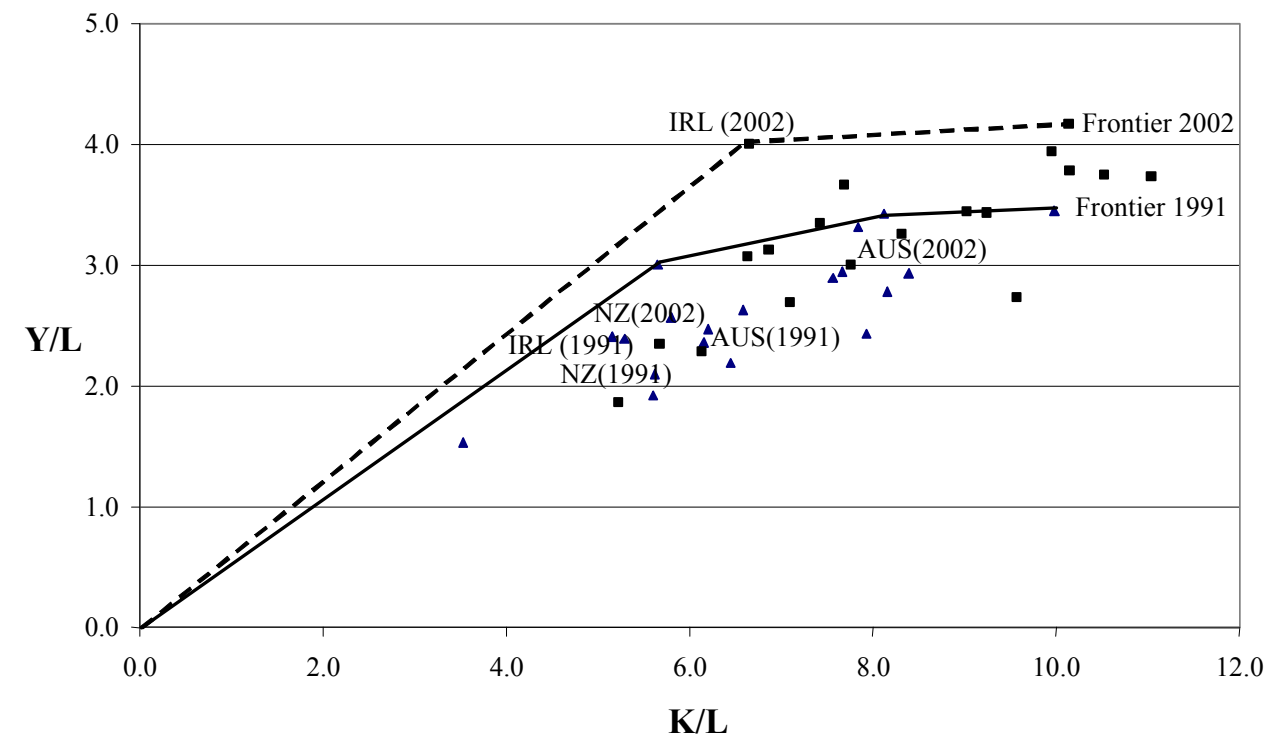

The difference in productivity improvements between the three countries is again demonstrated in Table 1. Output per labour unit in Ireland grew 158 per cent between 1979 and 2002, compared with 55 per cent for the OECD average, 44 per cent in Australia, and 20 per cent in New Zealand. This also shows New Zealand falling behind the OECD average over the period, with much lower growth in output per labour hour in both the 1980s and 1990s.

Table 1: Growth in Output per Labour Hour (Y/L)

\begin{tabular}{l|cccccc}
\hline & $Y / L$ & $Y / L$ & \% change & $Y / L$ & \% change & \% change \\
& 1979 & 1991 & $1979-1991$ & 2002 & $1991-2002$ & $1979-2002$ \\
\hline Australia & 2.08 & 2.36 & 13.5 & 3.01 & 27.4 & 44.6 \\
Ireland & 1.55 & 2.41 & 55.3 & 4.01 & 66.5 & 158.5 \\
New Zealand & 1.94 & 2.10 & 7.9 & 2.35 & 12.0 & 20.8 \\
OECD & 2.08 & 2.62 & 25.7 & 3.25 & 24.0 & 55.8 \\
Average & & & & & & \\
\hline
\end{tabular}


The three countries are also quite different in terms of capital depth (Table 2). New Zealand had slightly more capital per labour hour than the other two countries in 1979, but increases in capital were much lower in the 1980s, and negligible through the 1990s. Australia experienced capital deepening in line with the OECD sample average, while Ireland's capital stock (per labour hour) grew almost twice as fast as Australia's.

Table 2: Growth in Capital per Labour Hour (K/L), 1979-2002

\begin{tabular}{l|cccccc}
\hline & $K / L$ & $K / L$ & $\%$ change & $K / L$ & $\%$ change & \% change \\
& 1979 & 1991 & $1979-1991$ & 2002 & $1991-2002$ & $1979-2002$ \\
\hline Australia & 5.17 & 6.15 & 19.0 & 7.76 & 26.1 & 50.0 \\
Ireland & 3.36 & 5.15 & 53.5 & 6.65 & 29.0 & 98.0 \\
New Zealand & 5.22 & 5.62 & 7.8 & 5.67 & 0.9 & 8.7 \\
OECD & 5.59 & 6.72 & 20.1 & 8.16 & 21.5 & 45.9 \\
Average & & & & & & \\
\hline
\end{tabular}

Table 3 gives a summary description of the average multifactor productivity (MFP) performance of Australia, New Zealand, and Ireland, over the periods 1979 to 1991 and 1991 to 2002 . The multifactor productivity estimates reported in Table 1 are relative productivity performance results derived from comparing each country against the benchmark production frontiers as presented in figure 2 .

Table 3: Average Annual Multi-Factor Productivity Changes (\%)

\begin{tabular}{l|ccc}
\hline & $1979-1989$ & $1990-2002$ & $1979-2002$ \\
\hline Australia & 0.87 & 1.74 & 1.25 \\
Ireland & -0.44 & 2.65 & 1.46 \\
New Zealand & 0.35 & 0.82 & 0.56 \\
OECD Average & 1.33 & 1.17 & 1.26 \\
\hline
\end{tabular}

In the 1980s, Australia out-performed both Ireland and New Zealand in multi-factor productivity growth, but Ireland performed much better in the 1990s. All three countries lost ground on the average of the 19 OECD countries sampled through the 1980s, where on average multi-factor productivity growth was 1.33 percent in the period 1979-1989 and 1.17 percent in the period 1990-2002. Both Ireland and Australia performed better than average through the 1990s, while New Zealand continued to under-perform relative to the average.

Labour productivity is decomposed into efficiency change $(\mathrm{ECH})$, inputbiased technical change (IBTC), a (net) magnitude technical change component (MTC), and capital deepening ( $\mathrm{KCH})$, in Figure 3. This decomposition is broadly consistent with what the raw data in Table 1 and Table 2 suggest, with Ireland exhibiting high capital growth and higher labour productivity gains, and New Zealand showing low capital growth and low productivity gains. Ireland's growth in labour productivity is clearly the highest of the three countries and well above 
the OECD average. Multifactor productivity across the 19-country OECD sample is driven by (net) magnitude technological change and capital deepening, with negligible efficiency change. In contrast, New Zealand and Australia experienced negative efficiency change which offset the gains from capital deepening. Ireland also stands out due to large gains in capital intensity, considerable efficiency and (biased) technical change improvements.

Figure 3: Labour Productivity (YCH) Decompositions, 1979-2002

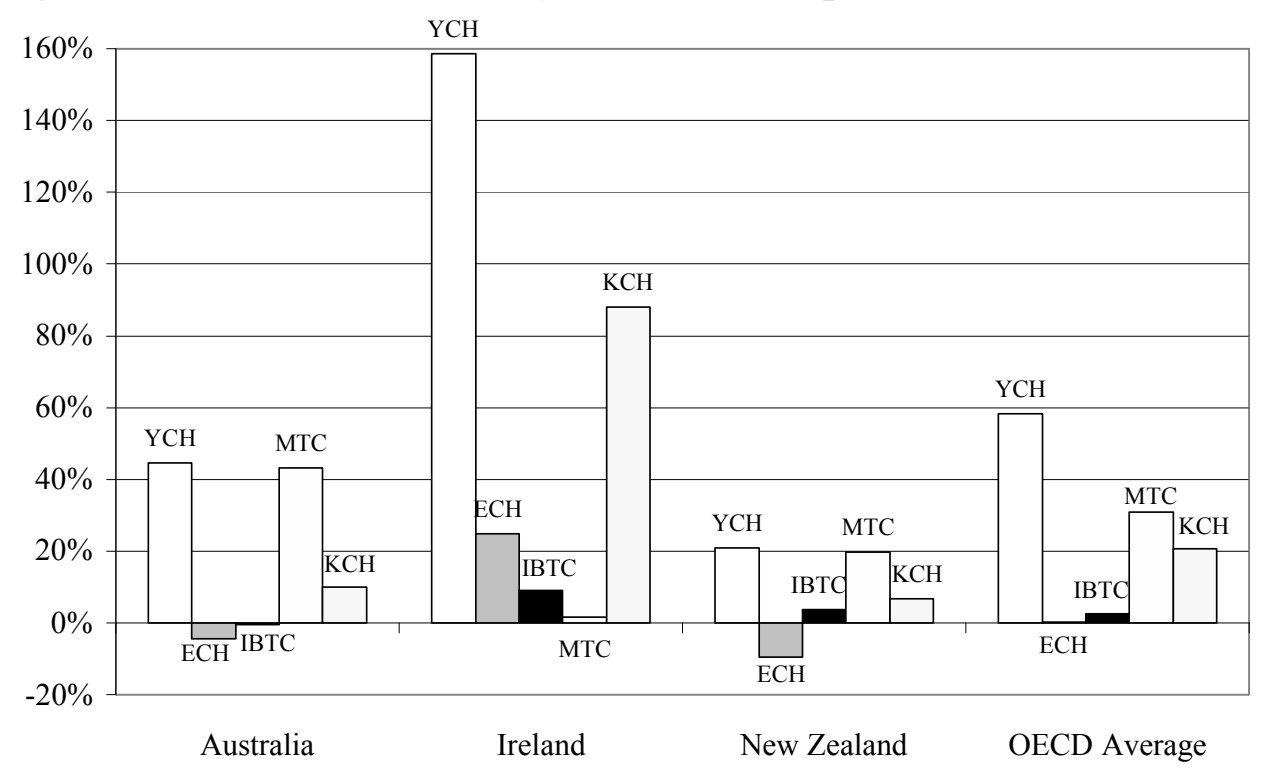

\section{Sectoral Productivity}

Shift-share analysis was used to gain further insights on the link between biased technical change and changes in sectoral composition. Shift-share analysis breaks down aggregate productivity growth into three components: an intersectoral or 'within' sector component which measures the (counterfactual) contribution of each industry to aggregate productivity growth; an 'in between' (static) component measuring the effect of changes in industry employment shares on aggregate productivity; and a dynamic (interaction) component which captures the residual effect of changes in both industry productivity and employment shares. These analyses indicate that industry contributions to aggregate labour productivity growth for the OECD countries are dominated by 'within' sector effects, with little contribution from sectoral shifts (the 'static' and 'dynamic' effects; data not shown). This suggests little impact on aggregate productivity growth from higher productivity industries gaining employment shares or lower productivity industries losing shares. 
Table 4: Labour Productivity Decomposition Changes, Ireland

\begin{tabular}{|c|c|c|c|c|c|c|c|c|}
\hline \multirow[b]{2}{*}{ Sector } & \multicolumn{4}{|c|}{1981 to 1990} & \multicolumn{4}{|c|}{1991 to 2000} \\
\hline & Within & Static & Dynamic & Overall & Within & Static & Dynamic & Overall \\
\hline $\begin{array}{l}\text { Agriculture, } \\
\text { forestry }\end{array}$ & 0.900 & -0.185 & -0.116 & 0.598 & 0.425 & -0.817 & -0.172 & -0.564 \\
\hline Mining & 0.031 & -0.086 & -0.017 & -0.072 & 0.106 & -0.051 & -0.030 & 0.025 \\
\hline $\begin{array}{l}\text { Manufacturing, } \\
\text { low-tech }\end{array}$ & 1.864 & -0.299 & -0.294 & 1.271 & 2.732 & -0.781 & -0.705 & 1.246 \\
\hline $\begin{array}{l}\text { Manufacturing, } \\
\text { high-tech }\end{array}$ & 0.963 & 0.146 & 0.168 & 1.277 & 22.426 & 0.285 & 2.905 & 25.617 \\
\hline Utilities & 0.107 & -0.012 & -0.008 & 0.087 & 0.398 & -0.256 & -0.217 & -0.074 \\
\hline Construction & -0.331 & -0.341 & 0.066 & -0.606 & 0.499 & 0.469 & 0.206 & 1.175 \\
\hline $\begin{array}{l}\text { Wholesale and } \\
\text { retail trade }\end{array}$ & 0.473 & 0.282 & 0.053 & 0.807 & -0.101 & 0.389 & -0.012 & 0.276 \\
\hline $\begin{array}{l}\text { Transport and } \\
\text { communication }\end{array}$ & -0.037 & -0.046 & 0.001 & -0.082 & 0.882 & -0.081 & -0.060 & 0.742 \\
\hline $\begin{array}{l}\text { Financial } \\
\text { services }\end{array}$ & -0.051 & 0.368 & -0.022 & 0.295 & 0.887 & 0.187 & 0.123 & 1.197 \\
\hline General services & 1.167 & 0.561 & 0.140 & 1.868 & 1.398 & 0.660 & 0.136 & 2.193 \\
\hline TOTAL & 5.087 & 0.386 & -0.029 & 5.444 & 29.652 & 0.006 & 2.175 & 31.833 \\
\hline
\end{tabular}

Table 4 shows the shift-share analysis for the Irish economy over the period 1981-2000. The figures represent the contribution to economy-wide change in labour productivity of each sector, and the decomposition into 'within', 'static', and 'dynamic' effects. The analysis suggests that Ireland's strong productivity performance has been almost entirely driven by productivity gains in the high-tech manufacturing sector, which provided 23 per cent (that is,1.277 of 5.444) of the economy-wide change in labour productivity for the period 1981-1990, and over 80 per cent of the change in labour productivity for 1991-2000. Significant productivity gains have also been made in low-tech manufacturing, construction, financial services and general services. In all cases these productivity gains have been dominated by 'within' sector effects, rather than by re-distribution of employment to more productive uses. However, Ireland is unique in recording a sizable positive dynamic effect, consistent with an effective process of economic restructuring. This is particularly true of the high-tech manufacturing sector.

The highest contribution to labour productivity growth in New Zealand was made by the transport and communications sector, the financial services sector in the 1980s, and the utilities sector in the 1990s (see table 5). Productivity growth in the transport and communication and utilities sectors was driven by 'within' sector effects. In the financial services sector productivity growth is dominated by 'static' effects, suggesting changes in the share of employment in this sector was a significant driver of productivity growth. In contrast with Ireland, the contribution 
of the high tech manufacturing and general services sectors to productivity growth has been much more modest.

Table 5: Labour Productivity Decomposition Changes, New Zealand

\begin{tabular}{|c|c|c|c|c|c|c|c|c|}
\hline \multirow[b]{2}{*}{ Sector } & \multicolumn{4}{|c|}{1981 to 1990} & \multicolumn{4}{|c|}{1991 to 2000} \\
\hline & Within & Static & Dynamic & Overall & Within & Static & Dynamic & Overall \\
\hline $\begin{array}{l}\text { Agriculture, } \\
\text { forestry }\end{array}$ & 0.570 & -0.118 & -0.043 & 0.408 & 0.746 & -0.521 & -0.165 & 0.060 \\
\hline Mining & 0.203 & 0.030 & 0.046 & 0.278 & -0.027 & 0.014 & -0.001 & -0.015 \\
\hline $\begin{array}{l}\text { Manufacturing, } \\
\text { low-tech }\end{array}$ & 0.672 & -0.232 & -0.047 & 0.392 & 0.494 & -0.292 & -0.039 & 0.164 \\
\hline $\begin{array}{l}\text { Manufacturing, } \\
\text { high-tech }\end{array}$ & 0.697 & -0.289 & -0.117 & 0.290 & 0.140 & -0.011 & -0.001 & 0.128 \\
\hline Utilities & 0.060 & 0.118 & 0.011 & 0.188 & 1.082 & -0.541 & -0.651 & -0.110 \\
\hline Construction & 0.470 & -0.146 & -0.062 & 0.262 & -0.282 & 0.303 & -0.072 & -0.050 \\
\hline $\begin{array}{l}\text { Wholesale and } \\
\text { retail trade }\end{array}$ & -1.868 & -0.050 & 0.015 & -1.904 & -0.184 & 0.693 & -0.028 & 0.481 \\
\hline $\begin{array}{l}\text { Transport and } \\
\text { communication }\end{array}$ & 1.290 & -0.261 & -0.209 & 0.820 & 2.186 & -0.270 & -0.233 & 1.684 \\
\hline $\begin{array}{l}\text { Financial } \\
\text { services }\end{array}$ & -0.036 & 1.598 & -0.019 & 1.542 & -0.476 & 0.782 & -0.082 & 0.224 \\
\hline General services & 0.029 & 0.168 & 0.004 & 0.201 & 0.297 & 0.052 & 0.010 & 0.359 \\
\hline TOTAL & 2.086 & 0.817 & -0.424 & 2.478 & 3.976 & 0.211 & -1.262 & 2.925 \\
\hline
\end{tabular}

Table 6: Labour Productivity Decomposition Changes, Australia

\begin{tabular}{l|cccccccc}
\hline & \multicolumn{9}{|c}{1981 to 1990} & \multicolumn{5}{c}{1991 to 2000} \\
Sector & Within & Static & Dynamic & Overall & Within & Static & Dynamic & Overall \\
\hline $\begin{array}{l}\text { Agriculture, } \\
\text { forestry }\end{array}$ & 0.322 & -0.253 & -0.073 & -0.004 & 0.313 & -0.150 & -0.038 & 0.124 \\
Mining & 0.601 & -0.187 & -0.113 & 0.301 & 0.666 & -0.288 & -0.135 & 0.242 \\
Manufacturing & -0.189 & -0.553 & 0.023 & -0.719 & 0.466 & -0.399 & -0.049 & 0.018 \\
Utilities & 0.882 & -0.377 & -0.455 & 0.051 & 0.636 & -0.350 & -0.271 & 0.016 \\
$\begin{array}{l}\text { Construction } \\
\text { Wholesale and }\end{array}$ & -0.440 & 0.339 & -0.074 & -0.175 & 0.094 & 0.290 & 0.015 & 0.399 \\
retail trade & -0.528 & 0.249 & -0.034 & -0.313 & 1.113 & -0.172 & -0.055 & 0.886 \\
$\begin{array}{l}\text { Transport and } \\
\text { communication }\end{array}$ & 0.587 & -0.356 & -0.125 & 0.106 & 0.775 & 0.001 & 0.000 & 0.776 \\
$\begin{array}{l}\text { Financial } \\
\text { services }\end{array}$ & -0.474 & 1.670 & -0.220 & 0.977 & 0.116 & 1.176 & 0.029 & 1.321 \\
$\begin{array}{l}\text { General services } \\
\text { TOTAL }\end{array}$ & -0.411 & 0.355 & -0.027 & -0.083 & 0.580 & 0.028 & 0.003 & 0.611 \\
\hline
\end{tabular}


Australia's productivity growth is dominated in both periods by the financial services sector. Similar to New Zealand, the static effect accounts for almost all productivity growth in this sector (see table 6). The transport and communication, and wholesale and retail trade sectors also contributed significantly to productivity growth in the 1990s, though dominated by 'within' sector effects. Manufacturing productivity growth in Australia was strongly negative in the 1980s and slightly positive in the 1990s, although both high- and low-tech manufacturing are included together, which may mask differences in the individual contributions of the high-tech and low-tech sectors.

\section{Comparison with Other Selected Estimates}

Cassidy (2004) reviewed aggregate and sectoral trends in Ireland's productivity performance, and found strong aggregate productivity growth, with an acceleration in the 1990s driven by the performance of high-technology sectors of the economy. He found that GDP per labour hour had increased on average by 3.6 per cent per annum over the period 1991-1995, and by 5.1 per cent per annum over the period 1996-2002. This corresponds to a 69 per cent increase in labour productivity over the twelve year period 1991-2002, which is similar to our estimate of 66.5 per cent for the same period. In decomposing productivity growth by sector, Cassidy attributed improvements in labour productivity over the period 1996-2000 to improvements in productivity within the manufacturing sector. This aligns well with our estimates that show productivity improvement in Ireland in the 1990s was dominated by the within sector effect of high-tech manufacturing.

Black, Guy and McLellan (2003) found an acceleration of multifactor productivity in New Zealand in the 1990s which is consistent with the results shown in Table 3. Gounder and Xayavong (2004) using a stochastic frontier production approach found that for the New Zealand manufacturing sector technical change increased in the post reform period (1984-1998), while efficiency declined. They also found that the deregulation period was associated with a decrease in allocative inefficiency which they attributed to a reduction in price distortions. These results are generally in line with those reported in Table 3 (for the whole New Zealand economy) and Table 5 (for the manufacturing industries) above. (Margaritis, Färe and Grosskopf (2005) report that IBTC in New Zealand was 0.32 per cent on average during 1990-2002 up from -0.01 per cent in the 1979-189 period. These improvements are likely to reflect the effect of better resource allocations (input mix) in response to relative changes in factor prices.)

Parham (2000) showed that Australia experienced acceleration in productivity growth in the 1990s which is consistent with the figures in Table 3. Parham (2004) estimated trend multifactor productivity for 12 industries, which showed multifactor productivity increases were greatest in the utilities and communications sectors through both the 1980s and 1990s. We found strong productivity growth in those sectors, but greater growth in the wholesale and retail trade and financial services sectors, both of which showed very little growth in the 
estimates by Parham. Parham and Roberts (2004) decomposed labour productivity growth into multifactor productivity growth and capital deepening, and found capital deepening was a significant contributor to labour productivity growth, contributing around 60 per cent of labour productivity growth for New Zealand 1996-2002 and Australia 1979-2003. This is a significantly greater contribution than we report in our decomposition in Figure 3.

The actual multifactor productivity estimates from Parham (2004) and Parham and Roberts (2004) are probably not directly comparable to our estimates, not only because of the different time period but also because of the different methodology used. The multifactor productivity estimates reported in this paper are measures of relative performance when compared to the efficient frontier. They are derived from a Malmquist productivity index as opposed to the Tornqvist and Fisher indices used in the Black, Guy and McLellan (2003) paper; these indices can be shown to be equivalent to a Malmquist index provided that the technology can be modelled by specific parametric functional forms, for example, translog for Tornqvist; they also assume optimisation (for example, profit maximisation) behaviour and perfectly competitive markets, a situation which is not often the case in practice. In addition, conventional TFP measures assume that production takes place on the technology frontier, that is, there is no inefficiency. As it is seen in Figure 2 there is always a chance that countries (or their industries) will not operate at the frontier of technology; this distance, given by the proportionate increase in output for given inputs required to reach the frontier (or the proportionate reduction in inputs to produce a given level of output), is a measure of inefficiency.

\section{Discussion}

The growth experiences of Australia, New Zealand, and Ireland are a study in contrast, particularly through the 1990s. While Australia has performed generally in line with the OECD average, New Zealand has slowly fallen away, and Ireland has outperformed any other OECD country in terms of productivity growth. New Zealand is estimated to have one of the highest rates of multifactor productivity growth in the 1980s, while Ireland's growth rate is significantly higher than any other OECD country in the 1990s (about 4 per cent per annum, on average).

In Ireland, increases in productivity growth were driven predominantly by capital deepening, with a significant improvement in efficiency, while in New Zealand and Australia efficiency change was negative, and productivity growth was dominated by (neutral) technical change effects. It is somewhat surprising that New Zealand should experience efficiency losses despite undertaking perhaps the most extensive economic restructuring program in the OECD. This poor efficiency record explains in part New Zealand's continual fall away from the OECD average in aggregate production measures. New Zealand's productivity performance has also been hampered by slow growth in capital accumulation, particularly during the 1990 s. 
Obviously, different sources of productivity growth will be manifest in different measures of efficiency change and technical change. Labour shedding may lead to improvements in efficiency and therefore productivity provided that labour is not efficiently utilised (there is a slack) and shedding leads to higher rates of utilisation of the most efficient segment of the labour force. Better diffusion of technology and management practices will also lead to improvements in efficiency. In all these cases, efficiency improvements are captured by movements towards the frontier (best practice) of technology. The frontier itself can change over time; this is what we refer to as technological change. It results from the adoption of better technology practices. Shifts in the frontier do not have to be parallel (that is, technological change does not have to be neutral). This is illustrated in figure 2 where the shift in the frontier is clearly not proportional at different capital-labour ratios. What we observe in practice is that countries and industries change their input mix (and output mix in the case of more than one output); this can be the result of structural changes or other regulatory reforms that lead to changes in relative (input or output) prices. Input-biased technical progress may be the result of this; for example, widespread economic reforms in New Zealand may have led to positive IBTC growth (that is, change in relative input prices leading to a different, more optimal, input mix) and this performance may have been better than other countries given that the New Zealand reforms were phased in much earlier and were far more comprehensive than in other OECD countries. Recall that performance measures are relative. In Australia on the other hand, the reform process was a lot more gradual with most benefits realised well into the 1990s; this is consistent with the IBTC numbers reported in figure 3.

Sectoral shifts contribute surprisingly little to productivity growth, which is predominantly driven by within sector effects. Ireland is the exception, with strong 'in between' effects consistent with an effective process of economic restructuring. The high-tech manufacturing and tertiary sectors were the major contributors to productivity growth in Ireland. High-tech manufacturing had a much smaller effect in New Zealand and Australia, where tertiary sectors drove productivity growth.

Parham (2004) provides a good review of the literature on sources of productivity growth in Australia, suggesting that growth was driven by (i) accumulation of physical and human capital; (ii) greater openness of the economy to trade and investment; and (iii) increased research and development and the adoption of technology, particularly information and communication technology. Again our results corroborate these suggestions, as capital deepening proves a significant source of labour productivity growth.

By contrast, Cassidy (2004) suggested that the strong productivity growth of Ireland was largely driven by (i) substantial foreign direct investment (FDI), particularly from the United States; and (ii) considerable shifting of capital and labour from relatively low productivity sectors into high-tech sectors; and facilitated by (iii) a favourable exchange rate; (iv) increased integration with the European Union; and (v) the availability of a young, well-educated workforce. Our results corroborate these suggestions, and though the effect of input-biased 
technical change is small in comparison to other effects, it is much larger than for Australia, New Zealand, or the OECD average. FDI inflows led to increasing capital deepening; adoption of better technology and diffusion (management practices); as well as facilitated 'dynamic' changes in sectoral productivity. All these appear to have been significant drivers of productivity growth in Ireland. In addition, the OECD (2004a) reports that Ireland's exposure to foreign trade (an indicator of export intensity and import penetration) increased in the 1990s; there was no change in the case of Australia; while New Zealand's exposure fell in the 1990s in comparison to the 1980s level. Given the discussion presented above it would appear that private research and development, innovation and technology spill-overs from the high-tech manufacturing sector have almost certainly driven the increases in productivity growth in Ireland. This was facilitated by significant foreign direct investment in this sector, particularly from the United States.

\section{Conclusion}

In this paper we investigated the growth experience of Australia, New Zealand, and Ireland over the period 1979-2002. Ireland has outperformed Australia and New Zealand, both in terms of economic growth, and labour productivity growth. In Ireland, increases in productivity growth were driven by both efficiency and technological change improvement and particularly by increases in labour productivity of the high-tech manufacturing and services sectors. Increases in labour productivity in the high-tech manufacturing sector in Ireland probably originated from research and development, innovation and technology spill-overs as a result of significant foreign direct investment.

Since productivity gains are realised at the firm level, it is difficult for policymakers to have a direct impact on productivity. However, productivity may potentially be improved by providing an economic policy environment with appropriate incentives for investment, entrepreneurship and innovation. This suggests a role for policymakers in addition to providing macroeconomic stability and encouraging human capital investment. Regulation of labour and financial markets also needs to be kept to a minimum to ensure a flexible supply of labour and financial capital is available.

Macroeconomic stability, appropriate regulation, efficient capital markets, higher education, and research and development are suggested to be important drivers of labour productivity growth. This is consistent with our findings. If Ireland is to be used as a model, our results suggest that policymakers should concentrate their efforts on providing an enabling economic environment that encourages investment (both foreign and domestic), entrepreneurship and innovation. This is in addition to existing goals of macroeconomic stability and human capital development. 


\section{References}

Black, M., M. Guy and N. McLellan (2003), 'Productivity in New Zealand 1988 to 2002', New Zealand Treasury Working Paper 03/06, New Zealand Treasury, Wellington.

Bollard, A., R. Lattimore and B. Silverstone (1996), 'Introduction', pp. 1-30 in B. Silverstone, A. Bollard and R. Lattimore (eds), A Study of Economic Reform - The Case of New Zealand, Elsevier Science, Amsterdam.

Burnham, J. (2003), 'Why Ireland Boomed', The Independent Review: A Journal of Political Economy 7(4):537-556.

Cassidy, M. (2004), 'Productivity in Ireland: Trends and Issues', Central Bank and Financial Services Authority of Ireland Quarterly Bulletin Spring:83-105.

Clark, P. (1982), 'Inflation and the Productivity Decline', American Economic Review 72(2):149-154.

Färe, R., S. Grosskopf and D. Margaritis (2005), 'Productivity Growth and Convergence in the European Union', Journal of Productivity Analysis 25:forthcoming.

Färe, R., S. Grosskopf, M. Norris and Z. Zhang. (1994), 'Productivity Growth, Technical Progress, and Efficiency Change in Industrialized Countries' American Economic Review 84(1):66-83.

Gounder, R. and V. Xayavong (2004), 'A Decomposition of Total Factor Productivity Growth in New Zealand's Manufacturing Industries: A Stochastic Frontier Approach', presented to the New Zealand Association of Economists Conference, Wellington, 30 June-2 July.

Industry Commission, (1998), Microeconomic Reforms in Australia: A Compendium from the 1970s to 1997, Canberra.

Kumar, S. and R. Russell (2002), 'Technological Change, Technological Catch-up, and Capital Deepening: Relative Contributions to Growth and Convergence', American Economic Review 92(3):527-548.

Link, A. (1987), Technological Change and Productivity Growth, Harwood Academic Publishers, New York.

Margaritis, D., R. Färe and S. Grosskopf (2005), 'Productivity, Convergence and Policy: A Study of OECD Countries and Industries', Journal of Productivity Analysis forthcoming.

Norsworthy, J., M. Harper, and K. Kunze (1979), 'The Slowdown in Productivity Growth: Analysis of Some Contributing Factors', Brookings Papers on Economic Activity 2:387-421.

O’Connell, P. (1999), Astonishing Success: Economic Growth and the Labour Market in Ireland, International Labour Organization, Geneva.

OECD (2003), The Sources of Economic Growth in OECD Countries, Paris.

OECD (2004a), Understanding Economic Growth, Paris. 
OECD (2004b), OECD in Figures, 2004 edition, Paris.

Parham, D. (2000), ‘A More Productive Australian Economy', Agenda 7(1):3-16.

Parham, D. (2004), 'Sources of Australia's Productivity Revival', The Economic Record 80(249):239-257.

Parham, D. and P. Roberts (2004), 'Productivity Growth and Its Sources: How do New Zealand and Australia Compare?', presented to 'Productivity: Performance, Prospects and Policies' Workshop, Wellington, 28-29 July.

The authors would like to acknowledge the helpful suggestions of colleagues at Auckland University of Technology and Waikato University along with those of the Editor and two anonymous referees. We also acknowledge the excellent research assistance of Gary Feng and the financial support of the NZ Foundation for Research Science and Technology via Project 7980-ABEP-UOW Modelling Efficiency, Growth, Innovative Practices and Exports of New Zealand Enterprises. 


\section{Dynamics of Financial Disadvantage}

\section{Gary Marks}

$\mathrm{R}$ esearch on financial disadvantage in Australia has focused mainly on income poverty. Income poverty is defined as living in a household whose income is below that of a designated poverty line. However, income poverty may provide only a limited understanding of financial disadvantage. Concepts such as subjective poverty, expenditure poverty, deprivation and financial stress are designed to overcome perceived inadequacies in the concept of income poverty. A major point of the submission by the Department of Family and Community Services (DFCS, 2003:xi) to the Senate (2004:xvii,18-20) inquiry into poverty was that financial disadvantage was too narrowly defined by income. Deprivation and financial stress are measures of households' financial situation that may complement income poverty (McColl, Pietsch and Gatenby, 2001). Saunders (1996) pointed out that income is at best an imperfect indicator of living standards. Travers and Richardson (1993) argued that financial disadvantage is better measured by several indicators, such as deprivation and financial stress, as well as income. Therefore, there is an implicit assumption that the different indicators are tapping the same underlying concept of poverty or financial disadvantage, but all do so imperfectly.

The purpose of this paper is to contribute to the understanding of financial disadvantage by analysing several of its indicators in addition to the commonly used measure, before-housing income poverty. The additional indicators are afterhousing income poverty, subjective poverty and financial stress. The paper examines the extent of financial disadvantage in Australia according to these four indicators, mobility in and out of financial disadvantage, and the interrelationships between indicators. The relationships between the indicators and a range of demographic, sociological and economic factors are also examined.

Before-housing Income poverty is defined as living in a household with disposable income, after adjusting for household composition, below a designated poverty line. After-housing measures adjust household disposable income and thus the designated poverty line for housing costs. Subjective poverty is defined as judging one's level of prosperity as 'poor' or 'very poor'. Individuals and households in financial stress are not coping financially; they have difficulty in meeting their financial obligations and may seek financial assistance from others.

Income poverty, subjective poverty and financial stress are by no means the only indicators of financial disadvantage. Other indicators include expenditure poverty which, similar to income poverty, is defined as expenditure levels less than a designated level (DFCS, 2003:92; Saunders, 1997; Saunders, 1998); relative deprivation, defined as the 'enforced lack of perceived social necessities

Gary N. Marks is Research Associate and Associate Professor at the Melbourne Institute of Economic and Social Research. 
in life' (Mack and Lansley, 1985:39); multidimensional approaches which combine several measures of poverty (Dewilde, 2004; Kangas and Ritakallio, 1998); and the social exclusion approach which broadens the concept of poverty to include social relationships and participation (Eurostat Task Force, 1998; Saunders and Kayoko, 2002:45-62; Tsakloglou and Papadopoulos, 2002; Whelan, Layte and Maitre, 2003).

However, due to data limitations this study is restricted to income poverty, subjective poverty and financial stress.

\section{Previous Studies}

\section{Incidence}

The dominant approach to the study of poverty in Australia and in other western countries is relative income poverty. The poverty line is most often drawn at half the median disposable household income (Atkinson, 1998; Brady, 2003; Moller et al, 2003; Oxley, 1997). Using the commonly used OECD equivalence scale to adjust for household size the half-median disposable income measure indicates that about 10 per cent of Australians were in poverty in 2000 (Harding, Lloyd and Greenwell, 2001:35). For the financial year, 2000-2001 the estimate by Headey, Marks and Wooden, (2005) is much higher at 14 per cent - the discrepancy is probably due to differences in the processing of households with very low, zero or negative incomes. After adjusting for housing costs, Harding, Lloyd and Greenwell (2001:36) found income poverty increased by 5 percentage points to around 15 per cent.

The measurement of non-income concepts such as subjective poverty and financial stress is less common in Australia and often varies between survey instruments. The 1998-99 Household Expenditure Survey included items that are often used as indicators of financial stress. About 16 per cent of households could not pay utility bills on time, 7 per cent could not pay car registration or insurance on time, 4 per cent pawned or sold something, 3 per cent went without meals, 2 per cent could not afford to heat their home and 3 per cent sought assistance from welfare organizations. A summary measure of financial stress indicated that about 13 per cent of households had high levels of financial stress, 21 per cent moderate stress and 66 per cent low or no stress (ABS, 2002; McColl, Pietsch and Gatenby, 2001).

\section{Dynamics}

Only recently has it been possible to study the dynamics of income poverty in Australia. Breusch and Mitchell (2003) reported that of households in the lowest equivalised income quintile in 1997, only 29 per cent were in the same quintile three years later. In a study of child poverty dynamics in Australia, Abello and Harding $(2004: 18,33)$ estimated that about 5 to 7 per cent were poor persistently over a three-year period. About 30 per cent were in poverty in one of the three 
years examined (p. 20). More recently, analysis of the first three waves of the Household, Income and Labour Dynamics in Australia (HILDA) survey estimated that about four per cent were in poverty (defined as below 50 per cent of median household income) consistently compared to annual rates of between 12 and 14 per cent (Headey, Marks and Wooden, 2005).

\section{Inter-relationships between indicators of financial disadvantage}

The relationships between income poverty and other indicators of financial disadvantage tend to be weaker than expected. Financial stress is higher among households in the lowest income quintile, and declines in each subsequent quintile. However, 70 per cent of households in the lowest income quintile had no cashflow problems in the previous twelve months (ABS, 2004:Table 32). Bray (2003:vi,23) noted that although lower incomes are associated with higher rates of financial stress, only a minority of households in the lowest income quartile experienced hardship or cash-flow problems. Generally, the correspondence between income poverty and other measures of financial disadvantage is not high. Saunders, Brashaw and Hirst (2002) found the poverty rate in the United Kingdom was halved when defined in terms of both income and expenditure. In Australia, only about 2.2 per cent of households were in both income and expenditure poverty. Bradshaw and Finch (2003) found only a weak correspondence between subjective evaluations on being in poverty and income poverty.

\section{Demographic and sociological correlates of financial disadvantage}

Most of the Australian research on the correlates of financial disadvantage has focused on income poverty. Income poverty is lower among older Australians especially on post-housing measures (Harding, Lloyd and Greenwell, 2001:17, 19; Korpi and Palme, 1998; Saunders, 1996). Harding, Lloyd and Greenwell (2001) found no substantial differences by gender in the risk of being in poverty. According to the Australian Institute of Health and Welfare, poverty among sole parents in 1989-90 was about three times the national rate (Saunders, 1996). Similarly, Harding, Lloyd and Greenwell, (2001) estimated that 22 per cent of sole parents were in poverty, compared to 18 per cent of single persons, 12 per cent of couples with children and only 6 per cent of couples without children. Among sole parents with two or more children the poverty rate is over 25 per cent (pp. 7-8). Eardley (1998) also found that income poverty is associated with sole parenthood and larger families. Poverty among Indigenous Australians is very high; about three times the rate among non-indigenous families (Ross and Whiteford, 1992). Overall, immigrants do not show a particularly high incidence of poverty although some immigrant groups do (Johnson 1991). Low education is also associated with income poverty. Among those with no post-secondary qualifications, income poverty (on the half mean disposal income measure) was 15 per cent compared to 11 per cent among those with diploma, certificate and trade qualifications and only 6 per cent among those with a Bachelor degree (or higher) qualification (Harding, Lloyd and Greenwell, 2001:14). Income poverty is 
strongly associated with labour force status. Among families with no wage earners, 28 per cent were in poverty in 2000 compared to less than seven per cent of families with at least one full-time wage earner (Harding, Lloyd and Greenwell, 2001:12). Eardley (1998) found that among full-year full-time employees, poverty, defined by the half median income, was very low at around one per cent.

Work on social correlates of other financial disadvantage indicators is limited to financial stress. Breunig and Cobb-Clark (2004) found that sole parenthood and children are associated with financial stress. La Cava and Simon (2005) reported that 'cash flow problems' were negatively related to age, being a couple without children, home ownership (and home value), disposable income and number of credit cards held, and was positively related to unemployment, family size, single parenting, and being on welfare. McColl, Pietsch and Gatenby (2001) found that financial stress was associated with larger families, disability, sole parenthood, unemployment, having a mortgage, and paying interest on credit cards.

\section{Data and Measures}

\section{Data}

The data used in these analyses are from the first three waves (2001 to 2003) of the longitudinal Household, Income and Labour Dynamics in Australia (HILDA) survey. Several features of HILDA make it particularly useful for investigations of financial disadvantage. It is the first large-scale Australian longitudinal survey of adults specifically designed to investigate dynamics, whereas previous studies of poverty have relied on cross-sectional data. Second, income data were collected from all available (and eligible) household members, improving the accuracy of income and other variables. Third, HILDA includes data from wave 2 on wealth, assets and debts allowing for the examination of their relationships with financial disadvantage. The HILDA Users Manual (Watson, 2005) details the sampling, weighting, imputation and other technical aspects of the study.

For each wave, three data files were created: a household data file derived from the household questionnaire, a responding person file derived from the person questionnaire and the self-completion questionnaire. The enumerated person data file was derived from the household grid. The questionnaires can be downloaded from the Melbourne Institute web-site.

\section{Measures}

The four measures of financial disadvantage measured are: housing income poverty, after-housing income poverty, subjective poverty and financial stress. Individuals living in a household with equivalised disposable income below 50 per cent of the median were defined as before-housing income poverty. Income includes income from wages and salary, unincorporated businesses, investments, private pensions (superannuation, workers' compensation), government benefits and pensions, and other regular sources (for example, child maintenance 
payments). Disposable income is calculated as the income received after adjusting for taxes and government transfers such as pensions, family benefits, unemployment and other benefits (Headey, 2003). Where information on any of the main income components was missing, its value was imputed using a method developed specifically for longitudinal data (see Watson, 2005). The equivalence scale used is the modified OECD scale which assigns a weight of 1 to the first adult, a weight of 0.5 to second and other adults and a weight of 0.3 for children under 14 years of age (Förster, 2000; OECD 2001:note 2; Whelan, Layte, and Maitre, 2002). The resulting measure differs slightly from other measures of before-housing income poverty constructed from the HILDA data. The poverty line is drawn at the household with the median income, not the household that includes the individual with the median income. Second, households with negative household incomes were not included in the calculation of income poverty.

The second measure - after-housing income poverty - is similar to the first. Following Harding, Lloyd and Greenwell, (2001) disposable family income has been recalculated by subtracting housing costs. From this distribution a second income poverty line was calculated at 50 per cent of the median. The third measure subjective poverty was defined by respondents indicating that they were 'poor' or 'very poor' in response to a question on their level of prosperity. Respondents were asked: 'Given your current needs and financial responsibilities, would you say you and your family are' (Prosperous, Very Comfortable, Reasonably Comfortable, Just Getting Along, Poor, and Very Poor). The fourth measure, 'financial stress', is defined in terms of seven behaviours due to $a$ shortage of money: could not pay utility bills on time, could not pay mortgage or rent on time, pawned or sold something, went without meals, was unable to heat home, asked for financial help from friends or family, and asked for help from welfare/community organisations. Individuals were defined as in financial stress if they experienced two or more of these events since the beginning of the year. One cash-flow problem, such as not paying a pay on time or borrowing money does not really constitute financial stress since there many reasons why this may occur. However, two or more cash-flow problems do suggest financial stress.

\section{Findings}

\section{The extent of financial disadvantage}

Table 1 presents estimates of the level of financial disadvantage according to the four indicators. The estimates are for each wave and weighted with the responding person weights. The standard errors (in parentheses) allow calculation of confidence limits for the estimates. These standard errors are adjusted for the clustering of individuals within households. The commonly used 95 per cent confidence limits are plus or minus 1.96 (or 2) standard errors of the estimate. The weights take into account differences between the samples and population benchmarks and to adjust for sample attrition. 
The four measures provide quite different estimates of the level of financial disadvantage. The level of subjective poverty is low at 4.3 per cent. Since the standard error is 0.4 per cent, the 95 per cent confidence limits for the incidence of subjective poverty is between 3.5 and 5.1 per cent (that is, $4.3 \pm 2 * 0.4$ ). In contrast, the level of financial stress is fairly high between 14 and 17 per cent. Before-housing income poverty was between 11 and 13 per cent. The afterhousing measure shows a higher incidence of income poverty: nearly 16 per cent in wave 1 and 13 per cent in wave 3 . Higher levels of poverty using the posthousing measure were also found by Harding, Lloyd and Greenwell, (2001:35-36). Although the incidence of financial disadvantage on any one indicator for a single year is generally low, the incidence for any one of the three years is substantially higher. A quarter was in before-housing income poverty in at least one of the three years, 30 per cent on the after-housing measure; 10 per cent judged themselves as 'poor' or 'very poor' in at least one of the 3 years and 32 per cent had some experience of financial stress. Overall, 53 per cent had experienced financial disadvantage on any indicator in at least one of the three years.

Table 1: Financial Disadvantage Measures: Australia, Persons over 18

\begin{tabular}{l|rrrr}
\hline Indicator & Wave 1 & Wave 2 & Wave 3 & Any Wave \\
\hline & \multicolumn{5}{|c}{ per cent (standard error) } \\
Before-Housing Income poverty & $12.6(0.4)$ & $11.6(0.4)$ & $10.8(0.4)$ & $25.0(0.6)$ \\
After-Housing Income poverty & $15.6(0.5)$ & $14.8(0.5)$ & $13.3(0.5)$ & $29.5(0.6)$ \\
Subjective Poverty & $4.3(0.2)$ & $3.9(0.2)$ & $3.7(0.2)$ & $10.7(0.4)$ \\
Financial Stress (2 or more instances) & $17.1(0.4)$ & $14.6(0.4)$ & $14.0(0.4)$ & $32.0(0.6)$ \\
\hline
\end{tabular}

Note: Standard errors adjusted for clustering of individuals within households.

Table 2: Year-to-Year Stability of Financial Disadvantage

\begin{tabular}{l|ccc}
\hline State in Wave 1 & \multicolumn{3}{|c}{ Same State in } \\
& Wave 2 & Wave 3 & Waves 2 \& 3 \\
\hline Income Poverty (Before Housing) & \multicolumn{3}{|c}{ per cent (standard error) } \\
Income Poverty (After Housing) & $45.7(1.7)$ & $42.1(1.8)$ & $24.0(1.5)$ \\
Subjective Poverty & $47.7(1.6)$ & $43.0(1.6)$ & $29.8(1.5)$ \\
Financial Stress (2 or more instances) & $42.1(2.8)$ & $30.0(2.6)$ & $21.4(2.5)$ \\
\hline
\end{tabular}

Note: Standard errors adjusted for clustering of individuals within households.

\section{The persistence of financial disadvantage}

Table 2 shows there is only a moderate degree of persistence of financial disadvantage over time. As for the preceding analyses the unit of analysis is the 
individual and weighting is based on the responding person weight for the first wave. Of those in before-housing income poverty in wave 1, about 46 per cent were in poverty, so defined, in wave 2, 42 per cent in wave 3 and less than quarter in waves 2 and 3 . Therefore, only 3 per cent were in before-housing income poverty in all three waves. The persistence of after-housing income poverty was slightly higher, but only 5 per cent were in post-housing income poverty in all three waves. Similarly, there was little year-to-year persistence in subjective poverty. Of those who indicated they were poor or very poor in wave 1,42 per cent were in subjective poverty in wave 2, 30 per cent in wave 3 and only about 20 per cent in both waves 2 and 3 . Therefore, less than 1 per cent defined themselves as 'poor' or 'very poor' every year. The year-to-year persistence of financial stress was higher than that for the other indicators of financial disadvantage. Of those in financial stress in wave 1, a majority (55 per cent) were in financial stress in wave 2, 49 per cent in wave 3 but only 36 per cent in waves 2 and 3 . Therefore, about 6 per cent of adults were in financial stress in all three waves.

\section{Correspondence among indicators of financial disadvantage}

The correspondence between the indicators of financial disadvantage at the same time point does not seem to be strong (Table 3 ). These analyses are also based on individuals weighted with the appropriate responding person weight for that wave.

Table 3: Correspondence Between Financial Disadvantage Indicators

\begin{tabular}{l|cccc}
\hline Indicator & 1 & 2 & 3 & 4 \\
\hline Wave 1 & \multicolumn{4}{|c}{ per cent (standard error) } \\
1 Before-housing income poverty & - & $80.9(1.3)$ & $10.5(0.9)$ & $26.3(1.3)$ \\
2 After-Housing Income poverty & $65.0(1.5)$ & - & $11.4(0.9)$ & $31.3(1.3)$ \\
3 Subjective Poverty & $29.7(2.3)$ & $40.7(2.6)$ & - & $68.0(2.5)$ \\
4 Financial Stress & $18.7(1.0)$ & $28.0(1.2)$ & $16.9(0.9)$ & - \\
Wave 2 & & & & \\
1 Before-housing income poverty & - & $78.2(1.4)$ & $9.3(1.0)$ & $23.4(1.5)$ \\
2 After-Housing Income poverty & $61.6(1.8)$ & - & $10.2(1.0)$ & $28.1(1.4)$ \\
3 Subjective Poverty & $25.8(2.5)$ & $35.1(2.8)$ & - & $65.4(2.7)$ \\
4 Financial Stress & $17.5(1.2)$ & $26.3(1.4)$ & $17.4(1.1)$ & - \\
Wave 3 & & & & \\
1 Before-housing income poverty & - & $76.8(1.6)$ & $9.2(1.1)$ & $23.2(1.6)$ \\
2 After-Housing Income poverty & $62.4(1.9)$ & - & $10.2(1.0)$ & $29.9(1.7)$ \\
3 Subjective Poverty & $25.2(2.7)$ & $35.3(3.0)$ & - & $65.6(2.9)$ \\
4 Financial Stress & $16.8(1.2)$ & $27.2(1.5)$ & $17.1(1.2)$ & - \\
\hline
\end{tabular}

Note: Percentages are proportions of each group listed on the left hand side. Standard errors adjusted for clustering of individuals within households. Diagonals $=100$ per cent. 
The correspondence between income poverty and the two non-income measures of financial disadvantage is surprisingly weak. Of those in 'beforehousing income poverty', only about 10 per cent indicated they were 'poor' or 'very poor' and between 20 or 30 per cent were in financial stress. The association between income poverty and financial stress was somewhat stronger on the after-housing measure than before-housing of income poverty. Of those who indicated they were 'poor' or 'very poor', fewer than 30 per cent were in before-housing income poverty and less than 40 per cent were in poverty on the post-housing measure. The relationship between subjective poverty and financial stress is stronger. Of those in subjective poverty, about two-thirds were in financial stress. However, only 17 per cent of those in financial stress judged their financial circumstances as 'poor' or 'very poor'.

Stronger relationships are found between the two measures of income poverty. Of those in before-housing income poverty about 80 per cent were also in after-housing income poverty. However, the correspondence in the other direction is much weaker. Of those in after-housing income poverty only 60 to 65 per cent were in before-housing income poverty.

\section{Correlates of financial disadvantage}

Table 4 presents the results from logistic regression analysis of the four measures of financial disadvantage with a range of demographic, socioeconomic and educational factors. The analyses are limited to adults aged 18 or older. To avoid problems with statistical independence when two or more adults are from the same household, one adult household member was randomly selected from each household. Therefore, the weights used were the household weights. In the text following, the logistic coefficients in Table 4 are converted to odds ratios, which are the exponents of the coefficients. For categorical variables - gender, Indigenous status, language background, type of school attended, education, and marital status - the effects are relative to the appropriate contrast group females, the non-Indigenous, an English speaking background, attended a government school, highest education level Year 12, and single and never married. So the interpretation of the odds ratio is relative to the contrast group, for example, the odds of men being in income poverty are so many times the odds for women, the odds of being in poverty for married persons is so many times that for single people etcetera. The interpretation of the effects for continuous variables depends on the unit of measurement. Here, the number of siblings and number of children are continuous variables ranging from zero. Therefore, the coefficients of these variables are the effects on being in financial disadvantage for a one unit change, that is, for one additional sibling or child. For two siblings or two children the effects are doubled and the odds ratios are squared. Similarly, the effects for three siblings or three children are three times the effects for one sibling or child and the odds ratios are cubed. Age has been divided by 10 so the effects are the change in the odds of being in poverty for a 10 year difference in age. Similarly, both 
parental and respondents' occupational status has been divided by 10 so that effects are for a 10 unit difference on the zero to 100 occupational status scale.

Table 4: Relationships of Financial Disadvantage with Demographic, Socioeconomic and Educational Correlates

\begin{tabular}{l|cccc}
\hline & $\begin{array}{c}\text { Before-Housing } \\
\text { Income poverty }\end{array}$ & $\begin{array}{c}\text { After-Housing } \\
\text { Income poverty }\end{array}$ & $\begin{array}{c}\text { Subjective } \\
\text { Poverty }\end{array}$ & $\begin{array}{c}\text { Financial } \\
\text { Stress }\end{array}$ \\
\hline Intercept & $-1.22^{* * *}$ & $-0.94^{* * *}$ & $-2.79^{* * *}$ & $-1.71^{* * *}$ \\
Male & $-0.19^{*}$ & $-0.19^{* *}$ & 0.20 & -0.03 \\
Age & $0.19^{* * *}$ & -0.02 & -0.08 & $-0.56^{* * *}$ \\
Number of Siblings & $0.03^{*}$ & $0.03^{* *}$ & 0.03 & $0.06^{* * *}$ \\
Not with Both Parents at Age 15 & 0.17 & 0.08 & 0.23 & 0.15 \\
$1^{\text {st }}$ Language not English & $0.70^{* * *}$ & $0.74^{* * *}$ & $0.52^{* * *}$ & $0.28^{* *}$ \\
Indigenous & $0.49^{*}$ & 0.28 & 0.05 & 0.26 \\
Parental Occ. Status (10s) & -0.01 & 0.00 & 0.02 & 0.00 \\
Catholic School & -0.18 & $-0.20^{*}$ & -0.17 & -0.03 \\
Independent School & 0.16 & 0.08 & 0.01 & 0.04 \\
Post-Graduate Quals & $-1.43^{* * *}$ & $-1.01^{* * *}$ & $-0.80^{* *}$ & $-1.10^{* * *}$ \\
Bachelor Degree & $-0.85^{* * *}$ & $-0.67^{* * *}$ & -0.30 & $-0.46^{* *}$ \\
Diploma & -0.30 & -0.22 & -0.07 & -0.03 \\
Advanced Certificate & -0.09 & -0.16 & 0.41 & 0.21 \\
Certificate & -0.17 & -0.07 & 0.25 & $0.29^{*}$ \\
<Year 12 & 0.18 & 0.11 & $0.45^{* *}$ & $0.44^{* * *}$ \\
Married & $-1.48^{* * *}$ & $-1.41^{* * *}$ & $-1.76^{* * *}$ & $-1.29^{* * *}$ \\
De facto & $-1.26^{* * *}$ & $-1.04^{* * *}$ & $-0.92^{* * *}$ & $-0.49^{* * *}$ \\
Separated & $-0.48^{* *}$ & -0.24 & -0.23 & 0.11 \\
Divorced & $-0.41^{* *}$ & $-0.48^{* * *}$ & 0.14 & $0.26^{*}$ \\
Widowed & $-0.38^{* *}$ & $-0.52^{* * *}$ & $-1.74^{* * *}$ & $-0.81^{* * *}$ \\
Number of Children & $0.13^{* * *}$ & $0.16^{* * *}$ & $0.15^{* * *}$ & $0.24^{* * *}$ \\
Rescaled R Square & 0.17 & 0.12 & 0.12 & 0.24 \\
\hline & & & & \\
\hline
\end{tabular}

Note: $* * * \mathrm{P}<0.001, * * 0.001<\mathrm{P}<0.01, * 0.01<\mathrm{P}<0.05$.

Source: HILDA Wave 1.

Consistent with the low correspondence between the four measures of financial disadvantage is their distinctive relationships with background factors. The odds of women being in income poverty were about 1.2 times that for men but there were no gender differences with subjective poverty and financial stress.

Before-housing income poverty is more common among older persons; but there were no statistically significant age differences on the after-housing measure and younger cohorts were substantially more likely to be in financial stress. Further analyses showed that financial stress is highest in the youngest cohort, and declines in successively older cohorts. The number of siblings, not living with 
both parents at age 15, parental occupational status and type of school attended all have weak or statistically insignificant relationships with financial disadvantage. In contrast, a first language other than English increased the odds of financial disadvantage on all four indicators: quite substantially for income poverty. Indigenous status increased the odds of before-income housing poverty but its effects on the other indicators were not statistically significant.

Post-graduate and bachelor degrees substantially reduce the chances of financial disadvantage. However, the strength of these effects of education varied with indicator and a bachelor degree had no impact on subjective poverty. Compared with completion of Year 12, bachelor degrees reduce the odds of before-housing income poverty 2.3 times, post-housing income poverty 2.0 times, and financial stress 1.6 times. Not completing school (Year 12) increased the odds of subjective poverty and financial stress by about 1.5 times. In contrast, diplomas and certificates did not reduce the odds of financial disadvantage. Certificates actually increased the odds of financial stress.

Table 5: Economic Characteristics of Disadvantaged Households

\begin{tabular}{|c|c|c|c|c|c|c|c|c|}
\hline & \multicolumn{2}{|c|}{$\begin{array}{c}\text { Pre-Housing } \\
\text { Income poverty }\end{array}$} & \multicolumn{2}{|c|}{$\begin{array}{l}\text { Post-Housing } \\
\text { Income poverty }\end{array}$} & \multicolumn{2}{|c|}{$\begin{array}{l}\text { Subjective } \\
\text { Poverty }\end{array}$} & \multicolumn{2}{|c|}{ Financial Stress } \\
\hline & Yes & No & Yes & No & Yes & No & Yes & No \\
\hline Means & \multicolumn{8}{|c|}{$\${ }^{\prime} 000$} \\
\hline Personal Income & 7.8 & 38.4 & 11.5 & 38.7 & 21.4 & 35.3 & 25.5 & 36.2 \\
\hline Personal Disposable Income & 7.0 & 29.2 & 9.7 & 29.4 & 17.6 & 26.9 & 20.6 & 27.5 \\
\hline Household Income & 9.7 & 70.1 & 16.1 & 70.7 & 33.4 & 63.9 & 39.6 & 66.6 \\
\hline $\begin{array}{l}\text { Equivalised Household (HH) } \\
\text { Income }\end{array}$ & 8.6 & 53.6 & 13.5 & 54.0 & 28.0 & 48.8 & 32.1 & 50.8 \\
\hline $\begin{array}{l}\text { Equivalised Disp. HH } \\
\text { Income }\end{array}$ & 5.5 & 32.3 & 8.2 & 32.6 & 18.6 & 29.5 & 20.1 & 30.6 \\
\hline $\begin{array}{l}\text { Equiv Disp. HH Income } \\
\text { after Housing }\end{array}$ & 2.2 & 27.6 & 2.1 & 28.4 & 13.7 & 25.0 & 14.9 & 26.3 \\
\hline Household Wealth & 252.2 & 450.8 & 223.5 & 462.1 & 103.3 & 447.6 & 158.4 & 479.5 \\
\hline Household Assets & 280.1 & 527.0 & 270.0 & 536.2 & 124.2 & 519.7 & 200.6 & 554.2 \\
\hline Household Debt & 31.0 & 76.4 & 45.2 & 75.0 & 23.6 & 72.8 & 46.4 & 75.0 \\
\hline Medians & \multicolumn{8}{|c|}{$\$ \cdot 000$} \\
\hline Personal Income & 10.0 & 30.5 & 10.8 & 30.8 & 14.8 & 27.2 & 21.8 & 28.0 \\
\hline Personal Disposable Income & 9.9 & 24.5 & 10.7 & 24.7 & 14.6 & 22.3 & 19.2 & 22.6 \\
\hline Household Income & 11.4 & 57.3 & 13.6 & 58.8 & 25.6 & 51.9 & 33.1 & 54.8 \\
\hline $\begin{array}{l}\text { Equivalised Household (HH) } \\
\text { Income }\end{array}$ & 11.3 & 45.2 & 13.5 & 46.2 & 22.8 & 41.7 & 27.8 & 43.6 \\
\hline $\begin{array}{l}\text { Equivalised Disposable } \mathrm{HH} \\
\text { Income }\end{array}$ & 10.1 & 27.8 & 11.0 & 28.2 & 14.9 & 25.6 & 17.6 & 26.7 \\
\hline $\begin{array}{l}\text { Equiv Disposable HH Income } \\
\text { after Housing }\end{array}$ & 6.5 & 23.2 & 6.5 & 23.7 & 11.1 & 21.4 & 12.9 & 22.5 \\
\hline Household Wealth & 103.9 & 261.5 & 42.6 & 272.4 & 25.1 & 258.5 & 48.3 & 290.5 \\
\hline Household Assets & 119.5 & 339.0 & 59.0 & 346.0 & 35.0 & 332.0 & 76.2 & 359.1 \\
\hline Household Debt & 0.0 & 18.0 & 1.7 & 16.0 & 3.7 & 13.0 & 10.0 & 13.0 \\
\hline
\end{tabular}


One striking finding from these analyses is the protective role of marriage and to a lesser extent de facto relationships. Compared to the 'single and nevermarried' group, marriage reduces the odds of financial disadvantage by between 3.6 and 4.0 times. Part of its effect is because there is a second adult who can provide income greater than the expenditure required. However, the benefits of marriage appear to be more than just two incomes since it has strong effects on both subjective poverty and financial stress. Additional analyses showed that the effects for marriage and de facto relationship were not substantially reduced when controlling for household disposable income and wealth as well as the variables listed in Table 4 (available from the author). Therefore, it appears that marriage is associated with a set of attitudes and behaviours that reduces financial disadvantage. De facto relationships also reduced the odds of financial disadvantage and the effects of being separated, divorced and widowed varied substantially with indicator. The number of children increased the odds of financial disadvantage, especially for financial stress.

Table 5 presents the means and medians of several measures of income and wealth for the groups defined as 'in', and 'not in', financial disadvantage in wave 3. The unit of analysis was the individuals randomly selected for the analyses presented in Table 4 and weighted with the household weights. Again these factors have different relationships with the indicators of financial disadvantage. The groups in income poverty have by definition low incomes but relatively high wealth compared to the subjective-poverty and financial stress groups. In contrast, the latter two groups have higher incomes. The subjective-poverty group have the lowest mean and median levels of wealth. The financial stress group have larger debt than the other three groups.

\section{Discussion}

Estimates of the extent of financial disadvantage in Australia vary enormously depending on the way in which it is defined. At one extreme more than half have had some experience of financial disadvantage over the three year period. At the other extreme, the proportion that were experiencing financial disadvantage every year on each single indicator is about 5 per cent or less. Similarly, the correspondence between income-based and other measures of financial disadvantage is low. The majority of those in income poverty do not see themselves as poor or experience financial stress. Furthermore, these indicators of financial disadvantage pertain to different sections of Australian society although both education and partnering provide substantial protection against financial disadvantage. So although many experience some form of financial disadvantage at some time, the proportion financially disadvantaged persistently over a three year period on two or more indicators is very small. These findings challenge the traditional understanding that there is a readily identifiable and sizable group of poor Australians, which consistently have low incomes, see themselves as poor and continually experience financial stress. 
Although measures of before-housing income poverty are often used in research on poverty, care should be taken with its use. For example, the beforehousing measure indicates higher poverty among older persons. However, this is likely to be misleading since sizable proportions of older persons have little or no housing costs so have relatively high discretionary incomes. On the after-housing measure there is no relationship with age. In contrast, younger cohorts are more likely to be experiencing financial stress.

An initial understanding is that subjective poverty and financial stress are both indicators of poverty that when combined with measures of income poverty would more accurately define 'true' poverty or disadvantage. However, they appear not to be indicators of the same underlying concept. For a start, their correspondence is not as strong as expected if they were indicators of the same concept. Furthermore, their relationships with social background, demographic, education and economic variables are in many instances different. Income poverty is about having an income less than that defined by the poverty line. Households experiencing income poverty do not have particularly high levels of debt. In contrast, subjective poverty is a judgement of one's level of prosperity, which is much less associated with education, and more strongly associated with wealth. It is a psychological judgement which probably involves a range of other factors such as type and standard of housing, the area of residence, networks and future prospects. Financial stress is about shortages of cash. It is much more strongly associated with age and the number of children than either income poverty or subjective poverty. A shortage of cash may be because of inexperience in the management of expenses (or lack of financial literacy especially among young people), large debts, and unforeseen expenses. It is possible to have a moderate or even high household income and experience financial stress. Therefore, these three aspects of financial disadvantage are quite distinct concepts and should be understood as such.

\section{References}

Abello, A. and A. Harding (2004), 'The Dynamics of Child Poverty in Australia', National Centre for Social and Economic Modelling, University of Canberra, Canberra.

Australian Bureau of Statistics (2002), 'Income and Welfare - Household Income, Living Standards and Financial Stress', (Cat. No. 1301.0 2002), Canberra.

Australian Bureau of Statistics (2004), 'General Social Survey: Summary Results, Australia Tables', Canberra.

Atkinson, A. (1998), Poverty in Europe, Blackwell, Oxford.

Australian Senate (2004), 'A Hand Up Not a Hand Out: Renewing the Fight Against Poverty', Community Affairs Reference Committee, Canberra.

Bradshaw, J. and N. Finch, (2003), 'Overlaps in Dimensions of Poverty', Journal of Social Policy 32(4):513-25.

Brady, D. (2003), 'Rethinking the Sociological Measurement of Poverty', Social Forces 81(3):715-52. 
Bray, R. (2003), 'Hardship in Australia: An Analysis of Financial Stress Indicators in the 1998-99 Australian Bureau of Statistics Household Expenditure Survey', Department of Family and Community Services, Canberra.

Breunig, R. and Cobb-Clarke, D. (2004), 'Understanding the Factors Associated with Financial Stress in Australian Households.' The Australian National University, Canberra, mimeo.

Breusch, T. and D. Mitchell (2003), 'Australian Family Income Dynamics: Preliminary Evidence from the NLC Project 1997 \& 2000', 8th Australian Institute of Family Studies Conference, Melbourne.

Department of Family and Community Services (2003), 'Inquiry into Poverty and Financial Hardship', Canberra.

Dewilde, C. (2004), 'The Multidimensional Measurement of Poverty in Belgium and Britain: A Categorical Approach', Social Indicators Research 68(3):331-370.

Eardley, T. (1998), 'Working but Poor? Low Pay and Poverty in Australia', Social Policy Research Centre, University of New South Wales, Sydney.

Eurostat Task Force (1998), 'Recommendation on Social Exclusion and Poverty Statistics. Document CPS/98/31/2', Luxembourg: Statistical Office of the European Communities.

Förster, M. (2000), 'Trends and Driving Factors in Income Distribution and Poverty in the OECD Area', Labour Market and Social Policy Occasional Papers No. 42, OECD, Paris.

Harding, A., R. Lloyd and H. Greenwell (2001), 'Financial Disadvantage in Australia, 1990-2000: The Persistence of Poverty in a Decade of Growth', The Smith Family, Camperdown, NSW.

Headey, B. (2003), 'How Best to Impute Taxes and Measure Public Transfers?', Melbourne Institute for Applied Economic and Social Research, University of Melbourne.

Headey, B., G. Marks and M. Wooden, (2005), 'The Dynamics of Income Poverty in Australia: Evidence from the First Three Waves of the HILDA Survey', Australian Journal of Social Issues 40(4).

Johnson, D. (1991), 'The Measurement and Extent of Poverty among Immigrants', Bureau of Immigration Research, Canberra.

Kangas, O. and V. Ritakallio (1998), 'Different Methods-Different Results? Approaches to Multidimensional Poverty', pp. 167-203 in H. Andress (ed.) Empirical Poverty Studies, Ashgate, Aldershot.

Korpi, W. and J. Palme (1998), 'The Paradox of Redistribution and Strategies of Equality: Welfare Institutions, Inequality and Poverty in the Western Countries', American Sociological Review 63(5):661-687.

La Cava, G. and J. Simon (2005), 'Household Debt and Financial Constraints in Australia', Australian Economic Review 38(1):40-60.

Mack, J. and S. Lansley (1985), Poor Britain, Allen \& Unwin, London.

McColl, B., L. Pietsch and J. Gatenby (2001), 'Household Income, Living Standards and Financial Stress' National Social Policy Conference, Australian Bureau of Statistics, Sydney. 
Moller, S., E. Heber, J. Stephens, D. Bradley and F. Nielsen (2003), 'Determinants of Relative Poverty in Advanced Capitalist Democracies', American Sociological Review 68(1):22-51

Organisation for Economic Co-operation and Development (2001), 'When Money is Tight: Poverty Dynamics in OECD Countries', Employment Outlook, Paris.

Oxley, H., J. Burniaux, T. Dang and M. d'Ercole, M. (1997), 'Income Distribution and Poverty in 13 OECD Countries', OECD Economic Studies 29(II):55-94.

Oxley, H., T. Dang and P. Antolin (2000), 'Poverty Dynamics in Six OECD Countries', OECD Economic Studies 30(1):7-52.

Ross, R. and P. Whiteford, (1992), 'Poverty in 1986: Aboriginal Families with Children', Australian Journal of Social Issues 27(2):91-111.

Saunders, P. (1996), 'Poverty and Deprivation in Australia' Year Book Australia (Cat No. 1301 1996), Special Article, Australian Bureau of Statistics, Canberra.

Saunders, P. (1997), 'Poverty, Choice and Legitimacy', Social Policy Research Centre, University of New South Wales, Sydney.

Saunders, P. (1998), 'Using Budget Standards to Assess the Well-being of Families', Social Policy Research Centre, University of New South Wales, Sydney.

Saunders, P., J. Bradshaw and M. Hirst (2002), 'Using Household Expenditure to Develop an Income Poverty Line', Social Policy and Administration 36(3):217-234.

Saunders, Peter and T. Kayoko (2002), 'Poverty in Australia: Beyond the Rhetoric', Centre for Independent Studies, Sydney.

Travers, P. and S. Richardson (1993), Living Decently: Material Wellbeing in Australia, Oxford University Press, Melbourne.

Tsakloglou, P. and F. Papadopoulos (2002), 'Aggregate Level and Determining Factors of Social Exclusion in twelve European countries', Journal of European Social Policy 12(3):211-225.

Watson, N. (2005), 'HILDA User Manual - Release 3.0', Melbourne Institute of Applied Economic and Social Research, University of Melbourne.

Whelan, C., R. Layte, and B. Maitre (2003), 'Persistent Income Poverty and Deprivation in the European Union: An Analysis of the First three Waves of the European Community Household Panel', Journal of Social Policy 32(1):1-19.

Whelan, C., R. Layte and B, Maitre (2002), 'Multiple Deprivation and Persistent Poverty in the European Union', Journal of European Social Policy 12(2):91-105.

This paper is based on analyses of the data in the unconfidentialised unit record file from the DFCS Household, Income and Labour Dynamics in Australia (HILDA) Survey, which is managed by the Melbourne Institute of Applied Economic and Social Research. The findings and views reported in the paper are those of the author and should not be attributed to either DFCS or the Melbourne Institute. The author thanks Simon Freidin, Nicole Watson, and Diana Warren for their assistance with the preparation of the data used in this paper. 


\title{
Application of Efficiency to Child Support
}

\author{
Anthony Farr and Gary Buurman
}

$\mathrm{R}$ ecently we published an article in this journal (Farr and Buurman, 2003) applying the economist's concepts of equity to the Australian Child Support legislation. Part of the intent of that article was to show that an analytic approach, originally established in the study of taxation, could be usefully applied to Child Support. In this paper, we submit that the concept of efficiency can also be taken from the study of taxation and usefully applied to Child Support.

Subsequent sections of the paper deal with the background; the Poverty Trap and Effective Marginal Tax Rates (EMTRs); the level of EMTRs for those subject to Child Support and a brief discussion of implications. Some comments on policy options conclude the paper.

\section{Background}

The Child Support Scheme, in its current Australian form, came into operation on 1 October, 1989. The Scheme provides for the transfer of income from a parent (normally the Non-Resident Parent or NRP) to a person caring for the children (normally the Resident Parent or RP). The amount of this transfer is determined by administrative assessment using calculations legislated in the Child Support (Assessment) Act 1989 (Cth). These calculations are generally referred to as the 'Child Support formula' - though assessment is, in reality, more complex than applying a single formula. The formula considers a number of inputs including the taxable income of parents, the number of children, and the amount of time the parents care for the children.

A key aspect of the formula is that the amount transferred from the NRP to the RP increases as the NRP's income increases. Increasing RP income is also considered and will decrease the amount of Child Support received by the RP, at least over some income ranges. This relatively simple situation is complicated significantly by interactions between Child Support payments, taxation and social security.

Given that the intent of Child Support is to provide for children, it may appear that efficiency — a basically technical concept — should be a relatively unimportant consideration. However efficiency issues have a direct impact on the children's standard of living. To explain, it is necessary to consider the concept of efficiency and its application in respect to Child Support.

Here we use the term efficiency in the same sense that it is used in the study of taxation, particularly income taxation. A number of quite distinct but equivalent formulations of the term are possible (see McGuire, Henderson and

Gary Buurman is a senior lecturer in Applied and International Economics at Massey University. Anthony Farr is a computer consultant. 
Mooney, 1995:ch. 5, for an example in health care). However, in this context we can (loosely) define inefficiency as the extent to which it causes parents to reduce their taxation and child support burden by reducing their income. The main mechanism by which this occurs is by a reduction in their labour supply, and hence overall production levels. The main determinants of the extent to which this occurs are the elasticity of labour supply and EMTRs, which affect take-home pay. (For our purposes, elasticity measures the rate of change in the quantity of labour supplied due to a change in the rate of take-home pay.)

The Effective Marginal Tax Rate (EMTR) is defined as the percentage of an extra dollar of income which is lost through either income taxation or withdrawal of government payment (particularly Social Security).

When social security benefits are considered as well, a particular instance of inefficiency, termed the 'Poverty Trap' is often seen. This occurs because social security benefits often phase out at quite low incomes and their phasing out can cause high EMTRs. The consequence is that when social security recipients take up work they are likely to end up with incomes very near to, or below, the point at which the benefits are withdrawn. In effect, the EMTRs that they face mean that there is little incentive to seek a job and the opportunity to escape poverty through on-the-job training, seniority, and other factors, is missed.

In any case, the result of efficiency problems is that income is reduced. For parents subject to Child Support, the result is less money available to invest in their children. The issue is particularly crucial because of the often poor financial circumstances of children in single-parent households (Harding et al, 2001). The obvious impact is upon the immediate welfare of the children. However, there is also ample evidence of long-term detrimental impacts caused by financial need (Duncan, 1994).

Historically, there has been some consideration of issues with Child Support that we can recognise as efficiency problems. The current formula was based on the recommendations contained in the May 1988 report from the Child Support Consultative Group. The Group stated that in arriving at the formula, they had considered a number of factors including, 'retention of appropriate incentives to earn for noncustodial parents' (CSCG, 1998). These considerations were echoed by the then Minister in his Second Reading speech (Blewitt, 1989).

In the formative years of the Child Support scheme, to the knowledge of the authors, there are no clear references to efficiency as applied to RPs. However in 1992, the Child Support Evaluation Advisory Group devoted considerable attention to the issue (CSEAG, 1992). Subsequently, one of the key recommendations of the Joint Select Committee was that the recognised objectives of the Child Support scheme be modified to include that "work incentives for both parents to participate in the labour force are not impaired' (JSC, 1994).

These issues have, to some extent, been reflected in the (often vigorous) public debate on Child Support. In particular it is often claimed that NRPs choose unemployment in order to avoid their Child Support liabilities. For example, a recent Parliamentary Enquiry concluded (HRSC, 2003) that 'It is apparent from 
the evidence heard by the committee that there is a proportion of paying parents leaving paid employment to avoid child support'.

This paper deals with separated parents who invoke the Child Support formula and each has time with the children. To simplify the discussion, they are assumed to have not re-partnered and to have no children from other relationships. Basically the model considers a single scenario in terms of the circumstances of the two parents. The model is then iterated to determine different outcomes in response to changing the important inputs such as the number of children, the percentage of nights spent with each parent and the parent's earnings from paid employment. Parameters include the cost of children data, tax rates and tables of social security benefits.

All income related parameters were inflated to May, 2002 in proportion to movements of the Average Weekly Earnings - All employees (ABS, 2002a). All cost of living data were inflated to $31 \mathrm{March}, 2002$ in proportion to movements of the All Groups Consumer Price Index (ABS, 2002b). Social security entitlements, taxation and Child Support transfers are at the level of 1 April, 2002. The interested reader can find more information on the model in our previous paper (Farr and Buurman, 2003).

For practical reasons including computational tractability and ease of graphical presentation, the EMTR results generated by the model are averaged over a $\$ 1,000$ income range. That is, results are generated for the average of the band from $\$ 0$ to $\$ 999$ annual income; for the band from $\$ 1,000$ to $\$ 1,999$ annual income; and so on. This approach has been referred to as Effective Average Tax Rate rather than EMTR (Toohey and Beer, 2003). However in this paper we retain EMTR as the preferred terminology.

As we have shown earlier (Farr and Buurman, 2003), involuntary Child Support payments have the effect of reducing the disposable income of the liable parent (usually the NRP). Our purpose is to examine the effect of these involuntary payments on EMTRs and hence the incentive to work.

The effect of Child Support on the work incentives of NRPs has been widely recognized in public debate. However high EMTRs also act as a disincentive to work for RPs. This occurs because as RP earnings increase, the amount of Child Support received by the RP can be reduced, thus increasing their EMTR.

\section{Results}

Before considering the results of our modelling of EMTRs, it is important to clarify some limits. We first define the following three variables with reference to a particular pair of separated parents:

- $\quad \mathrm{CS}$ - the amount of transfer mandated by the Child Support formula.

- $\mathrm{RP}_{\min }$ - the minimum amount which the Child Support recipient is prepared to accept.

- $\quad \mathrm{NRP}_{\max }$ - the maximum amount which the Child Support payer is prepared to transfer voluntarily. 
Note that all things being equal, $\mathrm{NRP}_{\max }$ will necessarily be less than the corresponding amount the NRP previously chose to spend on children in the intact family (Weiss and Willis, 1985). This is because, once a family separates, the RP controls the spending of any transfers from the NRP. Since some of the NRP's transfer may be spent by, or on, the RP, the NRP's price of investing in the children has increased, resulting in a lower (than when living together) level of investment from the NRP.

There are six potential rankings or permutations of these three variables. However, we can exclude half of these since they involve $\mathrm{RP}_{\min }<\mathrm{CS}$, that is, the Child Support recipient is prepared to accept less than the amount mandated by the Child Support formula. On one level, we can exclude these cases because they could not be acceptable to a rational Child Support recipient. In addition, the general principle has particular force in respect to Child Support. This is because the social security rules mean that the Child Support recipient is likely to be penalised by a reduction in social security benefits should they agree to less than the formula amount. This leaves three rankings of these variables which we consider in turn below.

- $\quad \mathrm{NRP}_{\max }>\mathrm{RP}_{\min }>\mathrm{CS}$

- $\quad \mathrm{RP}_{\min }>\mathrm{NRP}_{\max }>\mathrm{CS}$

- $\quad \mathrm{RP}_{\min }>\mathrm{CS}>\mathrm{NRP}_{\max }$

In the first scenario, separated parents will reach a cooperative agreement without invoking the Child Support formula. This situation can be termed 'loosely beneficial' for the children in terms of investment, since expenditure on them may remain very close to the pre-separation level. High EMTRs would have little effect on efficiency (in terms of reducing parental income and production), since the Child Support formula does not apply and the agreed amount of support is fixed cooperatively. Any extra work effort put in by a parent would result in extra net parental income. The parent can then choose to spend it, invest it in the children or split it between the two.

In the second scenario, the separated parents cannot reach a cooperative agreement since the amount the RP will receive is less than $\mathrm{RP}_{\min }$ - despite the fact that the NRP is willing to make voluntary transfers in excess of the amount required under the formula. Under these circumstances, the increased EMTRs resulting from the Child Support formula would not reduce the NRP's labour supply since that parent is prepared to contribute in excess of the formula amount voluntarily. However, the RP may be affected by the EMTR in this scenario.

The third scenario would be the most damaging to children. This concerns acrimonious separations when the Child Support formula is invoked and a classic 'prisoner's dilemma' situation results. That is, the parents feel that it is in their best interests not to cooperate. The formula is viewed by each parent as the maximum that each has to do. The NRP, affected again by high EMTRs, may try to hide extra income or work fewer hours, substituting leisure time for income so as to pay less in Child Support. There is also the possibility of avoiding Child 
Support. Here we would expect a large drop in the amount invested in the children. The RP also may be affected by EMTRs.

Surveys of parents subject to the CS formula give some insight into how common these three scenarios are. Only 2 per cent of NRPs believe that the Child Support formula amount is too low, while 80 per cent believe it is too high and 18 per cent believe it is fair (CSEAG, 1992). It can be inferred from this that in 98 per cent of cases, $\mathrm{CS}=\mathrm{NRP}_{\max }$ and the third scenario applies. This would mean that efficiency is relevant in the vast majority of cases. It is this scenario on which we focus in the remainder of this section.

Figure 1 shows the EMTRs faced by parents subject to Child Support. Two sets of data points are shown on each graph. One line shows the EMTR experienced by the RP as their earnings vary from $\$ 0$ to $\$ 120,000$ per annum. A second line shows the EMTR experienced by the NRP as their earnings vary from $\$ 0$ to $\$ 120,000$ per annum. In the case of the graph of the RP EMTR, it is assumed that the NRP earns the Average Weekly Earnings (AWE) as it was at May 2002 (ABS, 2002a). Similarly, the graph for the NRP assumes that the RP earns the AWE. (The significance of this assumption is examined later.)

Figure 1: EMTRs: Parents with 2 Children, Both Apply for FTB

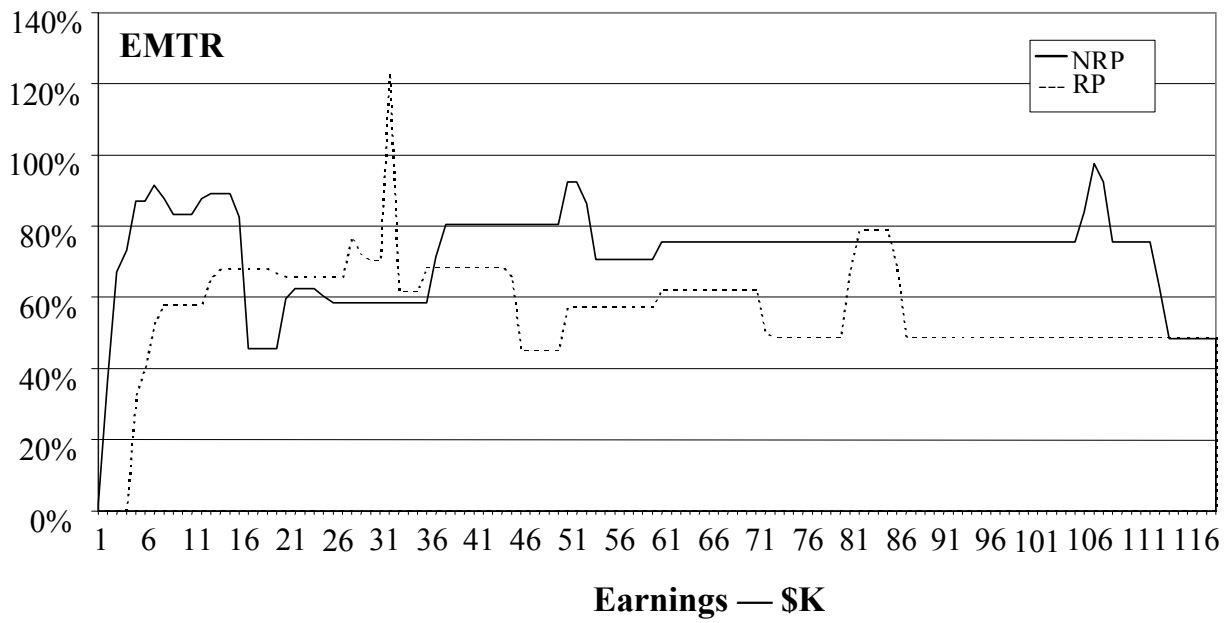

The particular circumstance shown is one where there are two children whose time is split according to the standard Family Court orders; where the NRP has access every second weekend and half of the school holidays. Further, it is assumed that the NRP applies for the Family Tax Benefit (FTB) where they are so entitled. The same assumptions are used in all graphs in this section except where explicitly described.

It is apparent that both parents face very high EMTRs. The EMTRs faced by the NRP are typically greater than 70 per cent and those for the RP are typically almost 60 per cent. The broad difference between the two percentages is mainly due to Child Support; while the NRP pays 27 per cent of income as Child Support, as RP earnings increase, Child Support is only withdrawn at 13.5 per cent. 
Importantly, there are high EMTRs even at quite modest earnings. The reader will note a couple of spikes in the EMTRs for both the RP and the NRP. The most significant are described below:

- The NRP EMTR is high from approximately $\$ 5,000$ to $\$ 15,000$ due mainly to the withdrawal of Newstart allowance - though taxation and Child Support also contribute.

- At earnings from $\$ 36,000$ to $\$ 52,000$ the NRP EMTR is again around 80 per cent. At this point, FTB is withdrawn and this, in combination with taxation and Child Support, causes elevated EMTRs.

- The narrow 'spike' in NRP EMTR around $\$ 105,000$ is also due to the withdrawal of FTB.

- The spike in RP EMTR around $\$ 85,000$ is also due to the withdrawal of FTB and is equivalent to the feature just described on the NRP graph.

The spike in the RP EMTR at earnings around $\$ 32,000$ is particularly notable - exceeding 100 per cent. It occurs at the point at which the Parenting Payment is completely withdrawn. Once this happens, the FTB is calculated differently and paid at a lower rate. This 'cliff effect' reduction in the FTB (combined with taxation and Parenting Payment withdrawal) explains the spike. Such effects are sometimes known as 'sudden death' income tests.

\section{Figure 2: EMTRs: Parents in the Absence of Child Support}

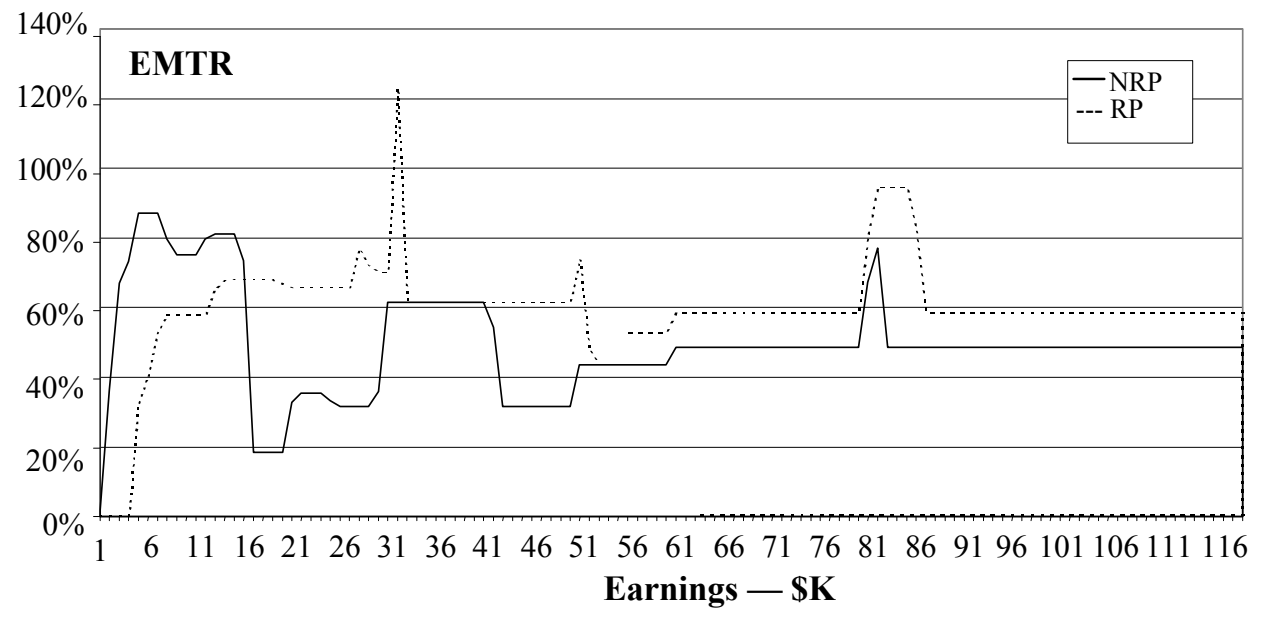

1 More precisely, the spike is due to an abrupt reduction in FTB - Part A. This, in turn, is due to the treatment of 'Income Excess' (one of the variables used to calculate FTB Part A). Where the FTB recipient also receives pension type payments, Income Excess is not considered. For those other than pensioners, every dollar of adjusted taxable income over $\$ 29,857$ constitutes Income Excess (using figures for April 2002 as described earlier). However the Parenting Payment phases out at a higher income level $-\$ 31,986$. At this point the Income Excess jumps from (effectively) $\$ 0$ to $\$ 2,129=\$ 31,986-\$ 29,857$. 
For comparison, Figure 2 shows the EMTRs the same parents would face in the absence of Child Support. All other parameters are the same as for Figure 1. The most obvious difference is that EMTRs for NRPs are now much lower because the additional burden of Child Support payments has been removed.

In the case of the RP, EMTRs are generally lower in the absence of Child Support and particularly so at incomes around $\$ 60,000$. This occurs because, without Child Support, there is no reduction in Child Support at these income levels. However, careful comparison reveals that in a small range, between $\$ 45,000$ and $\$ 49,000$, EMTRs are actually lower in the presence of Child Support. Briefly, the difference occurs because, without Child Support, the FTB is being withdrawn in this income range. The effect is due to the quite complex interactions between taxation, Child Support and Social Security benefits.

Another difference between this and the previous figure is in the overall shape of the EMTR faced by the RP. The RP EMTRs shown in Figure 2 reveal quite high EMTRs at low and middle incomes - giving rise to an inverted U-shape in the graph. This effect has been noted previously (Apps, 2004). However, this effect largely disappears in the presence of Child Support payments. Notwithstanding the fact that EMTRs are lower in the absence of Child Support, separated parents still face high EMTRs compared with other demographic groups (Beer, 2002). We have examined the sensitivity of the general increase in EMTRs to a number of factors. Some, such as the amount of time children spend with each parent, have only a marginal impact. Others are noted later in this section.

Our analysis has shown that the EMTR of a parent changes very little with changes in the other parent's income. The (important) exception occurs when the NRP is totally dependent on welfare. In this case, the RP receives virtually no Child Support and the RP EMTR is almost identical to that shown in Figure 2. The major impact, then, is that the RP EMTR is significantly lower for earnings between $\$ 35,000$ and $\$ 70,000$. (As noted previously, there is an exception at income levels in the middle of this band.)

Figure 3 shows the effect if the NRP does not apply for the FTB. While the overall levels of EMTR remain quite high, it is apparent that the highs and lows are less pronounced. We speculate that (because when the FTB was introduced it was unclear whether it was available to NRPs), the withdrawal rates may have been instituted on the assumption that the NRP would not have access to the FTB.

Figure 5 shows results for the same scenario as Figure 1 except that there are now three children. EMTRs are higher for both the RP and, especially, the NRP.

Not surprisingly, given the magnitude of Child Support transfers, EMTRs are quite sensitive to the number of children. Figure 4 shows results for the same scenario as Figure 1, except that there is only one child. EMTRs are lower for both the RP and, especially, the NRP. 
Figure 3: EMTRs: Parents with 2 Children, Only RP Applies for FTB

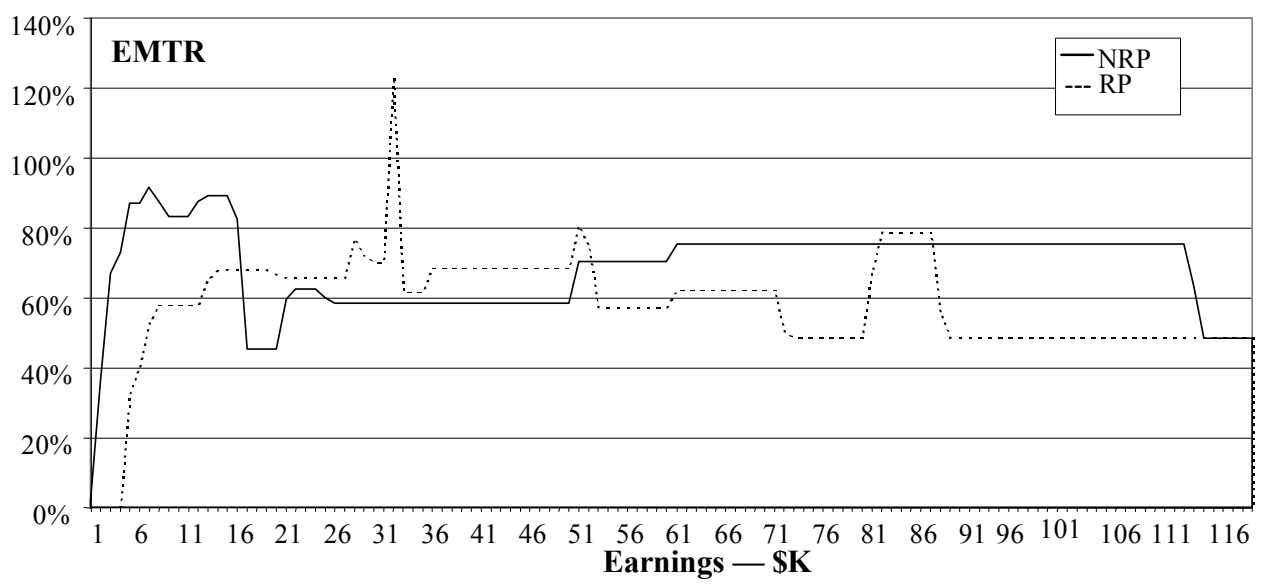

Figure 4: EMTRs: Parents with 1 Child: Both Apply for FTB

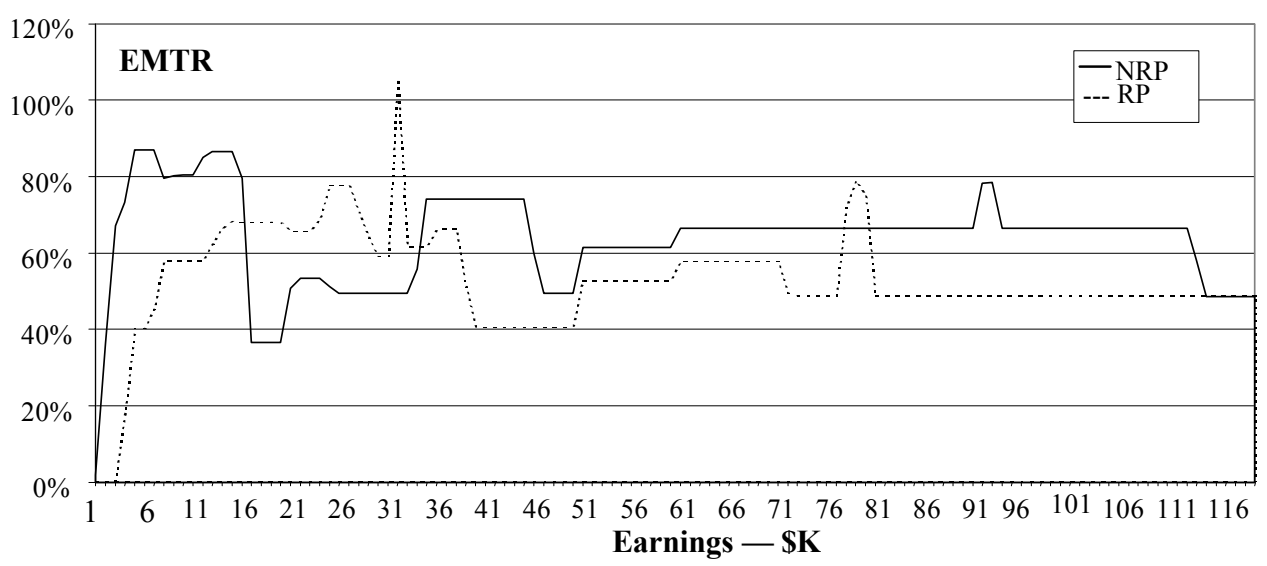

Figure 5: EMTRs: Parents with 3 Children, Both Apply for FTB

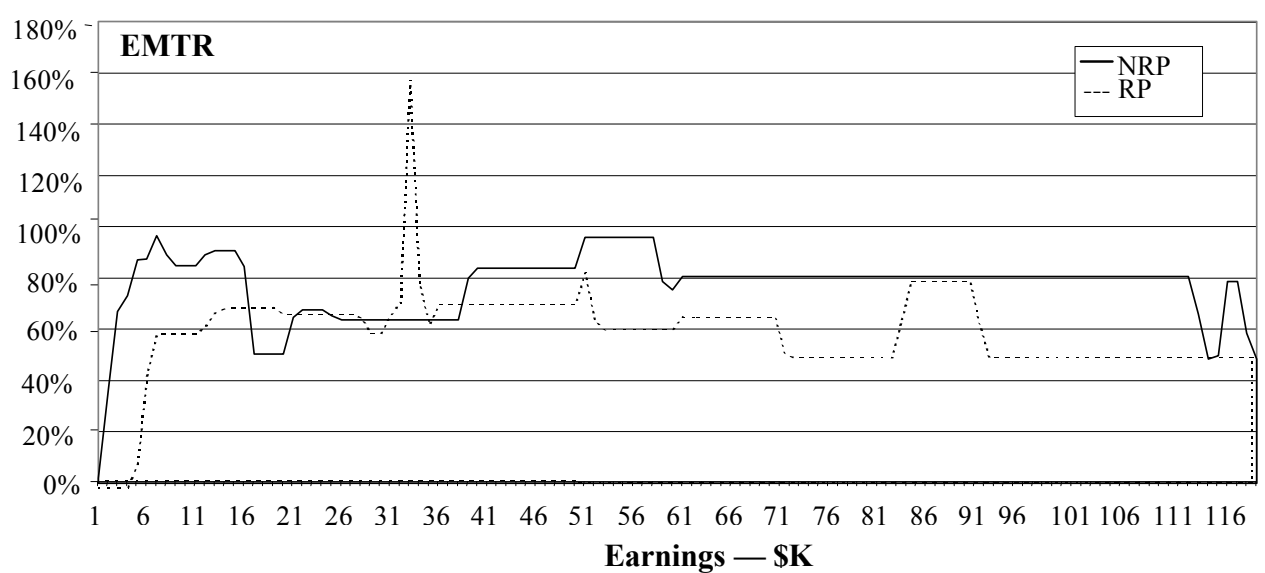




\section{Discussion}

It is often considered that EMTRs significantly greater than the highest marginal tax rate (48.5 per cent) should be judged high (Polette, 1994). On this basis, the EMTRs revealed by the preceding analysis are high indeed. Figure one shows EMTRs of 80 per cent or above for the NRP in the approximate income ranges of $\$ 5,000$ to $\$ 17,000, \$ 37,000$ to $\$ 53,000$ and just under 80 per cent from $\$ 53,000$ to $\$ 110,000$. The EMTR is either above or very near 60 per cent in the $\$ 20,000$ to $\$ 36,000$ income range. In this situation, one would expect many NRPs to look for alternatives to earning additional income in the normal economy. These might fall under the general headings of leisure, earnings in kind or cash jobs in the underground economy. In these cases, the level of investment on the children would be adversely affected. The same reasoning can be applied to RP earnings.

While, on this basis, we can state that EMTRs are high, moving beyond this to a quantitative formulation of efficiency losses is challenging. Any quantitative analysis requires an estimate of the elasticity of labour supply. Unfortunately available data is severely limited. Most data is from the United States where both income tax and Child Support are significantly lower, welfare withdrawal rates are much higher and the interaction between the two leads to quite different EMTRs. Of the Australian data, most is for married couples and hence not relevant here (for example, see Scutella, 2000).

In the absence of such evidence, it is tempting to accept the popular wisdom that it is common for parents to leave paid employment because of the impact of Child Support. However caution is required:

- In the case of NRPs, there is clear evidence that incomes are low and unemployment rates are very high. However, causality is unclear since incomes of males who subsequently become divorced are also lower than the general population. (Silvey and Birrell, 2004) Moreover there is evidence suggesting that divorce may reduce the work performance of males and so cause their subsequent unemployment.

- In the case of RPs, time series data are available (Funder, 1993) showing that it is common for them to leave paid employment after divorce. However, as with NRPs, this may be driven by the burden of being sole carer for children, rather than high EMTRs and the elasticity of labour supply.

Thus, while we can do little more than speculate here, the graphs would certainly lend support to the HRSC finding above, of parents leaving paid employment to avoid Child Support.

\section{Recent developments}

In December 2003, the House of Representatives Standing Committee on Family and Community Affairs presented its report (HRSC, 2003) on child custody. Among its recommendations was the establishment of a taskforce to examine the child support formula. That taskforce has recently handed in its own report 
(MTCS, 2005). Many of the recommendations in that report would, if implemented, impact efficiency issues.

Two of the key themes of the report are a more equitable sharing of the costs of children and recognition of the costs of contact for NRPs. As a consequence of these considerations, their recommendations would decrease the child support amount and the EMTR faced by NRPs in most circumstances. (The exception is that EMTRs will increase in the income range from $\$ 18,000$ to $\$ 65,000$ where the children are teenagers.) The size of the changes in EMTRs is fairly modest (around 5 per cent) save at high incomes where the proposals would reduce EMTR by as much as 10 per cent. Consequently while EMTRs for NRPs would improve, they would still remain high by the criteria used in the preceding subsection.

Another key theme of the report is that the costs of children should be shared between parents using an approach known as the income-shares method. This approach results in child support reducing much more slowly as the RP's income rises than is the case under the current formula. In combination with the changes already referred to, this results in reduced EMTRs for the RP over the income range $\$ 40,000$ to $\$ 75,000$. The extent of the improvement in EMTRs approaches 10 per cent and so, at some points in this range, the proposed formula would reduce EMTRs to less than the highest marginal tax rate.

As mentioned earlier, those subject to high EMTRs may elect to reduce their income either by reducing their work effort or by subterfuge. The Child Support (Assessment) Act 1989 (Cth) contains provision to address this in the courts particularly s $117(2)(c)(i)$. The report recommends increased resourcing for the Child Support Agency to investigate and pursue those who engage in subterfuge especially those who are self-employed. However, the report also suggests that the court's use of the existing provision has resulted in decisions which have been overly onerous on NRPs - for example ordering that the NRP work 80 hour weeks. The report recommends changes to the legislation that would restrict the circumstances in which the court could assess Child Support based upon an income greater than that actually enjoyed by the parent.

\section{Conclusion}

In the subsection on applicability, we feel that we have established efficiency is relevant in the vast majority of separations involving children. The results and discussion suggest that policy changes designed to raise the level of investment in children should be in two broad directions: either to prevent family break-up in the first place; or when this fails, to encourage cooperation (which would probably involve bargaining) between the parents. These policy directions are not new. Steps to help prevent family break-up are well known and include education, counselling, raising the cost of separation for both parents, and raising the cost of non-compliance with court orders. A well-known move to encourage cooperation and bargaining between separated parents involves various forms of shared parenting arrangements as practiced in many states in the USA. In New Zealand, 
there is now a move to make deliberations of the Family Court more open, partly to promote cooperation.

Policies leading to more cooperative agreements have the potential to lower the effect that high EMTRs have on disincentives to invest in these children. These types of solutions could result in situations very similar to the first scenario discussed earlier, where expenditure on the children would remain at, or near, the pre-separation level.

In terms of efficiency, commonsense tells us that a separation implies that there will be less money available for the children. This is because, when parents separate, in most cases something near the pre-separation income level now has to support two households which is much more expensive (Valenzuela, 1999; Henman, 2001). Given that the level of investment in children is crucial, two of the possible options to retain an acceptable level are:

- One or both of the separated parents could reduce their level of household expenditure (spending on themselves, food, petrol, and other personal consumption) in favour of extra spending on the children.

- The State could make up any shortfall through welfare payments.

Another obvious option, and the preferred one from a societal viewpoint, is for at least one of the parents to raise their income above the pre-separation level. However, with this option the part that Child Support plays in increasing EMTR levels stands in the way of an efficient level of spending on the children.

\section{References}

Apps, P. (2004), 'The High Taxation of Working Families', Australian Review of Public Affairs 5(1):1-24.

Australian Bureau of Statistics (2002a), Average Weekly Earnings of Employees, Table 6302.0, AUSSTATS, Canberra.

Australian Bureau of Statistics (2002b), Consumer Price Index, Table 6401.3B, AUSSTATS, Canberra.

Beer, G. (2002), 'Work Incentives Under a New Tax System: The Distribution of Effective Marginal Tax Rates in 2002', Paper presented to the 2002 Conference of Economists, Canberra, 30 September - 3 October (Revised November 2002).

Blewitt, N. (1989), House of Representatives Hansard, 1 June, p. 3441.

Child Support Evaluation Advisory Group (1992), Child Support in Australia, Vol 2, AGPS, Canberra.

Child Support Consultative Group (1988), Child Support: Formula for Australia, AGPS, Canberra.

Duncan, S. (1994), 'Economic Impact of Divorce on Children's Development: Current Findings and Policy Implications', Journal of Clinical Child Psychology 23:444-457. 
Farr, A. and G. Buurman (2003), 'Application of Equity to Child Support', Agenda $10(2): 113-128$.

Funder, K. (1993), 'Women's Post-Separation Employment and Reliance on Social Security', pp. 83-115 in K. Funder, M. Harrison and R. Weston (eds), Settling Down: Pathways of Parents After Divorce, Institute of Family Studies, Melbourne.

Harding, A., R. Lloyd and H. Greenwell (2001), Financial Disadvantage in Australia 1990 to 2000, Smith Family, Sydney.

Henman, P. (2001), 'Updating Australian Budget Standards Costs of Children Estimates', Policy Research Paper No. 7, Department of Family and Community Services, Canberra.

House of Representatives Standing Committee on Family and Community Affairs (2003), Every Picture Tells a Story, Australian Parliamentary Library, Canberra.

Joint Select Committee on Certain Family Law Issues (1994), Child Support Scheme Operation and Effectiveness: Recommendations and Conclusions, Australian Parliamentary Library, Canberra.

McGuire, A., J. Henderson and G. Mooney (1995), The Economics of Health Care: An Introductory Text, Routledge, London.

Ministerial Taskforce on Child Support (2005), In the Best Interests of Children Reforming the Child Support Scheme, Australian Parliamentary Library, Canberra.

Polette, J. (1994), 'Social Security Payments and the Taxation System', Technical Series no. 1, rev. K. Chan, Social Policy Division, Department of Social Security, Canberra.

Scutella, R. (2000), 'Labour Supply Estimates for Married Women in Australia', Melbourne Institute Working Paper No. 25/99, Melbourne.

Silvey, J. and B. Birrell, (2004), 'Financial Outcomes for Parents After Separation', People and Place 12(1):45-56.

Toohey, M. and G. Beer (2003), 'Is it Worth Working Now?: Financial Incentives for Working Mothers under Australia's new Tax System', Paper presented to the 2003 Australian Social Policy Conference, Canberra, 9 July.

Valenzuela, R. (1999), 'Costs of Children in Australian Households', Family Matters 53(Winter):71-76.

Weiss, Y. and R. Willis (1985), 'Children as Collective Goods and Divorce Settlements', Journal of Labor Economics 3(3): 268-92.

The authors would like to thank the referees for their considerable contributions. Any errors, however, are attributable to the authors. 


\title{
ACCC's Authorisation Decisions: Interpretation of Public Benefit
}

\begin{abstract}
John Fallon
$\mathrm{T}$

The issue of the interpretation of the welfare standard that should be adopted in assessing the competitive effects and public benefits of mergers is an important one for ensuring competition laws are best placed to maximise the overall welfare of the community. Mergers are reviewed under Section 50 of the Australian Trade Practices Act which prohibits mergers that 'would have the effect, or be likely to have the effect, of substantially lessening competition in a market'. Although not fully tested in the courts, Section 50 of the Australian Trade Practices Act is generally considered to embody a consumer welfare standard rather than a total or overall welfare standard that would give prominence to overall economic efficiency. (Economic efficiencies refer to any improvements in the productivity of resources or their value to consumers through either better use of resources in a particular activity or a better allocation of resources in terms of the mix of factors of production in a particular activity or the mix and scale of output that is produced. In addition, there are both static and dynamic dimensions that characterise economic efficiencies. The concepts of productive, allocative and dynamic efficiency are often used to describe the various aspects of economic efficiency.) This is because in determining if a merger would substantially lessen competition in a market, Section 50 (3) imposes the specific requirement to determine 'the likelihood that significant and sustainably higher prices or profit margins would result'. In practice this means that in assessing mergers in accordance with Section 50, economic efficiencies which promote competition and benefit consumers (or users of a product or service) directly are relevant but not efficiencies which only benefit producers even where there is relatively small harm to consumers (Walker, 2000:386). Note also that since the Act came into force in 1974 there have only been four fully argued merger cases and none of these have considered efficiencies (Everett and Ross, 2002:31 and Williams and Woodbridge, 2001:6). In addition, all four of these cases were argued under the old 'dominance test' which has been replaced by the 'substantial lessening of competition test'.

The authorisation provisions in Part VII of the Act that relate to both mergers and other anti-competitive arrangements provide scope for the adoption of a total welfare standard where all efficiencies can be treated as public benefits. In the context of a two-step process the existence of two welfare standards with the one for authorisation of mergers being more comprehensive than the one for testing for a substantial lessening of competition may be reasonable. Although the welfare
\end{abstract}

Dr John Fallon is a Vice-President in the Canberra office of CRA International. The views in this paper are personal and not necessarily those of CRA International. 
standard adopted by the Australian Competition and Consumer Commission (ACCC) for authorisations is potentially more comprehensive than a consumer welfare standard, in practice there seems to be a tendency to give greater weight to efficiencies that directly benefit consumers than to efficiencies that directly benefit producers. Reflecting this tendency, Smith (2003:5) has argued that a consumer welfare standard is usually applied to authorisation decisions in Australia.

This paper focuses on the evidence and implications of such a tendency by the ACCC in its authorisation decisions. It first reviews standards that have emerged in Australia and internationally in the consideration of efficiency gains and their distributional impacts. It then reviews numerous authorisation decisions of the ACCC highlighting key aspects that support the proposition that the ACCC tends to give greater weight to effects on consumers than to effects on firms and some of the weaknesses in the ACCC's approach. It concludes with a discussion of the policy implications of this tendency and suggestions for improvement.

\section{Welfare Standards}

Based on Everett and Ross (2002:20-23) and Duhamel and Townley (2002:26-35), the welfare standards that have emerged in the context of assessing mergers fall into six categories as follows: Price standard; Consumer Surplus standard; Total Surplus standard; Hillsdown standard; Balancing Weights standard; and other Weighted Surplus standards.

\section{Figure 1: Welfare Impacts of a Merger}

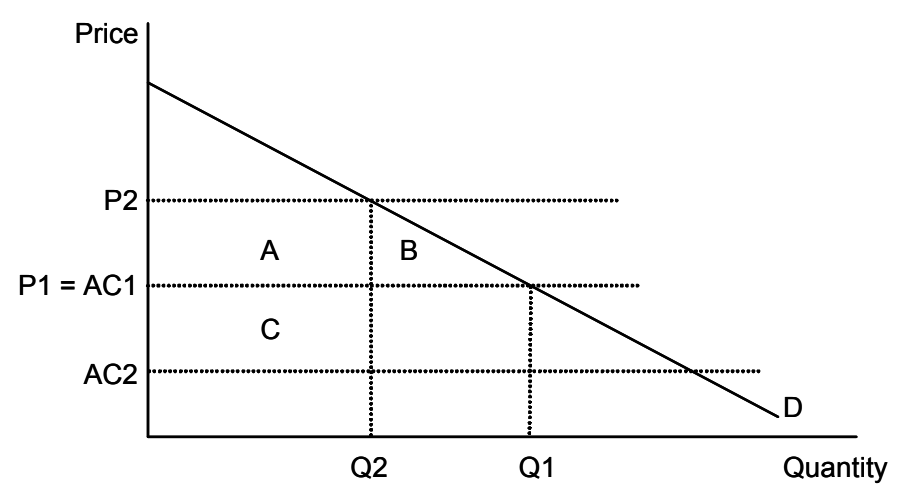

The standards can be understood by reference to Figure 1. In the pre-merger situation price is $\mathrm{P} 1$ equal to average cost $\mathrm{AC} 1$ and output is Q1. Following the merger price increases to $\mathrm{P} 2$ and output falls to $\mathrm{Q} 2$ as a result of the use of market power. However productive efficiency (for example, rationalisation) gains mean that average cost falls to AC2. The merger entails a deadweight (allocative efficiency) loss of B (as a result of the higher price and reduced output), a transfer of consumer surplus to producers of A (as a result of the higher price for output that is still purchased) and a producer surplus gain of $\mathrm{C}$ (as a result of productive 
efficiency gains). Note that the effects on consumer and producer surpluses net of transfers as depicted in Figure 1 are allocative efficiency losses and productive efficiency gains respectively.

\section{Price standard}

The price standard is simply that a merger leading to a price increase will not be approved. In terms of Figure 1, since the price rises, the merger would not be approved irrespective of the net efficiency effects. The standard is consistent with the actual Pareto improvement criterion in that at least one person is made better off with no person being made worse off. With this standard, efficiencies must be strong enough to lead to benefits to both producers and consumers. This standard is extreme in the sense that it effectively gives all the weight to consumers or a zero weight to producers if there is a price increase.

\section{Consumer surplus standard}

A variation on the price standard is the consumer surplus standard as defined by Everett and Ross (2002). It extends the price standard by allowing for other nonprice factors that impact on consumer surplus. Under this standard, if a merger leads to an increase in price but consumer surplus still rises (for example, because of improved quality or the value associated with new products or services) it would be approved. If consumer surplus does not increase, then the merger would not be approved irrespective of the gains in producer surplus. This is basically the same as the price standard in terms of the weight it gives to consumers, but it allows for other factors besides price effects.

\section{Total surplus standard}

The total surplus standard is simply that a merger that results in an increase in the sum of consumer and producer surplus would be approved. With this standard a pure transfer from consumers to producers would be treated neutrally. With reference to Figure 1, the merger would be approved if $\mathrm{C}>\mathrm{B}$. The total surplus standard is the standard total welfare approach that most economists adopt in analysing a merger where there is scope for productive efficiency gains (for example, cost savings through rationalisation) and enhanced market power. It is consistent with the potential Pareto improvement criterion in the sense that, assuming the marginal utility of income for different groups is the same, there are net gains and no one is worse off to the extent that hypothetical compensation could occur. This standard assumes that there is no need to make a distinction between a dollar gain to one group and a dollar loss to another group. Alternatively only efficiency effects need to be considered and distributional effects can be disregarded 


\section{Hillsdown standard}

For the Hillsdown standard a transfer from consumers to producers is treated as a net cost in the sense that the benefit to producers is not recognised. The producer surplus associated with efficiency gains counts but the producer surplus from the exploitation of market power does not.

The Hillsdown standard is based on a description by Justice Reed in the Canadian Hillsdown decision where she suggested that under some conditions the transfer of surplus from consumers to producers, associated with a post-merger price increase, should be viewed as a negative cost of the merger (Everett and Ross, 2002:22). Under the Hillsdown standard a merger would be approved, even if prices increased, provided the net efficiency gains were larger than any transfer from consumers to producers. In terms of Figure 1, the merger would only be approved if $\mathrm{C}>\mathrm{A}+\mathrm{B}$. Although this standard may have some popular appeal, there is no economic basis for it, and it represents an arbitrary compromise between the price standard and the total surplus standard.

\section{Balancing weights standard}

The balancing weights standard proposed by Duhamel and Townley (2002) entails calculation of distributional weights for different groups so that the net benefits of a merger would be exactly zero and asking whether such weights are reasonable. In terms of Figure 1, the balancing weight of $x$ (assuming $\$ 1$ to consumers has a weight of 1) would be found from the solution of $x(A+C)-(A+B)=0$. Note that from this relationship, $x$ is the ratio of losses to consumers relative to gains to producers and $1-x$ indicates the extent to which gains to producers would have to be discounted if the standard was just met or just failed. In considering whether the implied weight is reasonable, a value judgement is required as to whether producers should receive a weighting relative to consumers implied by the ratio $x$, that is, whether their gains should be reduced by a discount factor of $1-x$.

\section{Other weighted surplus standards}

Other weighted surplus standards assign some sort of 'social weight' to the various effects of a merger reflecting the importance the reviewing body gives to each group. Various approaches have been suggested by weights implicit in various public policy decisions (Boardman et al, 2001:456-472).

The most promising approach for taking account of distributional concerns is to try to determine a lower bound weight (that is, upper bound discount factor) based on the cost to higher income groups of implementing a social welfare transfer system. Under this approach an estimate could be made of the marginal cost of taxation needed to support a transfer to lower income groups. This is used to make an upper bound estimate of the cost that society considers is reasonable to provide an additional transfer to lower income groups. For example, suppose that the marginal cost of taxation implies an efficiency cost to the economy of $\$ 1.50$ to transfer an additional $\$ 1$ from higher to lower income groups. This can be used to 
determine the upper bound estimate of the extent to which gains to higher income groups should be discounted in order to transfer $\$ 1$ to lower income groups. In this case if the implicit 'balancing' weight that has been calculated is less than $1 / 1.5$ then the implication is that there is an alternative policy that would achieve the same 'broad' distributional objective as preventing the merger but at a lower cost to the economy and higher income groups. An objection could be raised that the individuals benefiting from or harmed by the merger would not necessarily correspond to those represented in this calculation, and in any case the scenario is hypothetical. However these same criticisms would apply to all public policy decisions wherever the hypothetical Kaldor-Hicks compensation principle was applied and rejection of consideration of policies based on hypothetical compensation would effectively lead to policy paralysis.

Note also that the setting of weights based on the tax system would not be sufficient to determine an optimal set of weights since the benefits of transfers and government expenditure on different groups of individuals would need to be incorporated. Alternatively the weights might also represent factors that represent the likelihood of the effects being sustained which appears to be the main justification of differential weights proposed by the ACCC.

\section{Qualifications and extensions}

It is important to recognise that the presentation of the above standards in terms of Figure 1 is from a highly simplified perspective where competition is assumed to diminish following a merger and static analysis is also appropriate. In Figure 1, the situation prior to a merger is assumed to be perfectly competitive and the merger leads to the realisation of both market power and some productive efficiency gains. However, the evaluation of whether market power is likely to be enhanced is more complex in the situation where prior to the merger the market is characterised by oligopolistic competition.

The basic welfare standards described above can still be applied in such circumstances. However, analysis of a merger's effects on competition and of its implications for price and efficiency outcomes becomes more complicated. In most cases there is a need to assess factors such as the nature of imperfect competition before and after a merger, the incentives for sustained efficiency gains given the expected impact on market structure and competitive rivalry, and the scope for different stakeholders to expend resources in securing some component of the efficiency gains (that is, the concept of socially wasteful rent seeking).

In relation to the competitive process, oligopolistic markets (where firms are aware of the interdependency of their decisions) can support a range of outcomes from highly competitive marginal cost pricing to a form of tacit collusion consistent with a monopoly outcome. Assessment of a merger's competitive effects therefore requires consideration of the nature of competition before and after the merger (see Ivaldi et al, 2003, for a thorough discussion). There is also a need to assess the extent to which efficiency gains are likely to be sustained given likely changes in the nature of competition or dissipated if competitive pressures 
are weakened. As will be explained below the ACCC has demonstrated concern about the dissipation of efficiency gains following a merger and such concerns seem to be the key rationale it offers to justify discounting of gains to producers.

\section{The ACCC Position}

The Trade Practices Act does not define what constitutes a 'public benefit' in relation to the statutory test for a public benefit. The only specific matters that the Act refers to are in Section 90(9) which specifies that a significant increase in exports or substitution of domestic products for imported goods must be treated as benefits as well as all relevant matters that relate to the international competitiveness of Australian industry.

Officer and Williams (1995:163-65) and Hanks and Williams (1987:165-67) perceived a longstanding difference between the ACCC and the Australian Competition Tribunal in their interpretations of public benefit. Fels and Grimwade (2003:202-205) also referred to a number of studies that consider that the ACCC favours a consumer welfare standard (where, in effect, benefits to consumers are valued over the benefits to producers) over a total welfare standard (where effectively benefits to producers and consumers are valued equally). However, they noted that the concern of the ACCC, at least in recent times, is not one based on redistribution of wealth from producers to consumers, but whether efficiency gains will be sustained over time or more likely to be dissipated through managerial slackness or rent seeking (pp. 201-02).

The key point is that the ACCC tends to discount benefits if they are not in a form of direct benefits to consumers. Thus efficiencies in the form of cost savings tend to be discounted by the ACCC if they are not substantially passed through to consumers in the form of lower prices or improved services. However, the discounting of such benefits is not based on a systematic and transparent process and the extent of implied discounting in decisions appears to vary depending on the extent of efficiencies and the extent to which pass through of cost savings to consumers are assessed to occur. In terms of the welfare standards described above, the ACCC is effectively adopting either a price or consumer welfare standard or applying weights to producers' gains that entail a substantial discount factor for uncertainty as to their sustainability. In a speech in 2002, Commissioner Jones suggested that it was possible for a merger to be authorised even where there are substantial anti-competitive consequences (Jones, 2002:20-22). However, as he noted, the cases he referred to where authorisation was granted, entailed either some pass through of efficiencies to consumers or improvements in international competitiveness or increased competition in other markets.

Examples of authorisations with these characteristics include the acquisition by Monier of the Wunderlich roof tile business (1983), the acquisition by Henderson's Federal Spring Works Pty Ltd of National Springs Pty Ltd (1987), the joint venture between Australian Mining and Smelting Limited and North Broken Hill Holdings Ltd (Pasminco Ltd 1988), the ACI Operations Pty Ltd acquisition of Smorgons (1991), the Davids acquisition of Composite Buyers 
(Trade Practices Commission, 1995), the agreement between Qantas Airways Limited and British Airways Pty Ltd to coordinate various aspects of their airline services (1995), the acquisition by Davids Limited of QIW Limited (ACCC, 1996a) and the joint venture for the exclusive marketing of sodium cyanide between Dupont (Australia) Limited and Ticor Limited (ACCC, 1996b).

In the 1999 Merger Guidelines (ACCC, 1999), there is a relatively broad interpretation of public benefit, although the ability to discount private benefits is noted, particularly where such benefits are not considered to be durable. This is demonstrated by the following excerpts from the 1999 Merger Guidelines:

6.42 The concept of a benefit to the public is not limited to benefit to consumers, a benefit to a private party which is a value to the community generally is a public benefit. ...

6.43 Furthermore when comparing the situation that is likely to prevail with and without the proposed merger, it is critical to consider the likely durability of the claimed public benefits. ...

Examples of the ACCC's tendency to discount benefits to producers that are not passed on to consumers and to give greater prominence to pro-competitive effects rather than pro-efficiency effects include the proposed joint venture between CSR Limited and Mackay Sugar Co-operative Association for sugar refining and sale in the domestic and export markets (1994), Wattyl (Australia) Limited's proposed acquisition of Taubmans Industries Ltd paint manufacturing and supply business (ACCC, 1996c), the proposed merger between Australian Pharmaceutical Industries Ltd and Sigma Company Ltd (ACCC, 2002), and the proposed alliance between Qantas and Air New Zealand (ACCC, 2003).

For example, in its Determination of the Qantas-Air New Zealand proposed alliance the ACCC (2003:para 13.65) said:

Finally it should again be noted that the cost saving benefits accrue to the Applicants and their shareholders. While the Commission is of the view that benefits to a particular group or segment of the Community may be regarded as benefits to the public, consideration needs to be given as to whether the community has an interest in that group being benefited and whether that benefit is at the expense of others - for, example, consumers through higher prices. The level of competition in a market will affect both the durability of the benefit and the likelihood and extent of that benefit being passed through to consumers. Where benefits are not passed on to consumers this may be symptomatic of a lack of competitive pressure that would otherwise cause such benefits to endure and be passed through. Such benefits are likely to be accorded a lower weight by the Commission.

This clearly indicates that in such circumstances a dollar gain to shareholders is not treated the same as a dollar loss to consumers by the ACCC. As noted, the ACCC's main justification for this does not appear to be one based on income distributional considerations but a concern that if cost efficiencies are not passed 
on, then this is evidence that it is most likely to be the case that such efficiencies will not be sustained because of a lack of competitive pressure. However there clearly seems to be confusion or inconsistency about this justification as reflected in the Australian Competition Tribunal's recent decision on the proposed QantasAir New Zealand alliance where it interpreted the ACCC's position as follows:

169 The Commission countered that the applicants were seeking to apply a total welfare or total surplus standard (the terms being inter-changeable) to determine net public benefit and submitted that this was not the correct approach to take. Both the Commission and the Gullivers Group submitted that, unless benefits were shared with consumers, it was inappropriate to characterise such benefits as 'public' benefits, except in exceptional circumstances, which circumstances they said were not present in this proceeding. They submitted that if these benefits were considered to be public benefits, when assessing the weight to be given to such benefits the Tribunal should regard them as deserving of little or no weight. By implication, the Commission and the Gullivers Group appeared to be advocating the use of the consumer welfare standard.

In its decision on the proposed airline alliance the Australian Competition Tribunal (2005) presented extensive reasoning on the interpretation of public benefit concluding that it preferred a total welfare standard but one which allowed different weights to be given to public benefits to the extent they are not shared among members of the community generally (para 190) or not likely to be sustained (para 189). It summarised its position as follows:

185 In our view, the objective and statutory language of the Act, as well as precedent, support the use of a 'form of' the total welfare standard because, as the passage cited from Re Howard Smith shows, whilst the Tribunal does not require that efficiencies generated by a merger or set of arrangements necessarily be passed on to consumers, it may be that, in some circumstances, gains that flow through only to a limited number of members in the community will carry less weight.

189 It follows that cost savings achieved by a firm in the course of providing goods or services to members of the public are a public benefit which can and should be taken into account for the purposes of s 90 of the Act, where they result in pass through which reduces prices to final consumers, or in other benefits, for example, by way of dividends to a range of shareholders or being returned to the firm for future investment. However, the weight that should be accorded to such cost savings may vary depending upon who takes advantage of them and the time period over which the benefits are received.

However, the Tribunal did not elaborate on how such weights would be determined or on the relevant time period when benefits accrue and how this would affect the weights. It is also important to recognise that the Tribunal's 
decision to authorise the alliance did not hinge on a different view of public benefits to the ACCC but rather a different assessment of the likely anticompetitive effects, particularly in the light of expansion of two other airlines on relevant routes since the ACCC's decision.

There is a perception that the Tribunal has a wider interpretation of public benefit than the ACCC and that its decision in the case brought by Qantas made reference to a wider test than precedents (see Crowe, 2005). This may have been true in the past but is not the case now.

Review of the Tribunal's reasoning in its airline decision and the ACCC's decision in that matter and in numerous other cases, and its Merger Guidelines suggests that both the Tribunal and ACCC now have a similar 'adjusted total welfare' standard. This standard is effectively a weighted surplus standard where public benefits can be weighted according to whether they accrue to particular groups and their likelihood of being sustained. Although the term 'total welfare' does not appear to have been used in the past, this form of a standard has been applied in previous determinations as has the concept of an 'adjusted total welfare' standard (see also Corones, 2005:307). What it is fair to say is that the ACCC may have moved to a broader standard or at least developed a more meaningful rationale for its 'adjusted total welfare standard' in recent years while the Tribunal in its latest decision provided more explanation for the standard to be applied in a public welfare test. However, they both effectively have the same standard now.

In terms of implementing the welfare standard, the ACCC's Merger Guidelines and various decisions provide an impression that adverse effects on consumers clearly are a detriment per se without any discounting in virtually all circumstances, whereas gains to shareholders may not be a public benefit per se and are likely to be given a lower weight if consumers suffer or there are no gains in international competitiveness or increased competition in other markets.

In particular, it seems that the ACCC may treat competition as an objective in itself, in the sense that any merger which clearly lessens competition substantially, even though it results in large efficiency gains, which may not be passed on to consumers, would be most likely to be rejected. To the extent that this is true it seems unreasonable in an assessment of public benefits since it provides no meaningful scope for a trade-off between efficiency gains and competition losses.

Although the ACCC might argue that the lack of pass through of efficiency gains may make such gains vulnerable to 'x-inefficiencies', the authorisation determinations do not report a transparent and economically meaningful approach to discounting for the extent to which gains to producers or shareholders are not passed on to consumers. Similar criticisms can be made about the ACCC's assertions that efficiency gains estimated by applicants are too large or efficiency losses too small without providing credible and transparent alternative estimates (see Ergas, 2003:8-9). Thus a key weakness with the approach of the ACCC to date is that there is no guidance on relevant weights so that the distributional/efficiency trade-off can be reasonably defined and evaluated and used as a basis to determine the likelihood of success of future proposed authorisations. 
Brunt (1994) has been influential in the ACCC's interpretation of public interest and in particular for the concept that benefits that are not passed on to consumers may not be durable because they are more likely to be dissipated through rent seeking or $\mathrm{x}$-inefficiencies as referred to in the ACCC's Merger Guidelines. She has recently summarised her thinking as follows (Brunt, 2003:83):

It is undeniable that 'the community as a whole' may be viewed as a collection of producers as well as a collection of consumers; it is undeniable that producers are just as good as consumers. What is advocated here as the public interest is not the sacrifice of one group to another but the placing of primary reliance upon an efficient and progressive process - if possible, a competitive process - which leads up to consumption. There is a sense in which in the long-run 'everybody is better off' if consumption becomes the end of production.

In response to Brunt it is undeniable as an economic principle that consumption (widely defined) as opposed to production is an ultimate objective in terms of maximising economic welfare. However, that does not necessarily mean that in evaluating mergers resulting in price increases, directly affected consumers should be given more weight than shareholders who benefit from efficiency gains as Brunt advocates. There is a need to take a broader view of economic welfare and in particular the perspective of the community as a whole. If efficiency gains are not passed on there can be income gains for the community as a whole that can support higher overall consumption including on a longer term basis. It also does not mean that competition should be given priority over economic efficiency, as the competitive process is a means to achieve economic efficiency but is not necessarily effective in achieving that objective in all circumstances.

Achievement of efficiency requires a wide view of the competitive process and efficient allocation of resources. In particular, there is a number of mechanisms reflecting competition for resources in the economy that ultimately benefit consumers. If for example a merger entails rationalisation so that certain production, storage or distribution functions are not required, then the assets and other resources associated with such functions become available for use elsewhere in the economy. Furthermore, such a reallocation of resources would normally be characterised by economists as a durable benefit for the economy as a whole.

There is also a need for a clearer understanding of the $\mathrm{x}$-inefficiency concept. The ACCC and Brunt appear to be concerned about the scope for x-inefficiency where rationalisation benefits are not passed on. It is helpful to consider the concept in more detail to highlight some weaknesses in its interpretation.

The x-inefficiency concept, originally developed by Liebenstein (1966), relates essentially to situations where the effort of employees and managers in a firm is less than is socially optimal (Liebenstein, 1998). According to Liebenstein, this arises because of non-maximising behaviour by employees and managers and the inability to implement a first-best monitoring and enforcement mechanism to ensure optimal effort is realised. The outcome is lower effort and 'an easier life' 
for employees and managers. Firms may anticipate the problem and adjust compensation and production techniques to try redress it but the outcome is a lower level of efficiency for the firm than in the absence of the problem.

It is also important to recognise that $\mathrm{x}$-inefficiency is not equivalent to economic inefficiency as part of the $\mathrm{x}$-inefficiency is simply a transfer from shareholders to factors of production. X-inefficiency can however entail some waste to the extent that resources are expended in attempting to secure and prevent transfers (often referred to as rent seeking). But some of these expenditures will be optimal to the extent that they are needed to secure an optimal level of effort in a situation where there are information problems (Stigler, 1976). An important implication that follows from Stigler's perspective is that in assessing the impact of a merger one needs to consider how the merger will impact on monitoring arrangements. That is, does the merger somehow lead to less effective performance monitoring arrangements? There is an extensive literature using the principal-agent framework that examines how competition might improve incentives for efficiency. However, generally the theoretical and empirical literature on the impact of competition on effort incentives is ambiguous.

Vickers (1995) provides a survey of concepts of competition highlighting the ambiguities in some of the theoretical literature including the application of the principal-agent methodology. He showed for example that 'competition-bycomparison' can improve effort incentives in a simple one-period model where explicit incentives can be created by performance contracts, the manager (agent) is risk averse, and the owner (principal) is risk neutral. With such assumptions, the ability to make comparisons reduces risk and facilitates explicit performance contracts that cause effort to be closer to the efficient level. However, with implicit incentives that arise naturally from market forces (for example, by affecting reputation and its effect on earnings prospects) the outcome of 'competition-by-comparison' on effort incentives is ambiguous because individual managers may be able to free ride on the efforts of others. Furthermore, Vickers shows that in a dynamic (more than one-period) setting, the 'ratchet effect', whereby good performance in the current period implies a higher target in the future weakens effort incentives. Studies by Meyer and Vickers (1997), Hart (2001) and Scharfstein (1988) using similar frameworks highlight similar ambiguities. Other studies highlight the countervailing mechanisms of the greater fear of liquidation in a more competitive market versus lower efforts induced by lower profits (Martin, 1993; and Schmidt, 1997).

The empirical literature is also equivocal. Interpretation of the empirical literature needs to recognise the difficulty in measuring competition by proxies such as market shares. One issue is that highly concentrated industries can still be characterised by intense competition. Another is that measures of market shares are themselves endogenous and affected by changes that influence both price and productivity performance and the intensity of competition. In addition many of the studies do not effectively isolate regulatory and other policy changes from competition measures. Although a review of the empirical literature is not provided here these issues are well highlighted by Symeonidis (2002). 
Finally the likelihood of $\mathrm{x}$-inefficiency effects worsening as a result of a merger needs to include an assessment of the relevance of capital market pressures in addressing any genuine cost inefficiencies that might arise as a result of $\mathrm{x}$ inefficiency effects. In this respect an interesting empirical study by Nickell, Nicolitsas and Dryden (1997) found evidence that financial market pressure and shareholder control can substitute for competition and that in particular the impact of competition on productivity performance is lower when firms are under financial pressure or have a dominant external shareholder.

The key point is that in relation to an assessment of $\mathrm{x}$-inefficiency, thorough and transparent analysis has not been evident in any of the ACCC's decisions reviewed in this paper.

\section{Implications for Policy}

In summary both the ACCC and the Tribunal advocate that the appropriate welfare standard for assessing public benefits is an 'adjusted total welfare standard'. This means that while the starting point is the standard total welfare concept that is well grounded in economic theory, the ACCC and the Tribunal consider it appropriate to adjust that standard depending on the distribution of the benefits and costs between consumers and firms and their employees and shareholders and the extent to which they perceive certain gains to be sustainable.

Although there may be a perception that this approach reflects income distributional concerns, the main justification offered by the ACCC is that efficiency gains are not likely to be sustained by firms unless they are passed on to consumers. The ACCC further contends that such gains will be dissipated in the form of $\mathrm{x}$-inefficiency and costly rent seeking effects. However, there remains some ambiguity in the positions of both the ACCC and the Tribunal about whether the dollar gains for firms and shareholders will be given the same weight as the same dollar costs for consumers when there is no sustainability issue and based perhaps on a legal interpretation of public benefit.

The standard total welfare concept in economics can take account of uncertainty and also incorporate income distributional concerns. However the incorporation of uncertainty requires a meaningful assessment of risk and the incorporation of distributional concerns requires setting of weights for different groups. The setting of such weights in turn entails value judgements about the optimal distributional impact. Thus, although there is scope in the standard framework to determine differential weights for effects on consumers and firms and their employees and shareholders, the problem remains that both the ACCC and the Tribunal have not clarified and established a consistent, transparent and economically sound framework for determining appropriate weights. Indeed they have provided very little information on how they approach these tasks.

Numerous decisions and the ACCC's Merger Guidelines suggest that it is unlikely to authorise a merger, regardless of the extent of any efficiency gains, if consumer prices increase and there are no improvements in competition in other markets or in international competitiveness. As noted, the main justification for 
this seems to be a perception that efficiency gains that are not passed on to consumers are less likely to be sustained than direct gains to consumers. However, there are grounds for suspicion that the risk of efficiency gains not being sustained is considered by the ACCC to be whatever is required to discount efficiency gains if they are not passed through to consumers and there are no improvements in competition in other markets or in international competitiveness. This is what is known in retailing as the 'butcher's thumb' approach.

In practice authorisation has played a limited role in respect of mergers, and together with the lack of transparency in the ACCC's decisions, where efficiency gains are discounted, this means that there is little clear precedent parties can draw upon in deciding whether to seek authorisation (see also Ergas, 2002). In addition it would seem that in order for a merger to pass the informal clearance process, there would be a need to demonstrate clearly that prices were not likely to rise or that enforceable undertakings were agreed to that effectively ensured that a consumer welfare standard was met. A consequent danger is that there are real risks that too many merger opportunities that would improve overall economic welfare are discouraged or precluded by the standards and the process.

Furthermore, in those situations where the sustainability of efficiency gains can be reasonably demonstrated, there is still the issue of whether a dollar gain to a shareholder should be treated the same as a dollar loss to a consumer. As noted, resolving such an issue requires a value judgement about optimal distributional impacts and there are considerable difficulties in determining appropriate weights from the perspective of society as a whole. However, it also raises the issue of ensuring sufficient and effectively designed policy instruments to address each major objective of the government and how to best use policy instruments to achieve specific policy objectives. There is a longstanding theorem in economics that the number of specific policy instruments should be at least equal to the number of specific policy objectives, otherwise conflicts emerge (Tinbergen, 1952). There is also a widespread acceptance amongst economists that in evaluating a public project a dollar should be treated as dollar irrespective of the incidence effects and that distributional concerns should be addressed through the tax and transfer system (Harberger, 1971; Parish, 1976; and Ng, 1984). There are some qualifications to these positions when there is uncertainty about the effectiveness of a policy instrument as this may mean that it is optimal to use more than one instrument to achieve a specific policy objective (Kelsey, 1988; and Ng, 1988). However, a reasonable case could be made that competition policy is not well designed to address income distributional goals, including when uncertainty of the effectiveness of policies is recognised, and that such goals would be more effectively addressed separately by the tax and transfer system.

From a public policy perspective it would be useful if the ACCC and the Tribunal were to make their deliberations about the extent of uncertainty of the sustainability of efficiency gains more meaningful from an economic perspective and more transparent. Similarly, it would be useful if they would clarify whether income distributional considerations should be part of the overall welfare standard that both the ACCC and the Tribunal should be required to consider. There is also 
a good case for legislative guidance to be provided on these issues. Both the ACCC and Tribunal can expect to continue to be pursued on these issues in academic, commercial and political fora until they are effectively resolved.

\section{References}

Australian Competition and Consumer Commission (1996a), 'Application for Authorisation by Davids Limited in Relation to the Proposed Acquisition of QIW Limited', A30174, 28 March).

Australian Competition and Consumer Commission (1996b), 'Application for Authorisation by DuPont (Australia) Ltd, Ticor Ltd, Howson Algraphy (Australasia) Pty Ltd and Ticor Chemical Company Pty Ltd', A90581 and A 90582, 8 May.

Australian Competition and Consumer Commission (1996c), Application for Authorisation by Wattyl (Australia) Pty Ltd, Courtaulds (Australia) Pty Ltd and Pinchin Johnson (Australia) Pty Ltd', A30175, 17 May.

Australian Competition and Consumer Commission (1997), 'Application for Authorisation by Bristile Holdings Limited', A70010, 3 November.

Australian Competition and Consumer Commission (1999), Merger Guidelines.

Australian Competition and Consumer Commission (2002), 'Application for Authorisation by Australian Pharmaceutical Industries Limited in Respect of a Proposed Merger with Sigma Company Limited', A30215, 11 September.

Australian Competition and Consumer Commission (2003), 'Application for Authorisation by Qantas Airways Limited of Ordinary Shares in Air New Zealand Limited and Cooperative Arrangements Between Qantas, Air New Zealand and Air Pacific', A30220, A30221, A30222, A90862, and A90863, 9 September.

ACI Operations Pty Ltd (1991), ATPR (Cth), ๆ50-108.

Australian Competition Tribunal (2005), Qantas Airways Limited [2004] AcompT 9, 16 May.

Boardman, A., D. Greenberg, A. Vining and D. Weimer (2001), Cost Benefit Analysis: Concepts and Practice, Prentice Hall.

Brunt, M. (1994), 'The Australian Antitrust Law After 20 years - A Stocktake', Review of Industrial Organisation 9(5):508.

Brunt, M. (2003), Economic Essays on Australian and New Zealand Competition Law, Kluwer Law International.

Canada (Director of Investigation and Research) v Hillsdown Holdings (Canada) Ltd. (1992), 41 C. P. R. (3d) in Everett and Ross (2002:22).

Corones, S. (2005), 'Restrictive Trade Practices: Tribunal Decision in Qantas: Assessing Anticompetitive Detriment and Public Benefit in Authorisation Proceedings', $A B L R$ 33:305-11.

Crowe, D. (2005), 'Beware, Graeme, There's a Watchdog Watching You', The Weekend Australian Financial Review, 6 August, p. 22. 
CSR Limited, Mackay Sugar Co-operative Association Limited, ED and F Man Australia Pty Ltd and Newco (1994), ATPR, $\mid 50-138$.

Duhamel, M. and P. Townley (2002), 'An Effective and Enforceable Alternative to the Consumer Surplus Standard', Competition Bureau, Industry Canada and Acadia University, mimeo.

Ergas, H. (2002), 'Review of Parts IV and VII of the Trade Practices Act 1974 (Cth): Note on Efficiencies in the Consideration of Mergers', Network Economics Consulting Group, mimeo.

Ergas, H. (2003), 'Quantifying Benefits in the Assessment of Authorisation Applications', Network Economics Consulting Group, mimeo.

Everett, A. and T. Ross (2002), 'The Treatment of Efficiencies in Merger Review: An International Comparison', University of British Columbia and Delta Economics Group Inc., mimeo.

Fels, A. and T. Grimwade (2003), 'Authorisation: Is it Still Relevant to Australian Competition Law?', Competition and Consumer Law Journal 11:187-214.

Hanks, F. and P. Williams (1987), 'The Treatment of Vertical Restraints Under the Australian Trade Practices Act', Australian Business Law Review 15:147-69.

Harberger, A.C. (1971), 'The Three Basic Postulates for Applied Welfare Economics: An Interpretative Essay', Journal of Economic Literature 9:785-97.

Hart, O. (2001), 'The Market Mechanism as an Incentive Scheme', Bell Journal of Economics 14:366-382.

Henderson's Federal Spring Works Pty Ltd (1987), ATPR (Cth.) ๆ50-054.

Howard Smith Industries Pty Ltd (1977), ATPR $\llbracket 40-023$, at 17,334.

Ivaldi, M., B. Julien, P. Rey, P. Seabright and J. Tirole (2003), 'The Economics of Unilateral Effects', Interim Report for DG Competition, European Commission.

Jones, R. (2002), 'The Rationale for Mergers Law', The Thirteenth Annual Workshop of the Competition and Policy Institute of New Zealand.

Kelsey, D. (1988), 'Policies to Achieve a Better Distribution of Income: Or is a Dollar a Dollar?’, Oxford Economic Papers 40:577-583.

Liebenstein, H. (1966), 'Allocative Efficiency vs 'X-efficiency', American Economic Review 56:392-415, June.

Liebenstein, H. (1998), 'X-efficiency Theory', 934-935 in J. Eatwell, M. Milgate and P. Newman (eds), The New Palgrave: A Dictionary of Economics, The Macmillan Press Limited, London.

Martin, S. (1993), 'Endogenous Firm Efficiency in a Cournot Principal-Agent Model', Journal of Economic Theory 59:445-450.

Meyer, M. and J. Vickers (1997), 'Performance comparisons and dynamic incentives', Journal of Political Economy 105(31):547-581.

Monier Limited (1983), ATPR (Cth) \50-062. 
Ng, Y. (1984), 'Quasi-Pareto Social Improvements', American Economic Review 74:10331050 .

Ng, Y. (1988), 'Is a Dollar a Dollar? A Response', Oxford Economic Papers 40(3):584586.

Nickell, S., D. Nicolitsas and N. Dryden (1997), 'What Makes Firms Perform Well?, European Economic Review 41:783-96.

Officer, R. and P. Williams (1995), 'The Public Benefit Test in an Authorisation Decision', 157-166 in M. Richardson and P. Williams (eds), The Law and the Market, The Federation Press, Sydney.

Parish, R. (1976), 'The Scope of Benefit-Cost Analysis', Economic Record 52:302-314.

Pasminco Ltd (1988), ATPR (Cth) $\mid 50-082$.

Qantas Airways Limited and British Airways Plc (1995) ATPR (Cth) ๆ50-184.

Scharfstein, D. (1988), 'Product Market Competition and Managerial Slack', Rand Journal of Economics 19:147-155.

Schmidt, K. (1997), 'Managerial Incentives and Product Market Competition', Review of Economic Studies 64:191-213.

Smith, R. (2003), 'Authorisation and the Trade Practices Act: More About Public Benefit', Competition and Consumer Law Journal 11:1-22.

Stigler, G. (1976), 'The Xistence of X-Efficiency', American Economic Review 66(1):21316.

Symeonidis, G. (2002), The Effects of Competition, MIT Press, Boston.

Tinbergen, J. (1952), On the Theory of Economic Policy, North-Holland, Amsterdam.

Trade Practices Commission (1975), First Annual Report (year ended 30 June) para. 3.83.

Trade Practices Commission (1978), Fourth Annual Report (year ended 30 June) para. 2.6.

Trade Practices Commission (1995), Application for Authorisation Lodged by Davids Limited in Relation to the Proposed Acquisition of Composite Buyers Limited, A30165, 29 May.

Vickers, J. (1995), 'Concepts of Competition', Oxford Economic Papers, 47:1-23.

Walker, J. (2000), 'Mergers', Chapter 7 in Butterworths Australian Competition Law.

Williams, P. and G. Woodbridge (2001), 'Antitrust Merger Policy: Lessons from the Australian Experience', National Bureau of Economic Research Twelfth Annual East Asian Seminar on Economics, Hong Kong University of Science and Technology.

I would like to acknowledge the helpful comments of Greg Cutbush, Henry Ergas and two anonymous referees and research by Jason Soon on some of the citations on $x$-inefficiencies and incentive schemes. 


\section{Competition in Regulated Industries: Some Reflections}

\section{Simon Cowan}

$\mathrm{L}$

iberalisation, privatisation and independent regulation of utilities were popularised by the UK and Chile in the 1980s. By then the United States already had long experience of private provision and public regulation of utility services, and independent power production had been mandated by the Public Utilities Regulatory Policies Act 1978 (PURPA). Many countries have subsequently adopted some or all of these policies. Competition has been introduced in telecommunications, in electricity production and in the supply of electricity and natural gas to large users. Franchise competition exists in water supply and in some rail systems. Yardstick or comparative competition is used by regulators in industries where there are regional monopolies with national regulation. At the same time direct competition in the provision of network services has usually not been on the agenda, except in the telecommunications industry. Whether there should be direct product market competition in retail electricity and gas supply, in water and sanitation, in rail and post are all controversial issues.

The main message of the paper is that competition can and should be introduced in many parts of utilities' operations, but that competition is not a panacea and it requires supporting regulation and institutions if it is to work well. Introducing competition into a regulated and monopolised industry requires both imagination and care, and often entails costs which need to be balanced against the expected benefits of competition. It is important for policymakers to remember that competition is not an objective but is an instrument for achieving ultimate goals.

The structure of the paper is as follows. The next section covers the general arguments in favour of competition. The costs of having various types of competition in regulated industries are then covered. This is followed by discussion of the parts of utilities where competition generally works well and where competition is of doubtful value. The interaction between regulation and competition is then considered. The penultimate section assesses the experience of competition in Californian electricity and a number of industries in the UK and conclusions are drawn.

\section{The General Arguments for Competition}

The textbook argument for competition is that it is a good instrument for achieving efficiency. In particular the argument for competition is based on the First

Simon Cowan is University Lecturer in Economics, Department of Economics, University of Oxford. 
Fundamental Theorem of Welfare Economics - see Varian (2003) for a simple treatment, or Varian (1992) for a more rigorous analysis of the theorems of welfare economics. Two types of efficiency may usefully be distinguished: allocative and productive. Allocative efficiency means that resources are allocated across sectors of the economy in such a way that no-one can be made better off without making someone else worse-off. In a market economy this requires prices to equal marginal costs, which is achieved if all markets are perfectly competitive and there are no missing markets or externalities. Productive efficiency (which is itself a necessary condition for allocative efficiency) implies that costs are minimised for given levels of output. Again competition ensures this, because firms that have excessive costs are driven out of the market or forced to adapt.

Theorists of regulation often suggest that an objective of policy should be the minimisation of excess profits (see, for example, Baron and Myerson, 1982; and Baron, 1989). In other words a dollar in the hands of the firm or its shareholders is worth less than a dollar in the hands of the consumer - unlike the treatment in standard welfare economics. Fortunately, however, competition ensures in any case that this outcome is achieved.

There are important additional benefits of competition. Competition can spur innovation and provide better products and production methods. Competition can promote choice and variety. Competition encourages radical thinking about cost structures that might not have been thought of without it. Many forms of outsourcing, for example in airlines, have probably been considered and implemented because of the incentives provided by competitive pressure in the product market. Finally competition might reduce the need for regulation, which is both expensive and inherently imperfect.

\section{The Costs of Competition in Regulated Industries}

What are the costs of having competition in regulated industries? Competition sometimes entails both set-up and transactions costs that would not be incurred in a monopoly system. To be concrete consider an electricity system that has been monopolised. Suppose that the network parts of the business, transmission and distribution, remain as monopolies, but that both electricity generation and retail supply are liberalised and competition is introduced. To make competition feasible a system for balancing electricity supply and demand needs to be established if there is upstream competition, and a system for switching customers has to be installed if there is also retail competition. In England and Wales a spot market for electricity generation was established in 1990 in place of the old command-and-control 'merit order', which determined which generating stations were used when. The move to full retail competition required an IT system that was expected to cost $£ 726 \mathrm{~m}$ (US\$1200m) over the first five years (see Newbery, 1999:228). At the time aggregate annual supply costs as a whole were only of the order of $£ 600 \mathrm{~m}$ (US\$1000m) so this represented a substantial increase in the cost base. In the competitive electricity markets of England and Wales the average cost to the supply companies of switching a customer is $£ 30$ (OFGEM website). 
The customer also bears switching costs if she or he changes supplier. If the customer is required to wait at home to have the meter read on the day that the switch-over happens there is an opportunity cost of the time taken. In the UK in the early days of retail energy competition some vulnerable customers were subjected to dubious high-pressure sales tactics on the doorstep, which in some cases were fraudulent. More innocent mistakes were made with customers who found that they were paying both the new and the old supplier simultaneously, and unwinding these mistakes took time and effort. Sometimes switching costs that consumers bear can be reduced by some simple mechanisms. Price comparison services operating over the Internet let consumers know instantly which retail supplier offers the best deal. In telecommunications number portability reduces the cost (to the customer) of switching supplier. Carrier pre-selection allows the customer easily to use one supplier for, say, broadband access and local calls, and another for international calls.

While competition may reduce the need for regulation, sometimes the opposite is true and competition requires additional regulation. This may take the form of access price regulation. Suppose there is a monopoly running a vertically integrated electricity system. Regulation of the price the final customer pays is required. Now let the incumbent firm remain vertically integrated and suppose that competition is allowed either in generation or in retail supply, or in both. Regulation becomes more complicated: typically both the incumbent's retail price and its access price will be regulated. This is not the place for a full discussion of the complexities of access pricing, but it suffices to note that regulation of both the access price and the retail price is difficult when the firm is vertically integrated. Integration is likely to give the firm an information advantage relative to the regulator, particularly about the allocation of costs. Allowing competition while retaining vertical integration requires costly regulation. This can be alleviated to some extent by a policy of vertical separation, which will allow competition and reduce the regulatory burden. See Cowan (2001) for a simple model of the tradeoffs involved. Vertical separation makes the regulatory problem easier, because it gives the regulator better information, but it also prevents the joint setting of the access and retail prices, which may be more efficient. In addition vertical separation implies that reorganisation costs are incurred and may entail a loss of economies of scope.

Another reason why competition and regulation are not perfect substitutes is that the introduction of competition usually requires strong competition or antitrust policies. This is particularly so in a utility were there is likely to be a dominant incumbent which might act as a price leader (or price in a predatory way). Similarly horizontal separation of an incumbent into only two or three components might not promote competitive behaviour and instead may facilitate collusion. Thus elimination of sector-specific regulation of, say, retail prices does not mean that regulation is abandoned, and instead extra attention from the general competition authorities is required.

Competition might make it infeasible to retain price structures that are socially valuable. By forcing prices to match costs competition prevents the use 
of cross-subsidies which might be thought to be desirable. The classic example is uniform geographical pricing that is used in postal services (combined with a universal service obligation). If new firms are allowed to cherry-pick markets then the original price structure may not be sustainable. In South Africa reform of utilities is constrained by requirements on state-owned utilities to set tariffs with large elements of cross-subsidy. Again this is not a knock-down argument against competition. Either making obligations symmetric, or requiring firms that do not have extra obligations to contribute to the costs that the obligated incumbent bears, will serve to reduce or eliminate this problem.

\section{Areas where Competition Tends to Work Well}

Competition tends to work well in upstream production of natural gas and electricity, in downstream supply of gas and electricity to large and medium-sized customers and in the retail parts of telecommunications. In addition franchise competition can work when there are local geographical monopolies, such as municipal water supply. As usual, though, there are exceptions and the details of each case matter.

In electricity generation several types of competition are feasible. At a minimum a vertically integrated grid can be required to buy power from independent power producers (IPPs) on reasonable terms, as the 1978 Act (PURPA) required in the USA. Typically such IPPs are small in relation to the overall market size so there is no issue about natural monopoly in generation. In practice the crucial question is whether the terms are reasonable or not. In England and Wales liberalisation to allow independent power producers to supply was enacted in 1983, when the generation industry was still monopolised, integrated with the national grid and state-owned. Because grid access terms were not regulated this liberalisation was entirely ineffective (see Armstrong, Cowan and Vickers, 1994:291). Much depends also on the objectives of the power purchaser. A profit-maximizing private-sector firm would presumably not want to discriminate against efficient independent power producers because they represent a new way to minimise costs. A state-owned firm might have other incentives.

The alternative form of competition in generation is to establish a real-time spot market in wholesale electricity (or indeed in gas), backed up by forward or futures markets. The Pool in England and Wales (which was replaced by the New Electricity Trading Arrangements in 2001), Nord Pool in Scandinavia and the Power Exchange in California are examples. This requires sufficient horizontal competition, which may in turn mean that an existing generator has to be broken up. Establishing a spot market requires that rules are drawn up for bidding, for payment mechanisms and for reserve capacity so that the market works in an orderly fashion and continuous electrical equilibrium is guaranteed. In practice the major problem with the spot markets in England and Wales, and in California, (though not in Nord Pool, which has many more players) is the exercise of market power by a handful of generators who can determine the spot price. For example in England and Wales the rules of the pool allowed the two dominant generators to 
declare some capacity unavailable, which then raised the equilibrium spot price and increased the profitability of infra-marginal capacity that was declared available. In a much more competitive market it would not pay to restrict supply in this way. A well-designed spot market requires regulatory monitoring to ensure that market power is not being abused. In natural gas the balancing market in the UK has been less problematic than the electricity market, partly because there are many more producers of gas than power generators. In conclusion it seems that direct competition in generation or production can work if the spot market rules are carefully designed and there is sufficient competition that the abuse of market power is not an issue. In some isolated systems, for example small Caribbean islands with a handful of power stations, competition in generation is hardly going to be worthwhile, and the system would be a natural monopoly.

Often the impetus for reform of electricity supply systems is the demand from large industrial and commercial users for cheaper electricity. Integrated monopoly systems may subsidise domestic customers at the expense of industrial customers, so competition will unwind these cross-subsidies. Alternatively the integrated monopoly may simply earn excess profits on all sales. Large customers sometimes have the option of self-supply. Competition in supplying such customers usually needs a competitive spot market to exist and requires users to have real-time meters. Very often the suppliers will be integrated with generators, but this is not essential.

In many countries the first state-owned network enterprises to be sold off are telecommunications operators. Changes in technology, shifts in demand and recognition of the critical importance of interconnection (or access pricing) have meant that competition is both feasible and desirable in many market segments. In the 1980s the dominant theme of reform in telecommunications was that competition was desirable in long-distance calls because of new technologies and demand growth, but that the 'local loop' at either end remained naturally monopolistic. In the UK in the early 1990s policy was revised to encourage entry at the local-loop end and it was expected that cable TV companies would provide this competition. The Telecommunications Reform Act 1996 in the USA also promoted local competition. In the end this facilities-based competition has not proved to be significant. But competition in the provision of retail services over the networks can be, and has been in many cases, successful. The terms of interconnection are critical here, and there is continual pressure for incumbent operators who provide both retail and network services to separate the activities (or for the regulators to split them). In the UK British Telecom (BT) is very dominant in network services but also has a large share of retail services nearly twenty years after competition first started. While retail competition in indirect access telephony services is now coming on stream, competition in the provision of broadband access has probably been constrained by BT's obstruction of localloop unbundling (which requires BT to allow broadband providers access to local exchanges).

In the water sector there are few opportunities for direct product market competition. The fact that water businesses are locally organised provides, 
however, the opportunity for franchise competition. In France and in many developing and middle-income countries, municipalities franchise out water provision. Competition for the market can reduce excess rents. Contracts, especially long-term ones such as concessions with investment requirements, will typically require on-going regulation because it is usually impossible to write complete contracts covering every contingency. The benefits of franchising are greatest when collusion between bidders is deterred. Regulatory capture is always a danger when municipalities are involved in awarding and monitoring long-term contracts.

\section{Areas where Competition Is of Doubtful Value}

In some cases competition is of little value and there is no point in promoting it. In other cases the case for or against competition is less clear. Direct product market competition in water hardly exists, and there are good reasons for this. In the absence of national or even regional water grids there is little prospect for competition via common carriage. Although in the UK such possibilities are being explored, it is fair to say that the policy-makers are being very circumspect about the application of competition. Some methods of introducing competition into water in a small way are feasible and will be discussed in the penultimate section.

Full retail competition for domestic customers of both gas and electricity started in the UK towards the end of the 1990s. While there are many obvious benefits of competition in the markets for larger customers the case for retail competition is not clear (see Giulietti, Waddams Price and Waterson, 2005 for an analysis of UK experience). In the absence of real-time meters multiple suppliers of electricity have to rely on load-profiling of customers to ensure that payments balance usage on average. In a second-best world, where customers face different prices depending on whether they have a real-time meter or not, competition is not axiomatically beneficial. In addition there are the set-up, transactions and switching costs described earlier which are incurred with competition but which are avoided with monopoly supply. While it is true that the introduction of competition lead to price reductions for customers who switched, and may have had some effect on price levels for those who have not switched, the fact that the cost base increased at the same time to facilitate competition makes the effect on social welfare ambiguous. The welfare analysis is very similar to the (reverse of the) classic textbook model of a merger than generates cost reductions but more market power. Competition in retail supply raises costs but reduces profit margins.

Direct competition in network provision is usually absent for the good reason that most networks constitute natural monopolies and network duplication would be wasteful. Telecommunications is the main exception, and even here competition in the local loop is limited. For voice services direct facilities-based competition is essentially a by-product of cable TV provision. In some countries, though, local-loop unbundling for broadband provision has advanced significantly. 
In gas, electricity, water, rail and post there is no prospect of stand-alone duplication of the local distribution networks. Depending on the size of the market, there can be competition in the provision of long-distance transportation, for example in natural gas in the USA. Of course even when a local distribution network is a natural monopoly there are some competitive possibilities. Franchise competition has been mentioned already. Yardstick competition, or comparative competition, can be used by a regulator as a surrogate for actual competition.

\section{Regulation and Competition}

The links between regulation and competition are complex, case-specific and can go either way. Sometimes competition will substitute for regulation. Most obviously this is true in the electricity and gas industries, where regulation of final prices for large customers could be dropped as soon as competition was introduced. In the UK price regulation for domestic customers has also been dropped in those industries, and retail price regulation in telecommunications has over time been reduced in scope. Since regulation is costly the fact that regulation can be dropped when competition has become effective is valuable. In two other ways, that have already been mentioned, the regulatory burden increases when competition comes in. Access price regulation is necessary when there is competition in the provision of services over the network, and if price regulation is abandoned there needs to be increased focus on general competition policy either by an industry-specific regulator or by the general competition authorities.

The UK telecoms regulator, OFTEL, had to act as a competition authority in 1999 in response to an incident of predatory pricing. Scoot plc entered the new market for operator-assisted classified directory advertising, which allowed endusers to phone a single number and be put directly through to a particular business, such as a local plumber or a restaurant. The business model involved end-users paying nothing for their calls, while businesses paid for listings and for each call put through to them. Two weeks after Scoot was the first entrant into this market, BT announced its own service, but with no charges for businesses to be listed and connected for the first year. The industry regulator deemed this to be predatory and had to intervene quickly to prevent BT from building up an unassailable position in this market.

A key issue is the role of regulation in the transition to full competition. A natural policy is to preserve retail price regulation of the dominant firm until competition is firmly established. This requires careful judgement about the optimal level and time path of the price cap. A price cap that is generous to the dominant firm is also generous to entrants and thus may promote competition, but at the same time consumer prices may not fall much. A tough cap will protect consumers but may not encourage much entry.

Often the policies used during the transition to competition are counterproductive (Armstrong and Sappington, 2005). Regulators and policymakers have occasionally acted in a way that suggests that they want to protect competitors rather than to promote efficiency. In the UK telecommunications sector an early 
policy was to allow only one new entrant (Mercury) into the long-distance market (and some local markets). In addition the determination in 1985 of interconnection or access charges for Mercury gave the latter access to BT's networks at what was essentially marginal cost. This did not compensate BT for the opportunity cost of providing access (which would include its lost profits), as the Efficient Component Pricing Rule (ECPR) of Baumol (1983) and Willig (1979) requires. An access price below the level indicated by the ECPR will encourage inefficient entry.

Market share targets for incumbents have been used by regulators in the UK in both the electricity and gas industries. As Armstrong and Sappington (2005:Section 6.3) point out, such policies have two problems. First, market share is not generally a good indicator of market power. A firm with a relatively small market share may still have considerable ability to raise prices above competitive levels. Second, market share targets can induce all firms to price less competitively. For an incumbent the simplest way to cut market share to the target level is to raise the price in a market where products are not perfect substitutes. The rival firms will typically then have incentives to increase their prices as well.

Regulations derived from social rather than purely economic considerations may affect the development of competition. Examples are universal service obligations and requirements to price uniformly irrespective of costs. Again these can be carefully designed to ensure that they do not lead to too much new entry (when entrants do not face similar obligations to incumbents) or too little entry (when incumbents use the existence of these obligations as an argument against any new entry).

\section{The Experience with Competition}

In this section the experience of introducing competition into a number of regulated industries is described briefly. The section begins with the infamous case of Californian electricity, and then looks at telecommunications, gas, electricity, water, rail and post in the UK.

\section{Electricity in California}

California's electricity reform of the late 1990s has become notorious. Vertical integration between electricity distributors/suppliers and generators was removed. The latter competed (imperfectly it turned out) in a spot wholesale market. All of the standard methods for sharing risks between different stages of electricity production were banned. Distributors were forbidden from integrating again with the generators. Often a good substitute for vertical integration is a long-term contract. In the interests of maintaining room for new entrants to the generation market, though, long-term contracts were only allowed to cover a fraction of each distributor's obligations. Distributors sold power to final customers at a capped retail price, and had obligations to supply, whatever the level of wholesale price. An unfortunate combination of individually unlikely events then led to the 
wholesale price rising well above the capped retail price until the distributors approached bankruptcy. These included a rise in the natural gas price, a dry spell which reduced the amount of water available for hydro-generation, a rise in the demand for electricity for air-conditioning and possible abuse of market power by the electricity generators.

The partial reform of electricity in California failed. What lessons can be learned from this? First, allowance for robust risk-sharing mechanisms needs to be made when designing a system. Closing off all the traditional routes for dealing with the shocks (vertical integration, long-term contracting, retail price flexibility) was a hostage to fortune. Second, while short-run efficiency is valuable in electricity markets another objective is long-run security of supply, which was not obviously promoted by the new system.

\section{Policy in the UK}

Competition in UK telephony began in 1986 with a single competitor, Mercury, being licensed to compete with BT, largely in the long-distance market. The change of policy in 1991 to allow a free for all was also based on the idea that there would be substantial facilities-based competition, but this time the entry was expected to be at the local level and come from cable TV companies. Again this has proved disappointing. BT's share of voice calls in the residential market was 68.5 per cent in 2004, and its share of lines was 64 per cent, with cable companies having 18 per cent and indirect access providers having the remaining 18 per cent. Retail price regulation of BT remains in existence after twenty years of competition, though the scope of the price cap is smaller than once was the case. For broadband provision 'local-loop unbundling', the process of allowing rival internet service providers access to BT's local exchanges to install their own equipment, has been delayed, and the country lags behind other European countries. A recent regulation requiring BT to cut the wholesale charge it makes for local loop unbundling may go some way to speeding up the process. Over time BT has been forced increasingly to separate its network and retail parts.

In natural gas the privatisation of British Gas in 1986 was accompanied by no discernable effort to promote competition. British Gas remained a vertically integrated monopolist that was also the only buyer of gas from producers. Regulation of retail prices was weak and though de jure competition for larger customers was allowed via common carriage there was no competition for five years because the access terms were not regulated. Subsequent reform concentrated both on the vertically integrated structure of British Gas (eventually the company separated itself) and on the regulation of the terms of access to the grid. The competition authorities, as well as the industry-specific regulator, became involved in monitoring the development of competition via common carriage (including at one stage imposing a maximum market share target on British Gas). Since the late 1990s retail competition in gas supply has been rolled out across the UK, and to date 47 per cent of households have switched supplier (some have switched back to British Gas after a period with a rival company). 
The reform of the electricity industry in England and Wales to some extent reflected the lessons learned from the mistakes made in gas. There was both vertical and horizontal separation. Ownership of the national transmission grid was taken away from the monopoly generating company and given to the twelve regional distribution and supply companies. Generation itself was split into three asymmetric companies and a power pool was established. The twelve distribution companies remained as regional monopolies in distribution but not in supply. Supply competition was introduced in three stages, with domestic customers being allowed to choose their supplier from 1999.

The electricity pool had good rules for determining prices but not enough competitors. In the early days of competition in generation the regulator intervened regularly and policies included a temporary pool price cap, bans on vertical mergers with distributors and the requirement that the two major generators sell some of their capacity to third parties. The pool was replaced by the New Electricity Trading Arrangements in 2001, which were designed both to increase flexibility and to reduce transparency so that tacit collusion would be less easy to sustain than under the Pool. Competition in the supply of electricity to domestic customers has resulted in some concentration of the market, with six major companies in a market place where once there were twelve. Just over half the customers had switched supplier by 2004 .

The water industry has few opportunities for competition, other than through franchising or through yardstick competition. In England and Wales competition for very large customers was allowed in 1996, which lead to the introduction of 'large-user tariffs' with substantial quantity discounts. The result was that no customer switched from their local suppliers. Three main types of competition are feasible: inset appointments (where a new supplier takes one particular customer, perhaps supplied with water from a new sources), competition for customers located at the boundary between two suppliers, and competition via common carriage. While there is a handful of examples of inset appointments the other types of competition have not yet started. There seems to be little prospect of widespread competition.

At the time of railway privatisation in 1994 there was a single company, British Rail, which operated train services, owned and serviced trains and owned and ran the tracks, signalling systems and stations. This was replaced with 84 different companies. There was radical vertical and regional separation. Train operation was franchised, with a small amount of direct competition, train ownership was separated from train operation and the tracks, signalling and stations were separated from train services and put into a single network company, Railtrack. The latter contracted out much of its maintenance work and was then bankrupted by the Government after two high-profile fatal accidents which were caused by inadequate maintenance. The vertical disintegration of the system has increased transactions costs as formal contracts between each layer of the system have to be devised and monitored.

The Post Office in the UK remains state-owned, but recently there have been moves to liberalise the market. Competition in bulk mail is currently allowed for 
more than 4,000 items, and full-blown competition will be allowed from 2006. Because competitors are unlikely to want to duplicate the distribution network, Royal Mail is required to offer access to rivals for delivery. Royal Mail is also required to maintain a universal postal service. Royal Mail has announced plans to price by size as well as by weight, but is required to price uniformly across the country.

\section{Conclusions}

Competition is valuable in promoting efficiency, but care needs to be taken when introducing it, and policymakers should always bear in mind that competition is not an objective but is an instrument. It can be costly to introduce competition, as set-up, transactions and switching costs are incurred that are not present when there is no competition. For competition to be successful it needs nurturing, but not over-protection. Structural separation of vertically integrated incumbents is often helpful in promoting competition, but has its own costs, and access price regulation and general competition policy need to complement the introduction of competition. When access terms have not been subject to regulation early on (as in the gas industry in the UK) the benefits that competition can provide have been delayed.

\section{References}

Armstrong, M., S. Cowan and J. Vickers (1994), Regulatory Reform: Economic Analysis and British Experience, MIT Press, Boston, MA.

Armstrong, M. and D. Sappington (2005), 'Regulation, Competition and Liberalization', Journal of Economic Literature, forthcoming, Available at http://www.econ.ucl.ac.uk/ downloads/armstrong/reg2.pdf.

Baron, D. and R. Myerson (1982), 'Regulating a Monopolist with Unknown Costs', Econometrica 50:911-930.

Baron, D. (1989), 'Design of Regulatory Mechanisms and Institutions', pp. 1347-1447 in R. Schmalensee and R. Willig (eds), Handbook of Industrial Organization: Volume II, North Holland, Amsterdam.

Baumol, W. (1983), 'Some Subtle Issues in Railway Regulation', International Journal of Transport Economics 10:341-55.

Cowan, S. (2001), 'Developments in Regulatory Principles: The UK Experience', Chapter 2, pp. 39-53 in C. Henry, M. Matheu and A. Jeunemaitre (eds), Regulation of Network Utilities: The European Experience, Oxford University Press, Oxford, http://www.oup.co.uk/pdf/0-19924415-4.pdf.

Giulietti, M., C. Waddams Price and M. Waterson (2005), 'Consumer Choice and Competition Policy: A Study of UK Energy Markets', Economic Journal 115:949-968.

Newbery, D. (1999), Privatization, Restructuring, and Regulation of Network Utilities, MIT Press, Cambridge, MA and London. 
Varian, H. (1992), Microeconomic Analysis, Third Edition, Norton, New York and London.

Varian, H. (2003), Intermediate Microeconomics: A Modern Approach, Sixth Edition, Norton, New York and London.

Willig, R. (1979), 'The Theory of Network Access Pricing', pp. 109-152 in H. Trebing (ed.), Issues in Public Utility Regulation, Michigan State University, Public Utilities Papers.

This is a revised version of a paper presented at the Regulatory Forum of the Australian Centre of Regulatory Economics (ACORE), the Australian National University, Canberra, on $17^{\text {th }}$ October 2005. I am very grateful to Flavio Menezes, Velu Ramasamy, Henry Ergas, Paul Paterson and the other participants at the Forum for very helpful comments. 


\title{
Airport Environmentalism
}

\author{
Claire Miller, Struggle for the Snowy: The Grassroots Campaign to Save \\ a National Icon, $A B C$ Books, 2005
}

\section{Reviewed by Alistair Watson}

$\mathrm{P}$ aul Krugman identified a style of economic commentary as 'Airport Economics'. Books for the busy traveller that are lively and readable, but do not tell the full story. This book by Claire Miller, long time environment reporter for The Age, deals with the decision to return water to the Snowy River for environmental flows. Her ambitious account of the personal, political and administrative dimensions surrounding the decision is absorbing, although disturbing in several respects.

Just as the pattern of irrigation development in Australia is the product of previous blind enthusiasm for irrigation and a memorial to swinging seats of the past, the eventual decision to return water to the Snowy River was the result of unsophisticated environmental policies and political manoeuvring. A local pressure group was lucky enough to achieve most of its objectives through unexpected political circumstances. An independent candidate supporting return of water to the Snowy was elected to represent East Gippsland in the 1999 Victorian State election. That election was much closer than anticipated. Deals over the Snowy were critical in the replacement of the Kennett Government by the first Bracks Government. The pressure group achieved its immediate objectives, but the long-term implications for environmental policy are not reassuring.

The book is slow to start with two forewords, an author's note and prologue. Premiers Bracks of Victoria and Carr of New South Wales provide the first foreword. The Premiers endorse the approach of the book as an exercise in story telling. The foreword is harmless enough but politicians should keep a healthy distance from journalists and (even more so) vice versa. The second foreword by Professor Sam Lake of Monash University is subtler, lamenting in particular the descent of environmental policy into 'an age of environmental battles'. Professor Lake also recognises that the result of existing promises 'still has to eventuate and may yet be compromised'. The extra water for the Snowy is supposed to come from water savings in irrigation areas and is proving expensive to find. Additional promises to find water savings for environmental flows for the Murray River have been made in the recent National Water Initiative. These plans are competing for the same water. The citizens of East Gippsland may find their aspirations for the Snowy expendable, now that they no longer have the same political leverage. 
The author's note describes the comprehensive interviews and source materials used in preparing the book concluding that 'this is a book about the Snowy River alone, which never got the chance to tell its side of the story.' Perhaps it is merely metaphorical shorthand, but frequent references to the Snowy River throughout the book as if it were a person are irritating. Can a river tell a story? Can a river be 'a rambunctious larrikin'? Editorial concern with anthropomorphisms is not a minor quibble but is about logical clarity. A river can no more tell a story than can an economist hide behind assumptions, theory and data and claim that 'the model says.'

The beginnings of the campaign to save the Snowy are described in an overblown prologue, attributing the plight of East Gippsland residents to the damaged state of the Snowy River. Many small towns have faded away over the years. The residents of Dalgety in New South Wales and Orbost in Victoria at least had the Snowy Mountains Hydro-Electric Scheme to complain about.

The history of the Scheme is summarised in chapter 1. The development ethos of earlier times and different public attitudes to the natural environment are revealed in a quote from an official document of the 1940s that describes water flowing to the sea as 'wasted.' The influence of electricity shortages in post war Australia in the genesis of the scheme is perhaps under emphasised in the book. The Scheme was conceived in an era of Keynesian macroeconomic policies, inspired by projects like the Tennessee Valley Authority of Roosevelt's New Deal. Public investment was viewed as a way of picking up expected slack in the post war labour market. In the event, the labour force was recruited through expanded migration. An influential player was Sir William McKell, wartime Premier of New South Wales and later Governor-General. Arguably, McKell overstepped the boundaries of Vice-Regal detachment in his enthusiasm for the Scheme, encouraging the Commonwealth Government to use its defence powers to overcome legal difficulties with the project. Nowadays, intervention by McKell's successors in support of popular environmental causes would not be thought out of the ordinary. There were some local misgivings even at the outset about effects of the scheme on the economy and amenity of East Gippsland.

The origins of the Snowy River Alliance are described in chapter 2 with sympathetic portraits of the main personalities involved and their environmental concerns. Miller describes the tensions experienced by public servants who identified too closely with local issues when they were employed to reflect a wider interest. Balancing local, regional, state and national interests in environmental management is an ongoing challenge in public administration. And it is a challenge that is not often being met.

The inherent weaknesses of catchment management as an organising principle in environmental management are exposed by the experience of the Snowy. At issue are complex arguments about spatial and inter-temporal equity. There is an important technical dimension. Who is to be held responsible for the past follies of the community as a whole? How is environmental repair to be funded? Is environmental damage reversible? How much is to be spent on data collection and detailed scientific studies? Local organisations cannot reconcile 
these conflicts. As shown in the controversy over the Snowy, local organisations with substantial public funding may not even try. In effect, public officials in catchment authorities and other regional resource management bodies are paid to be parochial.

The trigger that broadened the local campaign was the proposal in 1990 to corporatise the Snowy Mountains Scheme as part of a national agenda of electricity reform. The Snowy Mountains Authority was an obvious target for reform because after the period of substantial capital investment had come to an end, the Authority showed signs of rigidity and regulatory slackness. Reform of the electricity industry proved difficult in all Australian states. The economics of the Snowy Scheme are also bedevilled by the intractable economics of joint production, with water stored for both irrigation and electricity generation.

Hydroelectric power is valuable because it can supply peak demands for (non-storable) electricity far more quickly than thermal plants. The demand for storable irrigation water is annual according to seasonal conditions, but exact timeliness is not critical. Loss of stored water to irrigation and the environment reduces the flexibility of electricity generation, and potential profits at times of peak demand. Once the objective was corporatisation of the Snowy Mountains Scheme, the Snowy River Alliance confronted governments whose objective was to maintain the value of their electricity assets. How returning additional water to the Snowy would affect the value of the Snowy Scheme proved to be a contentious issue in the subsequent Snowy Water Inquiry.

The locals commissioned a scientific study in 1995 to assess environmental damage. A group of scientists, aided by the recollections of two 'old timers', was asked to undertake a rapid appraisal. Miller reports that the scientists took five days to assess numerous sites along 335 kilometres from the dam wall at Jindabyne to the river mouth at Marlo. The Expert Panel recommended an environmental flow for the upper Snowy based on the return of 28 per cent of the original flow at Jindabyne. This became a rallying call for the campaign. Not surprisingly, irrigators were unhappy at scientific conclusions based on a week's work, rather than extensive monitoring and measurement. It turned out that this flow was close to that proposed in an unreleased official study that had 'fallen off the back of a truck'.

The Alliance enlisted the support of peak environmental organisations and pushed for a public inquiry. The Snowy Water Inquiry of 1998 is described in chapter 4. The Commissioner for the Inquiry, the Hon. Robert Webster, was a former Minister of the New South Wales Government. The technical quality of the reports of this Inquiry and the objectivity and fairness of Inquiry procedures are insufficiently acknowledged in the book. Instead, there are lengthy and admiring descriptions by Miller of the political campaigns undertaken by the Snowy River Alliance and its associates. These campaigns involved celebrity politics, fund raising from philanthropic foundations prepared to bend taxation restrictions on funding political activities and the usual flim flam of press releases, protests and television appearances. Not everything is a branch of show business. Disputes should be settled within a logical framework and at reasonable cost. 
There were around 500 submissions to the Webster Inquiry, with write-in campaigns from both sides. Spurious arguments about multiplier benefits from irrigation and tourism were trotted out and rejected by the Inquiry. Market research conducted by the Inquiry revealed little public support for reduced hydroelectricity generation and re-diverting water from inland irrigation to the East Gippsland coast. With more resources than the earlier Expert Panel, a multidisciplinary Scientific Reference Panel surveyed riverine biota and habitat for each river reach. Environmental indexes were constructed. This research broadly supported the case for returning up to 20 per cent of flow to the Snowy River.

There is no serious attempt in this book to resolve technical issues of environmental damage measurement. Overall, Miller's approach is aesthetic rather than empirical, emphasising damage to landscape in the broad. Unhappily, there is considerable tension between scientists and farmers over the role of scientific investigations in assessing damage. Part of the problem is that 'flow' is both an instrument and an objective of environmental policy. It is common to talk about environmental flows as if they could be defined exclusively by 'the science'. Worse still, political discussion takes place as if there were a single number expressed in percentage or absolute terms that has the imprimatur of scientific authority. The recent Living Murray Initiative of the Murray-Darling Basin Commission is another case that trivialises serious analysis in popular discussion.

Environmental changes to rivers with reduced flows are multi-dimensional affecting riparian vegetation, in-stream biota, water quality, fish and more. These separate attributes have to be weighted. There may be threshold values with a minimum flow necessary before any benefit is obtained. Seasonality of flows is important. Some environmental changes may be unrepairable on any reasonable time scale. Community valuations of environmental attributes and the costs of making environmental improvements have to be considered alongside scientific information. This is a complex task involving a range of professional disciplines, and is not helped by giving credibility to the street corner science of environmental advocates or farmer organisations.

The Webster Inquiry considered the capital costs of returning water to the Snowy, costs to electricity generation and opportunity costs to agriculture if less water were available for irrigation. These costs were compared with potential tourism and related benefits in the Snowy region. Water saving options in irrigated areas were also considered. The final report went further than expected by selecting a preferred option ( 15 per cent) from all the options considered. Webster's reasons are set out in the book. The recommendation reignited conflicts between those prepared to compromise and those preferring the comfort of entrenched positions. Miller describes differing opinions within the New South Wales bureaucracy on how to respond to the recommendation by Webster.

Webster's conclusion was broadly consistent with existing Victorian water policy. A Sharing the Murray report thrashed out in difficult negotiations between interests from across the state included a modest allocation of water for the Snowy. Both that provision and the Webster recommendation did not please the people of East Gippsland, who stuck with their claim for 28 per cent. As revealed 
in the book, a major reason for failure to compromise was the firm belief that there was widespread economic inefficiency in Australian irrigation and water savings were there for the taking. This was wrong, especially following the introduction of water trading. As reported by Miller, local activists ignored sensible advice on this point from the Australian Conservation Foundation.

Political events following the decision by the Snowy River Alliance to stand an independent candidate in the Victorian Election are described in chapter 5. The then local National Party member was compromised by internal party discipline with several colleagues from irrigated areas in northern Victoria, and by his membership of the governing coalition. He was a sitting shot for a strong local candidate. The Labor opposition was more than willing to give explicit support to the 28 per cent claim as part of its strategy of chasing country votes from those disaffected with the Kennett Government. The strategy was more successful across the State than expected and the newly elected member for East Gippsland, Craig Ingram, was in a position to decide the fate of the Kennett Government.

Miller is in her element in chapter 6 describing the protracted negotiations resulting in three Independents siding with Labor to defeat Kennett and his coalition. Ingram had good reason for believing that the cause on which he had been elected would have more traction with Labor, who were also better placed to deal with their colleagues in New South Wales. In an accurate observation, Miller notes at page 141 that 'politics rules out the cheapest and easiest solution [for water recovery]: buying water on the open market'. In her explanation of why this is so, Miller recycles the widely held view that government purchases would inflate prices. This is unlikely because a high proportion of Australian irrigated output is exported. An elastic demand for exports translates to an elastic demand for irrigation water. For similar reasons, concerns with private 'water barons' controlling the water market are overheated. The reasons politicians prefer highcost ways of recovering water to water purchase are less complicated, and include their unwillingness to confront the public with the real cost of increasing environmental flows. Meanwhile, the search continues for engineering solutions to find environmental flows - a consultants' heaven, with no end in sight.

There are two separate strands to chapter 7 . The first, a brief description of irrigation in northern Victoria and southern New South Wales, belongs much earlier in the book. While there are many useful points in this section, including belated reference to rational critiques of irrigation by scholars like Bruce Davidson, other myths are perpetuated including excessive optimism about water savings. The discussion is biased in favour of the irrigation policies of Victoria vis-à-vis New South Wales with a one-sided account of how risks of variable supplies are managed. Miller also falls into the trap of worrying about which commodities are produced on irrigation farms. Issues for irrigation policy do include the volume of water extracted, and external effects on users downstream. The commodities produced are of no public policy significance because farmers are best placed to decide what they produce, taking into account the other resources available to them. The task for government is to assess environmental damage from irrigation and implement appropriate policies where necessary. 
The next part of the chapter is a blow-by-blow account of negotiations between the newly elected Victorian Government and their New South Wales colleagues to deliver commitments to East Gippsland. Resistance was forthcoming from the New South Wales Treasury and South Australia. This section would appeal to aficionados of the nether world of politics and public administration, where ministerial advisers with short planning horizons make decisions of long-term significance. In the event, the deal negotiated was 21 per cent not the 28 per cent expected by East Gippsland voters. ${ }^{1}$ A cosmetic arrangement was cobbled together to deliver the last seven per cent through public/private partnerships after the first ten years. What form this will take down the track remains to be seen.

To reconcile differences between jurisdictions over water for the Snowy and the Murray, a trilateral agreement between the Commonwealth, Victoria and New South Wales was established in September 2000 to create a Joint Government Enterprise to organise water for environmental flows. How this fits with the National Water Initiative is not obvious.

It would have made most interesting reading if Miller had used her considerable talents as an investigative journalist to delve into the progress of the Joint Government Enterprise over the last five years.

The book tails off towards the end. Technical details of the final agreement are mixed up in the penultimate chapter with unedifying accounts of politicians scrambling to look good at the launch of the program. The underlying problem of the book is that it is a patchy blend of anecdote and analysis. This problem continues in the concluding chapter. Miller recognises the dilemma of existing guarantees given to the Snowy and the new promises made on environmental flows for the Murray River. This should have been elaborated. Claims about water savings and environmental flows in the 2004 Victorian Government White Paper on water are taken at face value. These proposals were also worthy of much closer examination.

Apart from the main text, a final lengthy section presents various interesting materials on Aboriginal history, European settlement and the story of Paterson's The Man from Snowy River.

The bane of environmental writing and policy is meaningless slogans and catchphrases. The 'triple bottom line', 'precautionary principle', 'sustainability' and 'environmental footprint' spring to mind. The most overworked words in the book are 'icon' and 'iconic.' Miller would do well to read a short poem by Les Murray, Icons. She would not use those two words again.

Alistair Watson is a freelance agricultural economist based in Melbourne, aswatson@bigpond.net.au. He gave advice to Murray Irrigation Limited during the Snowy Water Inquiry in 1998.

${ }^{1}$ Arguing whether 21 or 28 per cent is the appropriate environmental flow rather than 20 or 30 per cent is completely spurious accuracy, given the way these estimates were (or could be) established. It is another symptom of the dominance of pure politics and cant in the debate over return of water to the Snowy. 


\section{$N O N-A G E N D A$}

With the view of causing an increase to take place in the mass of national wealth, or with a view to increase of the means either of subsistence or enjoyment, without some special reason, the general rule is, that nothing ought to be done or attempted by government. The motto, or watchword of government, on these occasions, ought to be - Be quiet... Whatever measures, therefore, cannot be justified as exceptions to that rule, may be considered as non-agenda on the part of government.

— Jeremy Bentham (c.1801)

\section{Deconstructing Corporate Social Responsibility}

\section{Gary Johns}

$\mathrm{C}$ orporate Social Responsibility (CSR) is a construct of non-owner, noncontract and non-government interests or 'stakeholders' to regulate corporations. It suggests that a corporation is not only responsible to the law, its investors, customers and employees, but to 'society'. As Henderson (2004:27) conceives it, CSR is a 'radical doctrine' because it purports to have its adherents 'both promote the general welfare and be seen to do so.' CSR does not, however, solve the problem of knowing what interests constitute society, nor of how to order its demands to achieve the general welfare. Until quite recently CSR has worked on private dealing between corporations and non-government organisations to bypass the traditional public consensus position as expressed in law. CSR is therefore a political ideology that wants private interests to be subsumed by the public interest as defined by a narrow range of players.

CSR encompasses two apparently contradictory forces: socialisation of the corporation and privatisation of regulation. In ideological terms, a left wing conspiracy dressed as a right wing conspiracy. Socialisation of corporations stems from a desire for public corporations to become public property, while leaving the financial risk with the owners. It seeks not only to internalise externalities but also the 'public interest', traditionally resolved in the public arena. Corporations will act as governments, political considerations will become more apparent, the language will become that of power rather than economics. Those most keen to socialise the corporation also want corporations to report their behaviour in dimensions that were previously thought to be the preserve of government rights, equity and the environment. Furthermore, CSR is measured by a host of

Gary Johns is Director of the Governance Unit at the Institute of Public Affairs. 
NGOs and professionals who are keen to expand their influence, or their income. Governments are left playing catch-up, the electorate left out of the picture.

The traditional regime for corporate regulation does not ignore CSR but seeks to secure the best rules for an entity's efficient organisation, give relief to those who do business with it, and prevent it from doing harm. In addition, it uses taxation and a host of very specific legislation such as contract, employment, insolvency, $\mathrm{OH} \& \mathrm{~S}$ and pollution emission as the principal means of ensuring it contributes to the common good. In the new terminology, tax laws are social justice laws, environment and planning laws are sustainability laws, employment, $\mathrm{OH} \& \mathrm{~S}$, consumer and contract laws are human rights laws, and self-regulation is governance. CSR regulation seeks to overturn the traditional regime, which is based on a consensus regulator, the parliament and the courts, and whose tenor is liberal, allowing freedom of action consistent with protecting others from harm.

The paper outlines the reasons for the growth and appeal of CSR regulation, despite evidence that it is not profitable. It describes two types of private regulators and what each hopes to achieve from the CSR regime. Further, it outlines the Australian government's response to the regime, which is to facilitate measurement, and the corporate response, which is to use it as a recruitment tool.

\section{Stakeholder Theory}

An intriguing aspect of CSR is, why now? What is the evidence that corporations are bad for society? The iconic corporate collapses such as Ansett and HIH failed their owners, and workers or policy-holders, not society. They did not diminish the environment or abridge human rights. They sent broke those with a specific contract with the company. The upshot is greater scrutiny of corporations and more powers to regulators for transparent decisions on financial matters, but little for a CSR agenda that seeks a governance role for corporations in society. Measuring the triple bottom line does not prevent insolvency, but insolvency prevents the corporation from playing any role in society. Perhaps the answer lies in the fact that CSR advocates have discovered that they can place corporations under some pressure without recourse to government, the so-called soft path to power. An example is the UN Secretary-General Kofi Annan's self-declared, The Global Compact (GC). The GC has the modest mission of striving (UN, 2005):

to be the world's most inclusive voluntary initiative to promote responsible corporate citizenship, ensuring that business, in partnership with other societal actors, plays its essential part in achieving the United Nations' vision of a more sustainable and equitable global economy.

In fact, the GC is a contrivance to entice the corporate world to deliver on the Universal Declaration of Human Rights, the International Labour Organization's Declaration on Fundamental Principles and Rights at Work, the Rio Declaration on Environment and Development, and the United Nations Convention Against Corruption. Using corporations to deliver overt political change was once thought 
to be imperialist or colonialist. Having them do so in the name of apparently good principles nevertheless leaves them open to the same accusation.

Note Annan's emphasis: business doing the work of government in conjunction with 'other societal actors'. The reference is to the fact that companies may 'negotiate performance standards with non-governmental organisations (NGOs) that include some form of monitoring. The NGOs arrogate to themselves, in this way, functions that belong to governments' (Wolf, 2004:10). The question must be asked, 'even if the public interest could be defined, why would a process of bargaining between publicity-seeking, single-issue NGOs and profit-seeking companies necessarily reach the right outcome? The process that generates the commitments to CSR is, let us be blunt, one of blackmail and concession' (Wolf, 2004:12). CSR diverts the corporation from its purpose, and places it, inappropriately, in the role of government.

The CSR phenomenon occurs at a difficult time to govern. The following observation of government holds true for corporations. 'It is clear that voters [shareholders] have, over time, become better informed about their governments' [corporations'] performance. Voters [shareholders] expect more of government [corporations] and their expectations are more divergent, consequently it becomes more difficult for government [corporations] to "identify any feasible set of policies that would satisfy its constituents"' (Pharr, Putnam and Dalton, 2000:20). More broadly, there is a long-term trend toward the individual, a trend which 'undercuts the authority of institutions' and is driven by the information society which has caused a 'creative destruction ... disrupt[ing] existing social patterns. This in turn creates anxiety and dissatisfaction in large parts of the public' (Nye and Zelikow, 1997:271). In addition to the loss of authority that corporations share in common with government, there is the added complication that the corporate 'constituency' should be widened from shareholder to stakeholder, which further serves to undermine the institution.

The decline in the trust of institutions and the dilution of the corporate constituency leads to a central problem, that all interests in an enterprise compete to obtain benefits from the enterprise but none has priority. This simple proposition is very confronting, because it is in effect posing the question, 'in whose interests should the enterprise be run?' (Weiss, 2002:1). It also assumes that society grants an enterprise the right to exist. Those whose business it is to advise corporations on social responsibility, for example SustainAbility (2004:38), are fond of arguing that corporations have a license to operate in the community. This is accurate at one level only; the community through its law-makers may grant licenses and certain privileges in return for the enterprise complying with the law. It does not license the activities of stakeholders at large to impose their views on the corporation.

The key perception is that company decision-makers 'need to consider a range of interests from customers and shareholders to employees, suppliers, local communities, pressure groups and even, potentially, future generations' (SustainAbility, 2004:38). A more honest assessment would be: a stakeholder is 'anyone who can do you damage'. The stakeholder dialogue ignores the fact that 
directors have to weigh all of the relevant stakeholder interests for the purpose of the corporation. CSR displaces the corporation with an entity, for which the directors patently cannot be responsible, the society. This is the nonsense of CSR, it sidelines the democratically responsible method for defining the public interest and ordering private interests, and substitutes it with a narrow definition. Much of this ruse follows from an acceptance of the community license concept, which argues that corporations are essentially social agents created by states to deliver 'social goods', and that 'Society grants corporations a license to operate because of their unparalleled capacity to mobilise human, natural and financial capital to produce goods and services' (SustainAbility, 2004:38). Corporations rarely deliver public goods, unless by contract or arrangement with government, or as a by-product of producing private goods and services. The logic of the social license is breathtaking in its implications for private property.

Nor does the theory satisfactorily answer the question of who, or what, produces economic value. Instead Weiss (2002:6) says: 'its focus is on the distribution of outcomes, the harms and benefits, and not on who produced the harms and benefits. It assumes value is produced by the enterprise itself and that stakeholders have a claim on some of this value because the enterprise is a creature of society'.

It radically overturns the social contract for business, which includes obligations to obey the law, honour contracts and agreements and respect the rights of others. It ignores the fact that economic value is produced by owners who make their savings available to other members of society to put them to use in productive ways. The owners have an exclusive moral claim to the benefits produced by their activities, as others have a moral claim for the benefits produced by their labour or other contracted services. Such a base provides the certainty from which claims and counterclaims may be settled.

By contrast, a second strand of stakeholder theory focuses less on equating the interests of stakeholders with shareholders, and more on their ethical treatment. This means that stakeholders, employees, customers, suppliers, owners, financiers and the community should be treated fairly and justly (Corfield, 1998:218). This thinking is consistent with those who regard the corporation as no more than a process for grievance-settlement in society at large. For example,

One of the most significant things that companies could do to make themselves good 'stakeholder corporations' is to ensure they give ... rights to external review, to stakeholders ... with legitimate complaints about the company. The right ... to make claims against individuals and institutions in order to advance shared ideals of social and political life and to rectify relations that have gone wrong - is an essential part of citizenship in a contemporary democracy. (Parker, 2002:227)

We are unnecessarily constrained by the belief that the representative institutions and legal system of the state should be the exclusive or even the primary, home of political deliberation. (Parker, 2002:7) 
Parker may well have her wish come true. The attempt to build politics into the corporation, without a clear means of settling claims upon the corporation will inevitably lead to the politicisation of the corporation. Asserting that nonshareholders have claims does not settle the claims, it simply raises expectations. Nor is it likely that the productive elements of corporate organisation will be enhanced by the new focus brought to bear on the division of the spoils.

Stakeholder theory has no recognition in Australian Corporations Law. According to the Commercial Law Association (CLA), directors owe strict fiduciary duties to the company in equity and by statute. They also owe a duty of care to the company at common law, which is supplemented by a statutory duty of care and diligence. The latter is qualified by the 'business judgement rule' in s180(2) of the Corporations Act 2001 (Cth). There are also various specific provisions in the Act and elsewhere imposing duties and liabilities on directors, particularly in insolvency (CLA, 2005:1). As McConvill (2005:3) argues:

the momentum towards broadening the duties of directors under company law ... is based on three false assumptions - company directors do not already take into account stakeholder interests; taking into account stakeholder interests is contrary to the best interests of the company; and emphasizing a stakeholder-oriented approach to corporate governance necessitates legislative intervention.

\section{CSR Is Not Profitable}

What of the claim that CSR is profitable as well as good? Claims about CSR occur in at least three areas of business - ethical consumerism, ethical investment and CSR ratings and profitability. Unfortunately, for the advocates, the claims are not well supported by the evidence.

A recent study (Auger et al, 2003:300) on the impact of ethical consumerism 'suggest[s] that consumers won't sacrifice product performance for ethical considerations in spite of what activists might hope'. The study tested the buying preferences of a large group of business students and by contrast, members of Amnesty International for personal products and sports shoes each parading various 'ethical' features such as biodegradable soap and runners made without sweatshop labour. The study attempted to clarify the extent to which consumers 'value' ethical product features when making purchases by using a 'structured choice' experiment. Rather than ask people what they liked in a product, the purchaser was faced with real trade-offs between features and price. Because of this realistic choice, the experiment was able to estimate the dollar value of specific products without the standard 'politically correct' (p. 281) bias that exists with traditional survey methods.

The study confirmed that while the ethical consumer exists, that is, that there is a market for ethical products, it made clear 'that the measurement of simple, unconstrained stated preferences will overestimate the importance of product features for which there are obvious, socially correct, responses' (p. 285). 
Elsewhere, Auger and Devinney (2005:21) were critical of the 'boosterism' that came with 'traditional survey methods that make use of simple rating scales [as they] may be overstating the importance of ethical issues to the purchase behaviour of consumers' because of the 'tendency of respondents to answer questions about ethical issues in a socially-acceptable way'. The experiment also suggested that while companies can potentially lose from having their products identified as being made under bad conditions they have little to gain from marketing their products as being made under good conditions.

A study of the returns on ethical investment products in Australia by Ali and Gold (2002) revealed that there was no substance in the claims that it is possible to have an investment portfolio without the very profitable returns from alcohol, tobacco and gambling and outperform those which include them. 'The empirical analysis demonstrates that a financial sacrifice is involved when excluding sinful industries from a market portfolio in the Australian context' (p. 13). In other words, ethical investment comes at a cost. The authors concluded that ethical products and their spruikers were simply marketers using an attractive label to lure a boutique investor.

The authors assessed the performance contribution of 'sinful' industries (alcohol, tobacco and gaming) compared to the broad stock market (or 'normal' portfolio). The analysis, conducted over a seven-year period, concluded that overall the sinful industries contributed positively to the market portfolio. Excluding sinful industries from the market portfolio therefore meant foregone returns. The removal of the sinful industries from the broad market portfolio reduced returns from 12.7 per cent per annum to 12.0 per cent per annum - an overall cost of 0.70 per cent per annum. While the exclusion of sinful industries reduced the volatility of the market portfolio (from 12.4 per cent per annum to 12.0 per cent per annum), the reward ratio also fell, reflecting a less than optimal tradeoff. The authors also surveyed the management expenses for Australian SRI funds and found that investors generally faced additional imposts compared to mainstream funds with similar investment portfolios. Depending on the type of investor the management expenses for SRI funds were on average 13.78 per cent higher than their mainstream counterparts. These costs included investment management fees and in some cases, fees paid to external service providers such as index vendors and SRI research providers.

A study was conducted of a prominent Australian CSR index (Johns, 2003) to ascertain, among other things, if performance on the Index changed corporate behaviour. The Good Reputation Index (devised by Reputation Measurement, now Reputex, and published by Fairfax) measured a corporation's performance across six major categories: Management of Employees; Environmental Performance; Social Impact; Ethics and Corporate Governance; Financial Performance; and Management and Market Focus (Reputex, 2005). Some of the 'measures' imposed in the index were as simple as asking whether a corporation had signed up to the UN declarations. How such a declaration would substitute for compliance with Australian labour laws, for example, is unclear. The study tracked the performance of the outliers, those whose performance rose or fell 
extraordinarily between two surveys. The conclusion from interviews with those who had completed the Reputex survey in the corporations was straightforward. 'Success in the rankings was determined by survey participation, not performance. The exercise had no apparent impact on the behaviour of the corporations. In that regard, it failed to achieve its objective' (Johns, 2003:15). In other words, it was a game played by the corporations to win the favour of the regulator, and by the regulator to advance their own interests and that of their constituency.

CSR measurement may not only be ineffectual it may not be profitable. A US study measured the relationship between CSR rank and profitability of 29 businesses that had been on the Business Ethics magazine '100 Best Corporate Citizens' list each year over the years 2000-2004. At the outset, the authors noted bias in the sample. CSR proponents defined a company as socially responsible, for example, if it maximized their economic, social and environmental impacts. Typically, the economic impact revolves around profitability, so a company is often defined as being socially responsible, in part, if it is profitable.

Because of the inter-relationship between profitability and being defined as socially responsible, it should be expected that the companies that are empirically defined as being socially responsible have abovemarket returns (Laffer, 2004:2).

A second bias arose because only profitable companies can engage in CSR. Where firms do not have the resources to engage in any CSR programs they are unlikely to be successful, or incidentally to be measured by private regulators. As such, 'any company whose profitability falls below a certain threshold cannot be socially responsible if only because their revenues and energies must be focused on survival.' (Laffer, 2004:2)

In the analysis, the authors found no significant positive correlation between CSR and business profitability as determined by standard measures. In each of the three profitability comparisons (compound annual net income growth, net profit margin and stock price appreciation), only a minority of the 'CSR-leading companies in each comparison outperformed their peers. Being a CSR-leading company was negatively or not correlated with compound annual net income growth, net profit margin and stock price appreciation' (Laffer, 2004:6).

There was no relationship between CSR and profitability within the list of Business Ethics Top 100 Corporate Citizens. The five CSR factors were heavily correlated with ranking in the list, but the two business factors were essentially not, and stock price appreciation was only weakly correlated. The five CSR factors were strongly inversely correlated with the two traditional business factors. The results do not conclusively prove that CSR initiatives have a negative impact on a business's financial performance, but they strongly suggest that the claim that 'CSR initiatives have universal or systematic positive financial impacts on companies' is false. The authors further argued that CSR initiatives imposed significant program and administrative costs, and that the businesses that are inclined to engage in CSR initiatives tend to be those that are already financially 
successful and can afford the added 'CSR overhead'. 'Since in these cases financial success occurred before CSR initiatives were implemented, it would be obviously incorrect to conclude that CSR-related activities caused the financial success, though a positive correlation may exist' (Laffer, 2004:6). CSR is an effect, not the cause, of profit and CSR advocates are not wealth producers, but rent-seekers.

CSR is not profitable per se. CSR may find a home in a niche market among some investors and consumers, but it is not clear that such products and purchases drive other than the values of some consumers and investors. If market decisions are not very powerful drivers of political change, in the way that advocates desire, it may be less costly to retreat to philanthropy and direct political action.

\section{Private Regulators - NGOs and Professionals}

Despite the weakness of stakeholder theory and evidence that CSR costs, it nevertheless continues to grow. A possible explanation is the broad-spectrum dissatisfaction with institutions in general - and corporations in particular which has created 'an opening for new, alternative forms of authority' (Furedi, 2002:184), non-government organisations, which claim to represent the voice of the public. Their modus operandi is (p. 185):

encouraging people to fear, mistrust, complain and litigate ... as a socially responsible act. Consequently, [such] advocates do not merely reflect the existing state of mistrust: they play an active role in educating people to believe the worst in most circumstances.

Whatever the reason, CSR continues to grow in two dimensions; the responsibilities of directors and the measurement of non-financial performance. There are two views for reforming director's duties. The 'pluralist' view and the 'enlightened shareholder' view - a UK compromise suggests 'Enlightened Shareholder Value' (Department of Trade and Industry, 2005:5). The two compete to widen the responsibilities of directors to force them to take account of the interests of stakeholders. This of course they already do, if only through the work of 'activist' shareholders, so the real aim of the pluralist view is to award legal rights at large to non-owners. Further, in the pluralist view, informing shareholders and stakeholders on a range of non-financial performance is a tool in the transfer of power. In the enlightened shareholder view, the directors would be forced to report company activities in such a way as to 'inform' the shareholder, and indeed anyone else, of the impact of the company on all manner of things not necessarily their responsibility. In this less radical view, measurement is an end in itself, but would nevertheless enhance the opportunity to intervene and may result in the further regulation of corporations or the diffusion of power among stakeholders.

In a perverse way, the growth of regulators may also account for the growth of CSR regulation. In this regard, there are two types of private regulators active 
in CSR, NGOs (which may be further divided into advocacy and regulatory) and professional associations. How do the private regulators line up in the two camps - pluralist and enlightened shareholder? Broadly, the NGOs want the pluralist view and the professionals want the enlightened shareholder view.

The Australian Conservation Foundation (ACF) cited some very mild transgressions of existing laws by corporations in a submission to a Parliamentary Committee on CSR. The examples were used to justify its view that:

The Corporations Act should make explicit what is already the best reading of the text of section 181: that the obligation to act in the best interests of the corporation means a director should consider the interests of all corporate constituencies ... The best way of doing this would be to specify a non-exclusive list of relevant constituencies. Such a list should specifically include employees, financial investors, shareholders, customers and suppliers, communities in which the corporation operates, and the environment. (ACF, 2005:8)

Note the concept of constituency, that the corporation is a democratic body responsible at large to constituents. The ACF is clearly in the pluralist camp.

Oxfam Australia not only desires a mandatory reporting mechanism for CSR, but also 'believes that an independent monitoring mechanism is crucial to the effectiveness and validity of corporate responsibility.' Oxfam cites its Mining Ombudsman Project, which 'has investigated community complaints against the actions of Australian Mining companies operating throughout Asia, Central America and the Pacific' (Oxfam, 2005:5). It does not mention that the Project is rarely linked to local communities and deals in accusation, not in established facts. The concept is one of universal but non-specific measures of good, promoted by NGOs and measured, not by government but by 'independent' NGOs. Oxfam is clearly in the pluralist camp.

The Australian Network of Environmental Defender's Offices (EDO, 2005:5) argue that 'companies ought to have regard to the broader interests of the community and other stakeholders to the extent that such interests are within their sphere of influence'. They suggest broad measures of compliance such as the UN conventions. The difficulty with the EDO proposition is that corporations cannot value environmental harm without an external measure or cost, and they cannot reduce inequality at large. Indeed, a successful corporation may increase inequality by reducing poverty for its own workforce or in the community in which it operates. That being so, either the EDO argument is that corporations should act outside of their powers, or the EDO is inviting further legislation that establishes measures to internalise costs, at least some of which should not be internalised by corporations. The EDO is also clearly in the pluralist camp.

The attention paid by the EDO, ACF, Oxfam and a host of other groups to corporations as the face of business, as well as the disregard for the wishes of consumers as expressed through market mechanisms, and the undercutting of the authority of legislators tends to suggest that, overall, the NGO-pluralist- 
stakeholder regime is a recipe for private regulation of public mores. Such a regime is a radical departure from current practice, which is the expression of public mores through the formal democratic means expressed through statute and interpreted through the courts.

SustainAbility is a private regulator, an NGO which sets standards it believes are the best and uses persuasion, embarrassment, and campaigning to have corporations adopt them. Its raison d'etre is to measure rather than advocate, although clearly, its values are on display. For example, it argues that

[Public] Governance is a social function designed to manage interdependencies within human societies. Governance systems include institutions, legal regimes and other arrangements that perform the function of governance by setting the 'rules of the game'. Governance can transcend government to encompass other actors including the business sector and civil society. (SustainAbility, 2004:38)

While it is true that not all rules of the game are held or established by statute or the common law - there is custom and practice - it is a new form of custom that witnesses private rule setters in the marketplace, often claiming to be the voice of the common good. In a parallel endeavour, the growth of Transparency International, a private regulator which tracks government and corporate corruption, has recently been charted in a paper, entitled, 'Transparency International: In Search of a Constituency' (de Sousa, 2005). The difficulty with the work of the private regulators is finding a convincing basis for their legitimacy. If it rests solely in their assertion of knowing what is 'good' then it is subject to challenge by any other group's view of what is good. In other words, it pre-empts rather than enhances democratic politics.

The St. James Ethics Centre (StJEC) can be categorised as a private regulator. It is not in the pluralist camp on directors' duties, in as much as it does not support recommendations to make it compulsory for company directors to base their decisions on the interests of stakeholders other than shareholders. However, it thinks that company directors should be required to consider those interests - even if in the end they opt to act exclusively in the interests of the company as a whole. In other words, the directors should be forced to justify their actions in acting in the best interests of the company. The Centre also recommends an amendment to the Corporations Act, similar to the provisions relating to the 'business judgment rule', allowing company directors to make decisions based on bona fide ethical considerations - and protecting them from liability for doing so when a reasonable person would judge those considerations to be well founded. As such, directors relying on the 'ethical judgement rule' as a defence would be required to produce documents demonstrating the quality of the reasoning employed in reaching their decision. Courts would be entitled to review only the substance of any decision if the quality of the decision-making process was first found to be inadequate (StJEC, 2005:4). The StJEC view is only slightly less antipathetic to corporations than the earlier NGOs, as it would require a 
procedural fairness with all of the complexity inherent in administrative law regimes as they apply to government decisions.

The punch line is that StJEC recommends 'the encouragement of corporations to participate in voluntary exercises such as the Corporate Responsibility Index (CRI). StJEC $(2005,5)$ is the 'trustee' for this instrument in Australia and New Zealand. In other words, StJEC has a proprietary interest in CSR. It is driven as much by the measurement as the outcome, but its role helps to create a climate whereby CSR moves in a pluralist direction.

There are a number of examples of regulators among the professions. The Association of Chartered Certified Accountants (ACCA) for example, organises sustainability reporting award schemes in four continents (including Australia/New Zealand). In the UK, it has been awarded the Queen's Award for Enterprise: Sustainable Development. ACCA is represented on the Board and Technical Advisory Committee of the Global Reporting Initiative (GRl), which is an 'independent' institution 'whose mission is to develop and disseminate globally applicable Sustainability Reporting Guidelines.' The GRI is an official collaborating centre of the United Nations Environment Programme and works in cooperation with UN Secretary-General Kofi Annan's Global Compact.

In seeking to make money from measuring CSR the ACCA has not taken the pluralist route, arguing that

it is, in principle, legitimate for the law ... to incorporate specific measures designed to reflect and promote the wider public interest. We consider, however, that it is a dramatic and ill-advised step to go from this to suggest that directors of limited companies be required to adopt a fully pluralist [directors serving the interests of stakeholders. Stakeholders having a legal right of redress] approach to corporate governance. (ACCA, 2005:5)

Their view is that directors should retain the discretion to decide what constitutes the best interests of their company.

Finally, another private regulator is exemplified by Standards Australia, which released in June 2003, a five-part 'suite' of standards on corporate governance to encourage a culture of compliance in non-listed private companies, government departments and not-for-profit organisations. Guideline AS 8003 deals with Corporate Social Responsibility. Standards Australia is the peak nongovernment standards development body in Australia. Its international equivalent, the International Organization for Standardization, will publish an International Standard providing guidelines for social responsibility in 2008. These organisations appear to be far less inclined to join debate to boost CSR, but seek to maintain their position as premier measurement organisations, though without expressing a view on the role of shareholders. 


\section{Government Response to CSR — Facilitate Measurement}

The picture so far suggests that, despite a weak rationale for CSR, a growing CSR phenomenon driven by an army of willing regulators has governments and corporations on the defensive. The government and corporate response to CSR is intriguing. Many corporations ignore CSR, seeing it as a threat to their autonomy, but some embrace it, possibly to forestall further regulation or as a public relations tool. The same applies to politicians; many look on unsure whether it is a useful instrument for regulation or for staving off regulation or a cheap means to look interested in the causes promoted by CSR. Many will encourage standard measures of CSR among private regulators in order to achieve a more informed market'. A few will argue for changes to the laws governing directors in order to give power and standing to non-owner interests.

CSR has begun to seep into Australian legislation in an advisory form. For example, the Australian Securities and Investment Commission (ASIC, 2003) notes that the Financial Services Act 2003 (amending the Corporations Act 2001) requires issuers of financial products that purport to be socially responsible, for example, ethical investments, to disclose the extent that social, environmental and labour standards are considered. The guidelines do not establish labour standards or environmental, social, or ethical standards, or what methodology product issuers should use for considering these issues. They do, however, make it clear that (ASIC, 2003:8):

If a Public Disclosure Statement states that labour standards or environmental, social or ethical considerations are taken into account in selecting, retaining and realizing an investment, the PDS must have information on what those standards or considerations are.

The guidelines do not apply if the standards are not taken into account. The trouble is: who can say that some notice of ethical matters has not been taken into account? After all, selling legal products is to abide by the ethical standards of legislation. Which, of course, begs the question, is the legislation dealing with standards that the legislators have not signed up to?

The Parliamentary Joint Committee on Corporations and Financial Services is completing its inquiry into Corporate Responsibility and Triple-Bottom-Line reporting. It wants to know the extent to which organisational decision-makers have and should have 'regard for the interests of stakeholders other than shareholders, and the broader community' for profit and not-for-profit incorporated entities under the Corporations Act. There is also a March 2005 Reference to the Corporations and Markets Advisory Committee (2005) on directors' duties and corporate social responsibility. The issue concerns the extent to which the duties of directors under the Corporations Act 2001 should include corporate social responsibilities to take account of the interests of stakeholders other than shareholders. 
In addition, Senator Ian Campbell, Minister for the Environment has asked the Australian Stock Exchange (ASX) Corporate Governance Council to 'consider developing a [non-compulsory] standard for sustainability reporting' for listed companies. Since 1 July 2004, listed companies in Australia have been required, in order to comply with the ASX Principles of Good Corporate Governance and Best Practice Recommendations (ASX, 2004) to have in place and post on their website, a Code of Conduct and Ethics indicating how they intend to deal with stakeholder concerns. Corporations must either comply with each recommendation, or explain why not in the annual report. Comparable guidelines apply to non-listed companies.

From the above, it is likely that some form of reporting, without set standards will be recommend by the Parliamentary Committee. This allows politicians to look interested, keeps the interest groups busy and allows corporations to think they may stave off more restrictive regulation.

\section{Corporate Response to CSR - Recruitment}

At an international level, some parts of the corporate world have organised around the World Business Council for Sustainable Development (WBCSD). WBCSD is a coalition of 175 international companies, which promotes sustainable development, as they see it, through economic growth, ecological balance and social progress. Members are drawn from more than 35 countries and 20 major industrial sectors. The organisation has a network of 50 national, regional business councils, and partner organisations involving some 1,000 business leaders. WBCSD believes 'that the pursuit of sustainable development is good for business and business is good for sustainable development' (WBCSD, 2005). The bravest interpretation of the group is that it is attempting to hold back the tide of CSR regulation by being CSR friendly. Particular examples are as follows.

Coles Myer (2005:1) has established a Board sub-committee 'to oversee the development of a corporate responsibility strategy' and in 2005 for the first time published The Corporate Social Responsibility report as an insert into the Coles Myer Ltd Annual Report. It baulked, however, at legislation, 'we at Coles Myer believe it would be extremely difficult to develop appropriate legislation and reporting standards'. Similarly, BHP Billiton (2005:4) argued that 'the existing legal framework does not discourage or preclude directors or officers from having regard to the interest of non-shareholder stakeholders and the broader community'. And, perhaps the most pro-CSR corporation (see Johns 2005), IAG Insurance (2005:14), 'believes that the current legal framework ... provide[s] an appropriate incentive for our directors ... to have regard to a wide range of stakeholder interests, while ensuring that the interests of investors are protected'.

Clearly, to forestall pluralist regulation, the corporate world is singing to a different tune to the NGO advocates and regulators. However, they run the risk of not distinguishing their case sufficiently for politicians who will play along with some version of CSR. There must be some gain in the CSR strategy, to offset the cost of CSR regulation, and it appears that the gain comes in using CSR as a 
recruiting tool. For example, Westpac puts considerable effort into CSR ratings as a means of attracting and retaining staff. The bank in question (as had others) had reached a point, following events such rural bank closures and the ruination of clients with encouragement to deal in the foreign exchange market, where their staff were coming to work in civvies and changing in to their uniform at work! Turnover was very high, with all of the training and administrative costs that such turnover incurs. Involvement in CSR has apparently stabilised their staff turnover and presumably lowered their HR costs. Another example is a major Melbourne law firm, which undertakes pro bono work for various worthy charities, mainly environmental, as a means of attracting the brightest graduates.

These firms are not alone in using their version of CSR. A KPMG survey of 1600 of the world's largest companies across 16 industrialised countries, including Australia, examined why they are committed to corporate responsibility and what influenced the content of the reports (Human Resources Magazine, 24 August 2005). 'Almost half of the world's largest companies believe employee motivation is a key driver when it comes to corporate social responsibility.' The study, which included a detailed analysis of the reports of the global top 250 companies, found business drivers for CSR are economic (75 per cent) and ethical (50 per cent), while other drivers include innovation and learning (53 per cent) as well as improved shareholder value ( 39 per cent) and reputation or brand (27 per cent). The study also found that there has been a dramatic change in the type of CSR reporting, which has changed from purely environmental reporting up until 1999 to sustainability (social, environmental and economic reporting), which has now become mainstream among the global top 250 companies ( 70 per cent).

\section{Conclusion - Inform the Shareholders}

The debate over who owns the corporation is likely to prove too hot for legislators. The debate over the benefits and costs of CSR is likely to prove that better corporations indulge CSR. The evidence does not suggest that it helps make them better corporations or as Kofi Annan would wish, promote UN agendas. Some successful corporations use CSR as a recruiting tool and as a reputational device to mask the real decisions that they must make in order to survive. The outcome is increased compliance costs but little change in the way corporations do business. To the extent corporations' change because of CSR regulation there may be no benefit to anyone. Perhaps the most intriguing aspect of CSR is that it has spawned a whole range of private regulators.

One of the principal dangers of stakeholder theory is that managers who can claim to be serving the general interests of society in the name of the public good can invoke it. Such claims are not within the powers of managers. Only those with a mandate from the public — elected members of parliament — can make such claims, and they only do so cautiously, in the knowledge that if they do so wrongly, they will be lose their jobs.

It may be too strong a response by critics of CSR to insist that boards and CEOs gain the permission of shareholders before they invest in CSR programs. 
At the very least CSR should be seen as a cost of regulation and the costs and benefits should be presented somewhere in the accounts so that shareholders can at least be informed of the 'good' that is done in their name.

\section{References}

Ali, P. and M. Gold (2002), 'Analysing the Cost of Ethical Investment.' Journal of the Australian Securities Institute Issue 3 (Spring):9-14.

Auger, P. and T. Devinney (2005), 'Do What Consumers Say Matter?', Melbourne Business School, unpublished.

Auger, P., P. Burke, T. Devinney and J. Louviere (2003), 'What Will Consumers Pay for Social Product Features?' Journal of Business Ethics 42:281-304.

Australian Network of Environmental Defender's Offices (2005), Submission to the Parliamentary Joint Committee on Corporations and Financial Services, 'Inquiry into Corporate Responsibility', Parliament of Australia, 28 September.

Australian Stock Exchange (2004), Principles of Good Corporate Governance and Best Practice Recommendations, http://www.asx.com.au/supervision/governance/corporate_ governance_reporting.htm.

Australian Securities and Investment Commission (2003), 'Section 1013DA Disclosure Guidelines: ASIC Guidelines to Product Issuers for Disclosure about Labour Standards or Environmental, Social and Ethical Considerations in Product Disclosure Statements'.

BHP Billiton (2005), Submission to the Parliamentary Joint Committee on Corporations and Financial Services, 'Inquiry into Corporate Responsibility', Parliament of Australia, 9 September.

Coles Myer (2005), Submission to the Parliamentary Joint Committee on Corporations and Financial Services, 'Inquiry into Corporate Responsibility', Parliament of Australia, 6 September.

Commercial Law Association of Australia (2005), Submission to the Parliamentary Joint Committee on Corporations and Financial Services, 'Inquiry into Corporate Responsibility', Parliament of Australia,15 September.

Corfield, A. (1998), 'The Stakeholder Theory and its Future in Australian Corporate Governance: A Preliminary Analysis', Bond Law Review 10:217-29.

Corporations and Markets Advisory Committee (2005), 'Reference in Relation to Directors' Duties and Corporate Social Responsibility', March, http://www.camac.gov.au.

Department of Trade and Industry (2005), Company Law Reform White Paper, UK.

de Sousa, L. (2005), 'Transparency International in Search of a Constituency: The Franchising of the Global anti-Corruption Movement', Discussion Paper 05-14, Asia Pacific School of Economics and Government, The Australian National University.

Furedi, F. (2002), Culture of Fear: Risk-Taking and the Morality of Low Expectation, Continuum, London.

Global Reporting Initiative, http://www.globalreporting.org/G3/\#. 
Henderson, D. (2004), The Role of Business in the Modern World: Progress, Pressures and Prospects for the Market Economy, The Institute of Economic Affairs, London.

IAG Insurance (2005), Submission to the Parliamentary Joint Committee on Corporations and Financial Services, 'Inquiry into Corporate Responsibility', Parliament of Australia, 6 September.

Johns, G. (2003), 'The Good Reputation Index: A Tale of Two Strategies.' IPA Backgrounder 5(2), Institute of Public Affairs, Melbourne.

Johns, G. (2005), 'Insurance Company Whips Up a Storm', The Australian Financial Review, 16 August.

Laffer, A., A. Coors and W. Winegarden (2004) 'Does Corporate Social Responsibility Enhance Business Profitability?', Laffer Associates, unpublished.

McConvill, J. (2005), 'Directors' Duties to Stakeholders: A Reform Proposal Based on Three False Assumptions', The Australian Journal of Corporate Law 18:1-13.

Nye, J. and P. Zelikow (1997), 'Reflections, Conjectures and Puzzles', pp 269-285 in J. Nye, P. Zelikow and D. King (eds), Why People Don't Trust Government, Harvard University Press, Mass.

Oxfam Community Aid Abroad (2005), Submission to the Parliamentary Joint Committee on Corporations and Financial Services, 'Inquiry into Corporate Responsibility', Parliament of Australia, 9 September.

Parker, C. (2002), The Open Corporation: Effective Self-Regulation and Democracy, Cambridge University Press, Cambridge, UK.

Pharr, S, R. Putnam and R. Dalton (2000), 'A Quarter Century of Declining Confidence', Journal of Democracy 11(2):19-27.

Reputex, http://www.reputex.com.au/.

St. James Ethics Centre, 2005, Submission to the Parliamentary Joint Committee on Corporations and Financial Services, 'Inquiry into Corporate Responsibility', Parliament of Australia, 28 September.

Standards Australia. http://www.standards.org.au/default.asp.

SustainAbility and The Global Compact (2004), 'Gearing Up: From Corporate Responsibility to Good Governance and Scaleable Solutions', SustainAbility Ltd.

United Nations (2005), 'The Global Compact's Next Phase', 6 September.

Weiss, A. (2002), 'Cracks in the Foundation of Stakeholder Theory', http:/www.mngt.waikato.ac.nz/depts/sml/journal/commissi/stake.htm.

Wolf, M. (2004), 'Corporate Social Responsibility', New Zealand Business Roundtable, Wellington.

World Business Council for Sustainable Development, http://www.wbcsd.org.

The author is grateful for helpful comments from two anonymous referees. 